\title{
DFT and MD Studies of Formaldehyde-derived DNA Adducts: Molecular Level Insights into the Differential Mispairing Potentials of the Adenine, Cytosine and Guanine Lesions
}

Katie A. Wilson, Josh L. Garden, Natasha T. Wetmore, Lindey R. Felske, and Stacey D. Wetmore* Department of Chemistry and Biochemistry, University of Lethbridge, 4401 University Drive West, Lethbridge Alberta, Canada T1K $3 \mathrm{M4}$

\section{Supporting Information}

(41 Pages)

\section{Table of Contents}

Figure S1. DFT structures for the $\mathrm{HOCH}_{2}-\mathrm{C}$ nucleobase adduct. Key structural features and relative energies provided.

Figure S2. DFT structures and binding energies for base pairs between the Watson-Crick or Hoogsteen face of $\mathrm{C}$ and the canonical nucleobases......

Figure S3. DFT structures and binding energies for base pairs between the Hoogsteen face of $\mathrm{HOCH}_{2}-\mathrm{C}$ and the canonical nucleobases when the bulky moiety is directed away or toward the lesion WatsonCrick face.

Figure S4. Lesion dihedral angle distributions and MD representative structures of the three $\gamma^{\prime}$ orientations adopted by the $\mathrm{HOCH}_{2}-\mathrm{C}$ lesion with the bulky moiety directed away from the lesion Watson-Crick face when paired opposite $\mathrm{G}$.

Figure S5. Average base pair parameters for $\mathrm{HOCH}_{2}-\mathrm{C}$ adducted DNA with the lesion paired opposite $\mathrm{G}$ and the bulky moiety directed away from the lesion Watson-Crick face...... .S8

Figure S6. Average base step parameters for $\mathrm{HOCH}_{2}-\mathrm{C}$ adducted DNA with the lesion paired opposite $\mathrm{G}$ and the bulky moiety directed away from the lesion Watson-Crick face. .S9

Figure S7. a) Representative structure and b) C:G base-pair hydrogen-bonding geometry across the MD simulation trajectory for undamaged DNA. .S9

Figure S8. Average base pair parameters for natural DNA containing C paired opposite $\mathrm{G}$. ..S10

Figure S9. Average base step parameters for natural DNA containing C paired opposite G. . $\mathrm{S} 10$

Figure S10. Representative structure, $\mathrm{HOCH}_{2}-\mathrm{C}$ : G base-pair hydrogen-bonding geometry (with hydrogenbonding occupancies, energetics and key geometrical information), and dihedral angle distributions across the MD simulation trajectory for $\mathrm{HOCH}_{2}-\mathrm{C}$ adducted DNA when the bulky moiety is directed toward the lesion Watson-Crick face. 
Figure S11. MD representative structures of the three $\gamma^{\prime}$ orientations adopted by the $\mathrm{HOCH}_{2}-\mathrm{C}$ lesion with the bulky moiety directed toward the lesion Watson-Crick face when paired opposite $\mathrm{G}$. S12

Figure S12. Average base pair parameters for $\mathrm{HOCH}_{2}-\mathrm{C}$ adducted DNA with the lesion paired opposite $\mathrm{G}$ and the bulky moiety directed toward the lesion Watson-Crick face. S12

Figure S13. Average base step parameters for $\mathrm{HOCH}_{2}-\mathrm{C}$ adducted DNA with the lesion paired opposite $\mathrm{G}$ and the bulky moiety directed toward the lesion Watson-Crick face. S13

Figure S14. DFT structures for the $\mathrm{HOCH}_{2}-\mathrm{G}$ nucleobase adduct. Key structural features and relative energies provided.

Figure S15. DFT structures and binding energies for base pairs between the Watson-Crick or Hoogsteen

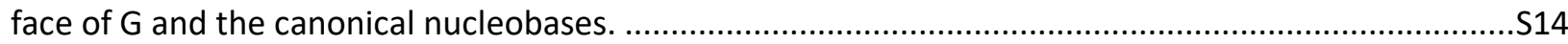

Figure S16. DFT structures and binding energies for base pairs between the Hoogsteen face of $\mathrm{HOCH}_{2}-\mathrm{G}$ and the canonical nucleobases when the bulky moiety is directed away or toward the lesion WatsonCrick face.

Figure S17. Dihedral angle distributions and MD representative structures of the three $\gamma^{\prime}$ orientations adopted by the $\mathrm{HOCH}_{2}$-G lesion with the bulky moiety directed away from the lesion Watson-Crick face when paired opposite $\mathrm{G}$.

Figure S18. Average base pair parameters for $\mathrm{HOCH}_{2}-\mathrm{G}$ adducted DNA with the lesion paired opposite $\mathrm{C}$ and the bulky moiety directed away from the lesion Watson-Crick face. .S16

Figure S19. Average base step parameters for $\mathrm{HOCH}_{2}-\mathrm{G}$ adducted DNA with the lesion paired opposite $\mathrm{C}$ and the bulky moiety directed away from the lesion Watson-Crick face.

Figure S20. Representative structure and G:C base-pair hydrogen-bonding geometry across the MD simulation trajectory for undamaged DNA.

Figure S21. Average base pair parameters for natural DNA containing G paired opposite C.

Figure S22. Average base step parameters for natural DNA containing G paired opposite C.

Figure S23. Representative structure, $\mathrm{HOCH}_{2}-\mathrm{G}: \mathrm{C}$ base-pair hydrogen-bonding geometry, and lesion dihedral angle distributions across the MD simulation trajectory for $\mathrm{HOCH}_{2}-\mathrm{G}$ adducted DNA when the bulky moiety is directed toward the lesion Watson-Crick face.

Figure S24. MD representative structures of the three $\gamma^{\prime}$ orientations adopted by the $\mathrm{HOCH}_{2}$-G lesion with the bulky moiety directed toward the lesion Watson-Crick face when paired opposite $\mathrm{C}$ S20

Figure S25. Average base pair parameters for $\mathrm{HOCH}_{2}-\mathrm{G}$ adducted DNA with the lesion paired opposite $\mathrm{C}$ and the bulky moiety directed toward the lesion Watson-Crick face. .S20

Figure S26. Average base step parameters for $\mathrm{HOCH}_{2}-\mathrm{G}$ adducted DNA with the lesion paired opposite $\mathrm{C}$ and the bulky moiety directed toward the lesion Watson-Crick face.

Figure S27. DFT structures for the $\mathrm{HOCH}_{2}-\mathrm{A}$ nucleobase adduct. Key structural features and relative energies provided.

Figure S28. DFT structures and binding energies for base pairs between the Watson-Crick or Hoogsteen face of $A$ and the canonical nucleobases. .S22

Figure S29. Dihedral distributions across MD simulations for $\mathrm{HOCH}_{2}-\mathrm{A}$ adducted DNA .523 
Figure S30. MD representative structures of the three $\gamma^{\prime}$ orientations adopted by the $\mathrm{HOCH}_{2}-\mathrm{A}$ lesion with the bulky moiety directed away from the lesion Watson-Crick face when paired opposite T.........S24

Figure S31. Average base pair parameters for $\mathrm{HOCH}_{2}-\mathrm{A}$ adducted DNA with the lesion paired opposite T and the bulky moiety directed away from the lesion Watson-Crick face.

Figure S32. Average base step parameters for $\mathrm{HOCH}_{2}-\mathrm{A}$ adducted DNA with the lesion paired opposite T and the bulky moiety directed away from the lesion Watson-Crick face.

Figure S33. Representative structure and A:T base-pair hydrogen-bonding geometry across the MD simulation trajectory for undamaged DNA.

Figure S34. Average base pair parameters for natural DNA containing A paired opposite T.

Figure S35. Average base step parameters for natural DNA containing A paired opposite T.

Figure S36. MD representative structures of the three $\gamma^{\prime}$ orientations adopted by the $\mathrm{HOCH}_{2}-\mathrm{A}$ lesion with the bulky moiety directed toward the lesion Watson-Crick face when paired opposite $T$

Figure S37. Average base pair parameters for $\mathrm{HOCH}_{2}-\mathrm{A}$ adducted DNA with the lesion paired opposite T and the bulky moiety directed toward the lesion Watson-Crick face.

Figure S38. Average base step parameters for $\mathrm{HOCH}_{2}-\mathrm{A}$ adducted DNA with the lesion paired opposite T and the bulky moiety directed toward the lesion Watson-Crick face.

Figure S39. MD representative structures of the three $\gamma^{\prime}$ orientations adopted by the $\mathrm{HOCH}_{2}-\mathrm{A}$ lesion with the bulky moiety directed toward the lesion Watson-Crick face when paired opposite $\mathrm{C}$

Figure S40. Average base pair parameters for anti $\mathrm{HOCH}_{2}-\mathrm{A}$ adducted DNA with the lesion paired opposite $\mathrm{C}$ and the bulky moiety toward the lesion Watson-Crick face.

Figure S41. Average base step parameters for anti $\mathrm{HOCH}_{2}-\mathrm{A}$ adducted DNA with the lesion paired opposite $\mathrm{C}$ and the bulky moiety directed toward the lesion Watson-Crick face.

Figure S42. MD representative structures of the three $\gamma^{\prime}$ orientations adopted by the anti $\mathrm{HOCH}_{2}-\mathrm{A}$ lesion with the bulky moiety directed toward the lesion Watson-Crick face when paired opposite A ...S30 Figure S43. Average base pair parameters for anti $\mathrm{HOCH}_{2}-\mathrm{A}$ adducted DNA with the lesion paired opposite $A$ and the bulky moiety directed toward the lesion Watson-Crick face.

Figure S44. Average base step parameters for anti $\mathrm{HOCH}_{2}-\mathrm{A}$ adducted DNA with the lesion paired opposite $A$ and the bulky moiety directed toward the lesion Watson-Crick face.

Figure S45. MD representative structures of the three $\gamma^{\prime}$ orientations adopted by the syn $\mathrm{HOCH}_{2}-\mathrm{A}$ lesion with the bulky moiety directed toward the lesion Watson-Crick face when paired opposite $A$

Figure S46. Average base pair parameters for syn $\mathrm{HOCH}_{2}-\mathrm{A}$ adducted DNA with the lesion paired opposite $A$ and the bulky moiety directed toward the lesion Watson-Crick face.

Figure S47. Average base step parameters for syn $\mathrm{HOCH}_{2}-\mathrm{A}$ adducted DNA with the lesion paired opposite $A$ and the bulky moiety directed toward the lesion Watson-Crick face.

Figure S48. MD representative structures of the three $\gamma^{\prime}$ orientations adopted by the syn $\mathrm{HOCH}_{2}-\mathrm{A}$ lesion with the bulky moiety directed toward the lesion Watson-Crick face when paired opposite G...... .S33

Figure S49. Average base pair parameters for syn $\mathrm{HOCH}_{2}-\mathrm{A}$ adducted DNA with the lesion paired opposite $\mathrm{G}$ and the bulky moiety directed toward the lesion Watson-Crick face. S33 
Figure S50. Average base step parameters for syn $\mathrm{HOCH}_{2}-\mathrm{A}$ adducted DNA with the lesion paired opposite $\mathrm{G}$ and the bulky moiety directed toward the lesion Watson-Crick face.

Table S1. Charges and atom types for the $\mathrm{HOCH}_{2}-\mathrm{C}$ lesion.

Table S2. Charges and atom types for the $\mathrm{HOCH}_{2}-\mathrm{G}$ lesion. S35

Table S3. Charges and atom types for the $\mathrm{HOCH}_{2}-\mathrm{A}$ lesion. .536

Table S4. Heavy atom rmsd with respect to the representative structure for Trial 1 .536

Table S5. Hydrogen-bonding occupancies and geometric features for the lesion, as well as the $5^{\prime}$ and $3^{\prime}$ flanking base pairs, in $\mathrm{HOCH}_{2}-\mathrm{C}$ adducted DNA.

Table S6. Hydrogen-bonding occupancies and geometric features for $\mathrm{C}$, as well as the $5^{\prime}$ and $3^{\prime}$ flanking base pairs, in natural DNA with the sequence that mirrors the $\mathrm{HOCH}_{2}-\mathrm{C}$ adducted DNA

Table S7. Hydrogen-bonding occupancies and geometric features for the lesion, as well as the $5^{\prime}$ and $3^{\prime}$ flanking base pairs, in $\mathrm{HOCH}_{2}-\mathrm{G}$ adducted DNA

Table S8. Hydrogen-bonding occupancies and geometric features for $\mathrm{G}$, as well as the $5^{\prime}$ and $3^{\prime}$ flanking base pairs, in natural DNA with the sequence that mirrors the $\mathrm{HOCH}_{2}-\mathrm{G}$ adducted DNA

Table S9. Hydrogen-bonding occupancies and geometric features for the lesion, as well as the $5^{\prime}$ and $3^{\prime}$ flanking base pairs, in $\mathrm{HOCH}_{2}-\mathrm{A}$ adducted DNA with the lesion paired opposite $\mathrm{T}$

Table S10. Hydrogen-bonding occupancies and geometric features for A, as well as the $5^{\prime}$ and $3^{\prime}$ flanking base pairs, in natural DNA with the sequence that mirrors the $\mathrm{HOCH}_{2}-\mathrm{A}$ adducted DNA S39

Table S11. Hydrogen-bonding occupancies and geometric features for the lesion, as well as the $5^{\prime}$ and $3^{\prime}$ flanking base pairs, in $\mathrm{HOCH}_{2}-\mathrm{A}$ adducted DNA with the lesion paired opposite $\mathrm{C}$.

Table S12. Hydrogen-bonding occupancies and geometric features for the lesion, as well as the $5^{\prime}$ and $3^{\prime}$ flanking base pairs, in $\mathrm{HOCH}_{2}-\mathrm{A}$ adducted DNA with the lesion paired opposite $\mathrm{A}$

Table S13. Hydrogen-bonding occupancies and geometric features for the lesion, as well as the $5^{\prime}$ and $3^{\prime}$ flanking base pairs, in $\mathrm{HOCH}_{2}-\mathrm{A}$ adducted DNA with the lesion paired opposite $\mathrm{G}$ 


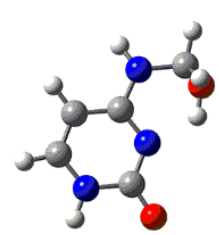

$0.0 \mathrm{~kJ} / \mathrm{mol}$

$\alpha^{\prime}: 5.7^{\circ}$

$\beta^{\prime}: 59.2^{\circ}$

$\gamma^{\prime}:-68.0^{\circ}$

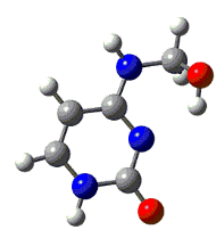

$0.0 \mathrm{~kJ} / \mathrm{mol}$

$\alpha^{\prime}:-5.7^{\circ}$

$\beta^{\prime}:-59.2^{\circ}$

$\gamma^{\prime}: 68.0^{\circ}$

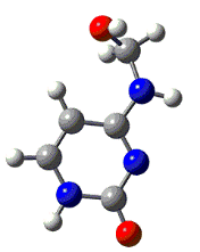

$13.6 \mathrm{~kJ} / \mathrm{mol}$

$\alpha^{\prime}: 163.9^{\circ}$

$\beta^{\prime}: 73.5^{\circ}$

$\gamma^{\prime}: 51.2^{\circ}$

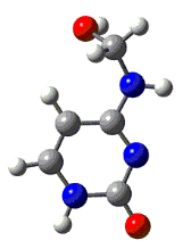

$13.6 \mathrm{~kJ} / \mathrm{mol}$

$\alpha^{\prime}:-163.9^{\circ}$

$\beta^{\prime}:-73.5^{\circ}$

$\gamma^{\prime}:-51.2^{\circ}$

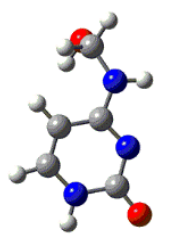

$16.4 \mathrm{~kJ} / \mathrm{mol}$

$\alpha^{\prime}: 162.6^{\circ}$

$\beta^{\prime}:-75.6^{\circ}$

$\gamma^{\prime}: 62.5^{\circ}$

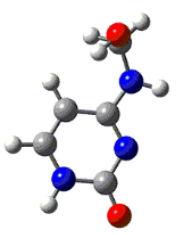

$16.4 \mathrm{~kJ} / \mathrm{mol}$

$\alpha^{\prime}:-162.6^{\circ}$

$\beta^{\prime}:-75.6^{\circ}$

$\gamma^{\prime}:-62.5^{\circ}$

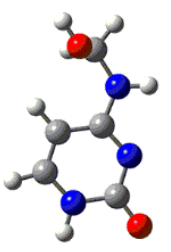

$19.9 \mathrm{~kJ} / \mathrm{mol}$

$\alpha^{\prime}: 174.3^{\circ}$

$\beta^{\prime}:-70.0^{\circ}$

$\gamma^{\prime}: 178.2^{\circ}$

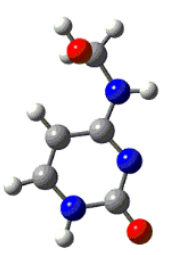

$19.9 \mathrm{~kJ} / \mathrm{mol}$

$\alpha^{\prime}:-174.3^{\circ}$

$\beta^{\prime}: 70.0^{\circ}$

$\gamma^{\prime}:-178.2^{\circ}$

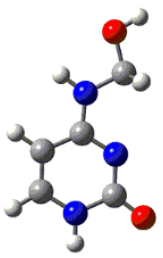

$17.6 \mathrm{~kJ} / \mathrm{mol}$

$\alpha^{\prime}: 0.0^{\circ}$

$\beta^{\prime}: 180.0^{\circ}$

$\gamma^{\prime}: 180.0^{\circ}$

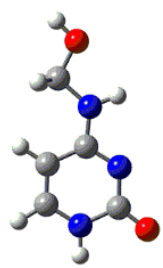

$29.7 \mathrm{~kJ} / \mathrm{mol}$

$\alpha$ : $180.0^{\circ}$

$\beta^{\prime}: 180.0^{\circ}$

$\gamma^{\prime}: 180.0^{\circ}$

Figure S1. B3LYP-D3(BJ)/6-311+G(2df,2p)//B3LYP/6-31G(d,p) structures for the $\mathrm{HOCH}_{2}-\mathrm{C}$ nucleobase adduct. Key structural features (deg.) and relative energies $(\mathrm{kJ} / \mathrm{mol}$ ) provided. See Figure 1 in the main text for definitions of dihedral angles. 

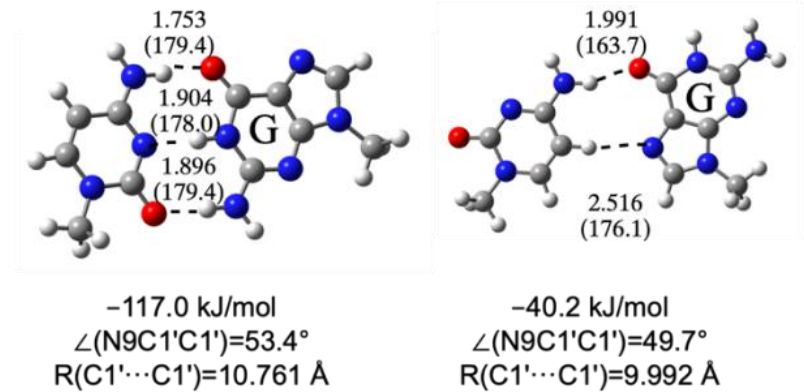

$$
\begin{gathered}
-40.2 \mathrm{~kJ} / \mathrm{mol} \\
\angle\left(\mathrm{N} 9 \mathrm{C} 1^{\prime} \mathrm{C} 1^{\prime}\right)=49.7^{\circ} \\
\mathrm{R}\left(\mathrm{C} 1^{\prime} \cdots \mathrm{C} 1^{\prime}\right)=9.992 \AA \\
\text { Interplanar angle }=2.1^{\circ}
\end{gathered}
$$
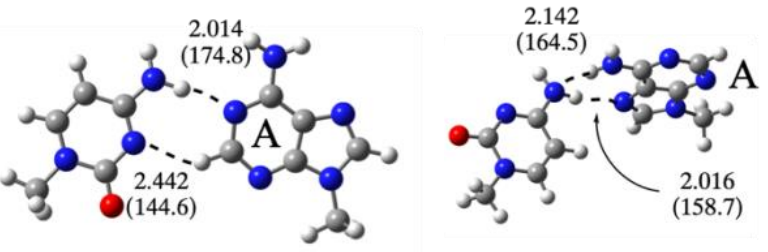

$-30.2 \mathrm{~kJ} / \mathrm{mo}$ $\angle\left(\mathrm{N} 9 \mathrm{C} 1^{\prime} \mathrm{C} 1^{\prime}\right)=51.9^{\circ}$ $R\left(C 1^{\prime} \cdots C 1^{\prime}\right)=10.402 \AA$ Interplanar angle $=15.3^{\circ}$

$-38.8 \mathrm{~kJ} / \mathrm{mol}$ $\angle\left(\mathrm{N} 9 \mathrm{C} 1^{\prime} \mathrm{C} 1^{\prime}\right)=29.6^{\circ}$ $R\left(C 1^{\prime} \cdots C 1^{\prime}\right)=10.607 \AA$ Interplanar angle $=81.2^{\circ}$

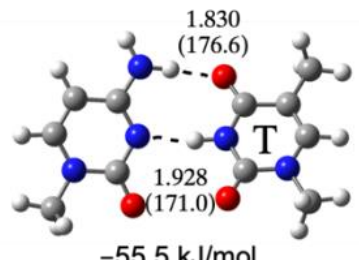

$-55.5 \mathrm{~kJ} / \mathrm{mol}$ $\angle\left(\mathrm{N} 9 \mathrm{C} 1^{\prime} \mathrm{C} 1^{\prime}\right)=60.5^{\circ}$ $\mathrm{R}\left(\mathrm{C} 1^{\prime} \cdots \mathrm{C} 1^{\prime}\right)=8.616 \AA$ Interplanar angle $=26.6^{\circ}$
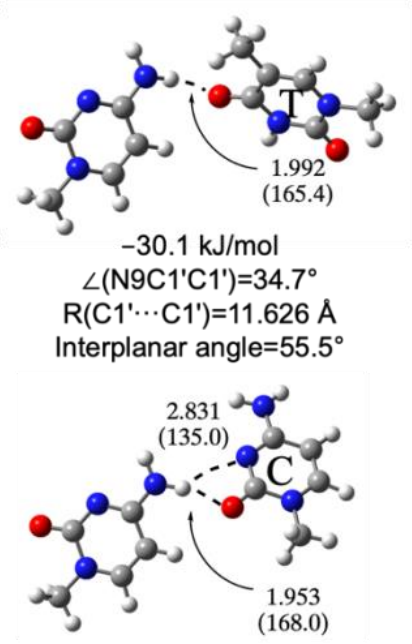

$-41.1 \mathrm{~kJ} / \mathrm{mol}$ $\angle\left(\mathrm{N} 9 \mathrm{C} 1^{\prime} \mathrm{C} 1^{\prime}\right)=32.0^{\circ}$

$R\left(C 1^{\prime} \cdots C 1^{\prime}\right)=9.195 \AA$

Interplanar angle $=42.8^{\circ}$

Figure S2. DFT structures (distances in $\AA$ and angles in deg.) and binding energies $(\mathrm{kJ} / \mathrm{mol})$ for base pairs between the Watson-Crick (left) or Hoogsteen (right) face of $\mathrm{C}$ and the canonical nucleobases. 


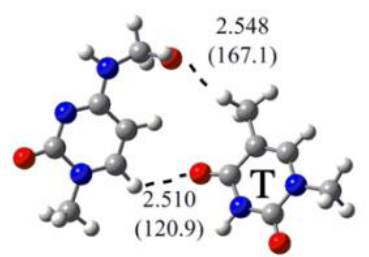

$-21.4 \mathrm{~kJ} / \mathrm{mol}$ $\angle\left(\mathrm{N} 9 \mathrm{C} 1^{\prime} \mathrm{C} 1^{\prime}\right)=67.6^{\circ}$ $R\left(C 1^{\prime} \cdots C 1^{\prime}\right)=9.916 \AA$ Interplanar angle $=46.7^{\circ}$

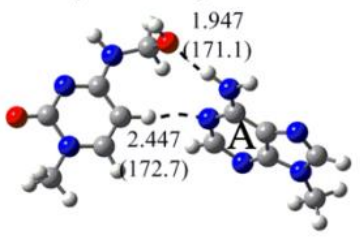

$-34.7 \mathrm{~kJ} / \mathrm{mol}$ $\angle\left(\mathrm{N} 9 \mathrm{C} 11^{\prime} \mathrm{C} 1{ }^{\prime}\right)=60.8^{\circ}$ $R\left(C 1^{\prime} \cdots C 1^{\prime}\right)=10.588 \AA$ Interplanar angle $=72.6^{\circ}$

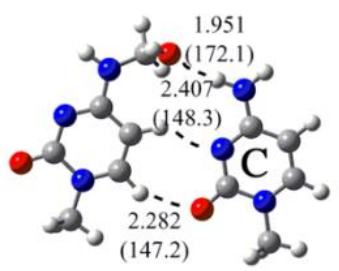

$-50.6 \mathrm{~kJ} / \mathrm{mol}$ $\angle\left(\mathrm{N}^{\prime}{ }^{\prime} 1^{\prime} \mathrm{C} 1^{\prime}\right)=78.9^{\circ}$ $\mathrm{R}\left(\mathrm{C} 1^{\prime} \cdot \cdots \mathrm{C} 1^{\prime}\right)=7.143 \AA$ Interplanar angle $=9.2^{\circ}$

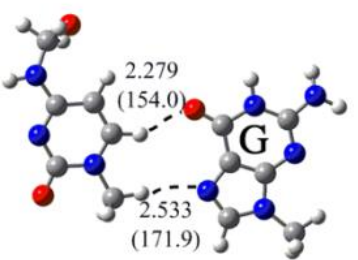

$-29.9 \mathrm{~kJ} / \mathrm{mol}$ $\angle\left(\mathrm{N} 9 \mathrm{C} 1^{\prime} \mathrm{C} 1^{\prime}\right)=130.0^{\circ}$ $\mathrm{R}\left(\mathrm{C} 1^{\prime} \cdots \mathrm{C} 1^{\prime}\right)=7.018 \AA$ Interplanar angle $=4.6^{\circ}$

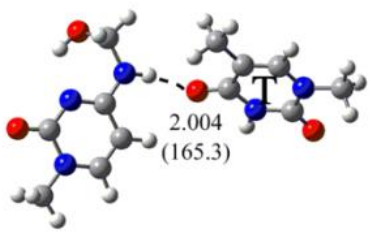

$-32.1 \mathrm{~kJ} / \mathrm{mol}$ $\angle\left(\mathrm{N}^{\prime} \mathrm{C} 1^{\prime} \mathrm{C} 1^{\prime}\right)=34.2^{\circ}$ $R\left(C 1^{\prime} \cdots C 1^{\prime}\right)=11.776 \AA$ Interplanar angle $=52.8^{\circ}$

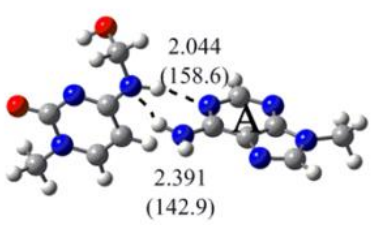

$-36.8 \mathrm{~kJ} / \mathrm{mol}$ $\angle\left(\mathrm{N} 9 \mathrm{C} 11^{\prime} \mathrm{C} 1^{\prime}\right)=31.7^{\circ}$ $R\left(C 1^{\prime} \cdots C 1^{\prime}\right)=12.099 \AA$ Interplanar angle $=87.5^{\circ}$

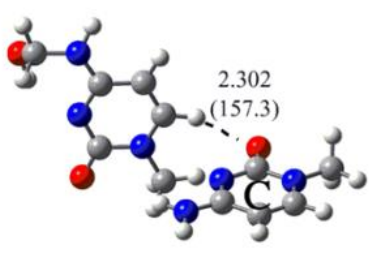

$-36.5 \mathrm{~kJ} / \mathrm{mol}$ $\angle\left(\mathrm{N} 9 \mathrm{C} 1^{\prime} \mathrm{C} 1^{\prime}\right)=103.1^{\circ}$ $\mathrm{R}\left(\mathrm{C} 1^{\prime} \cdot \cdots \mathrm{C} 1^{\prime}\right)=6.005 \AA$ Interplanar angle $=83.2^{\circ}$

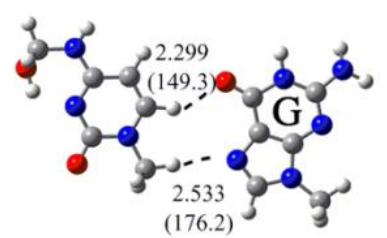

$-32.2 \mathrm{~kJ} / \mathrm{mol}$ $\angle\left(\mathrm{N} 9 \mathrm{C} 1^{\prime} \mathrm{C} 1^{\prime}\right)=128.1^{\circ}$ $\mathrm{R}\left(\mathrm{C} 1^{\prime} \cdots \mathrm{C} 1^{\prime}\right)=6.990 \AA$ Interplanar angle $=1.1^{\circ}$

Figure S3. DFT structures (distances in $\AA$ and angles in deg.) and binding energies ( $\mathrm{kJ} / \mathrm{mol}$ ) for base pairs between the Hoogsteen face of $\mathrm{HOCH}_{2}-\mathrm{C}$ and the canonical nucleobases when the bulky moiety is directed away (left) or toward (right) the lesion Watson-Crick face. 
a)

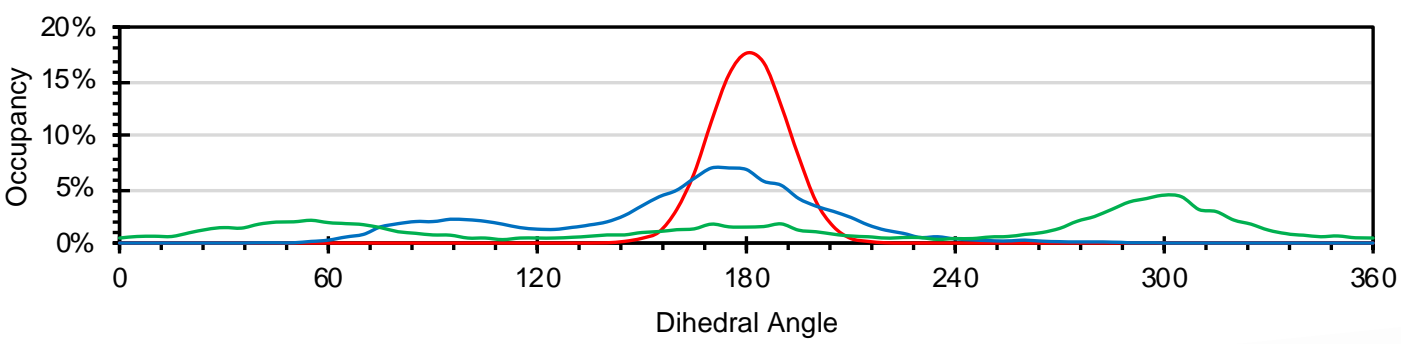

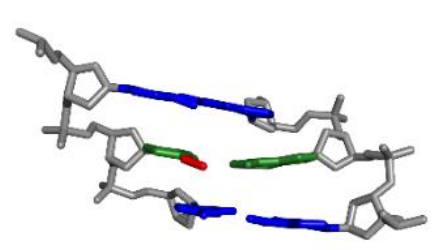

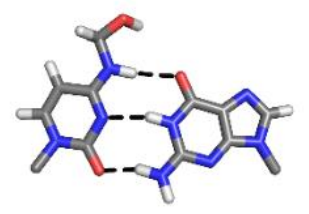

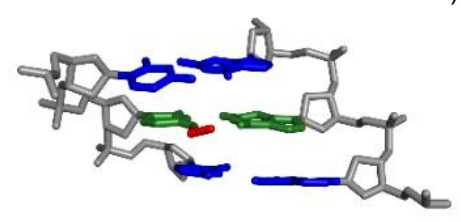
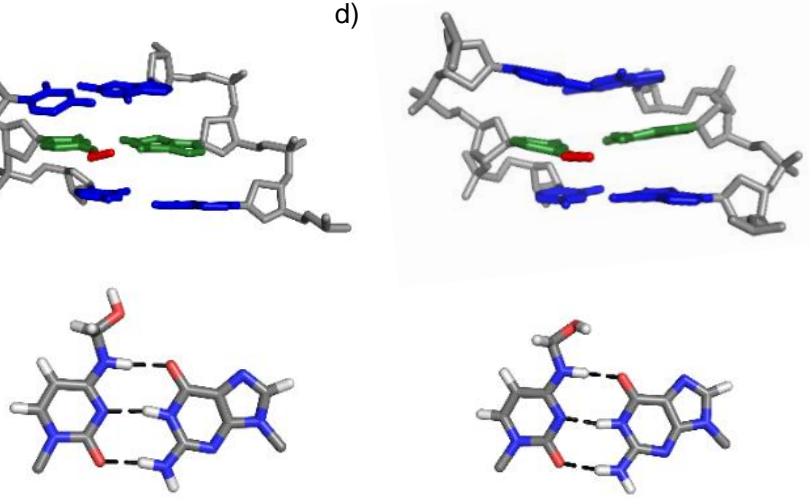

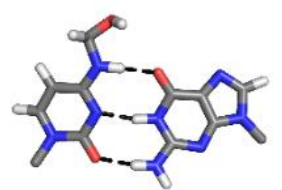

Figure S4. a) $\alpha^{\prime}$ (red), $\beta^{\prime}$ (blue) and $\gamma^{\prime}$ (green) dihedral angle distributions and MD representative structures of the three $\gamma^{\prime}$ orientations adopted by the $\mathrm{HOCH}_{2}-\mathrm{C}$ lesion with the bulky moiety directed away from the lesion Watson-Crick face when paired opposite $G$, with $\gamma^{\prime}$ approximately equal to a) $60^{\circ}$ b) $180^{\circ}$ and c) $300^{\circ}$.
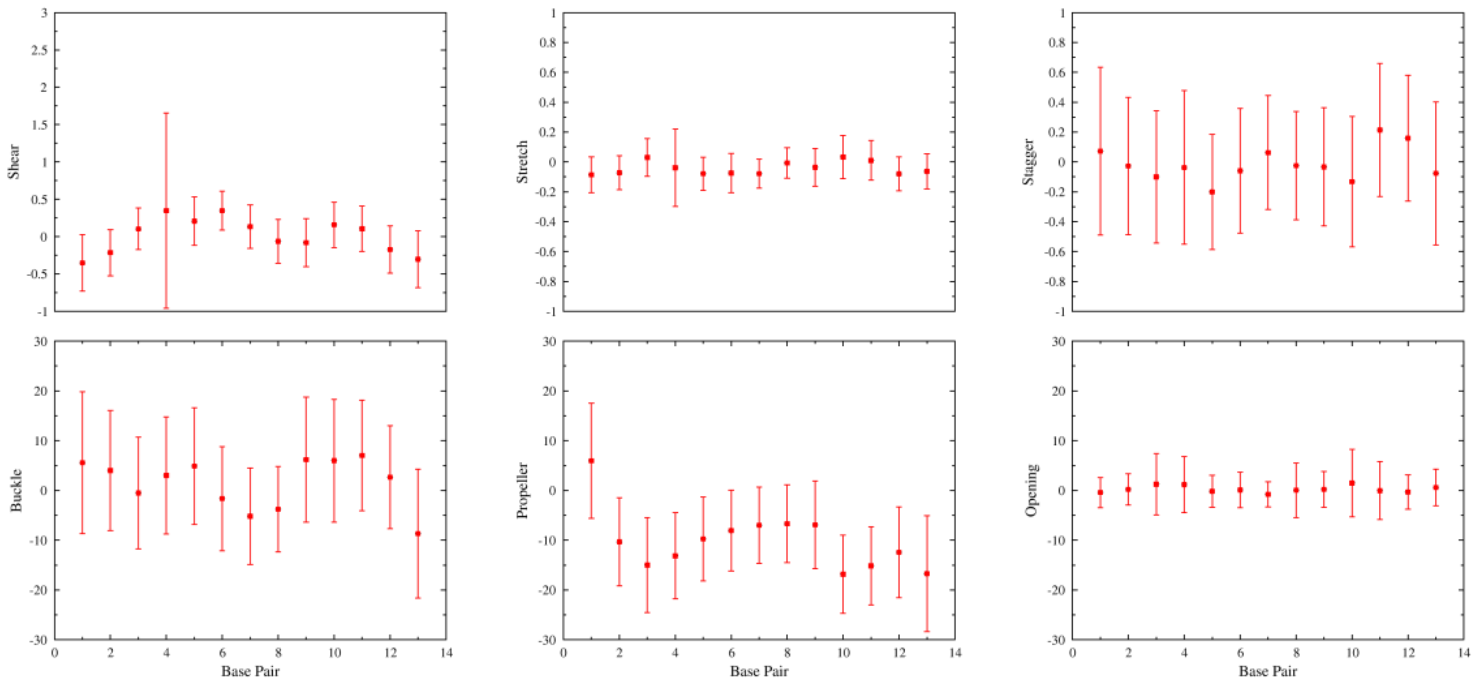

Figure S5. Average base pair parameters for $\mathrm{HOCH}_{2}-\mathrm{C}$ adducted DNA with the lesion paired opposite $\mathrm{G}$ and the bulky moiety directed away from the lesion Watson-Crick face. 

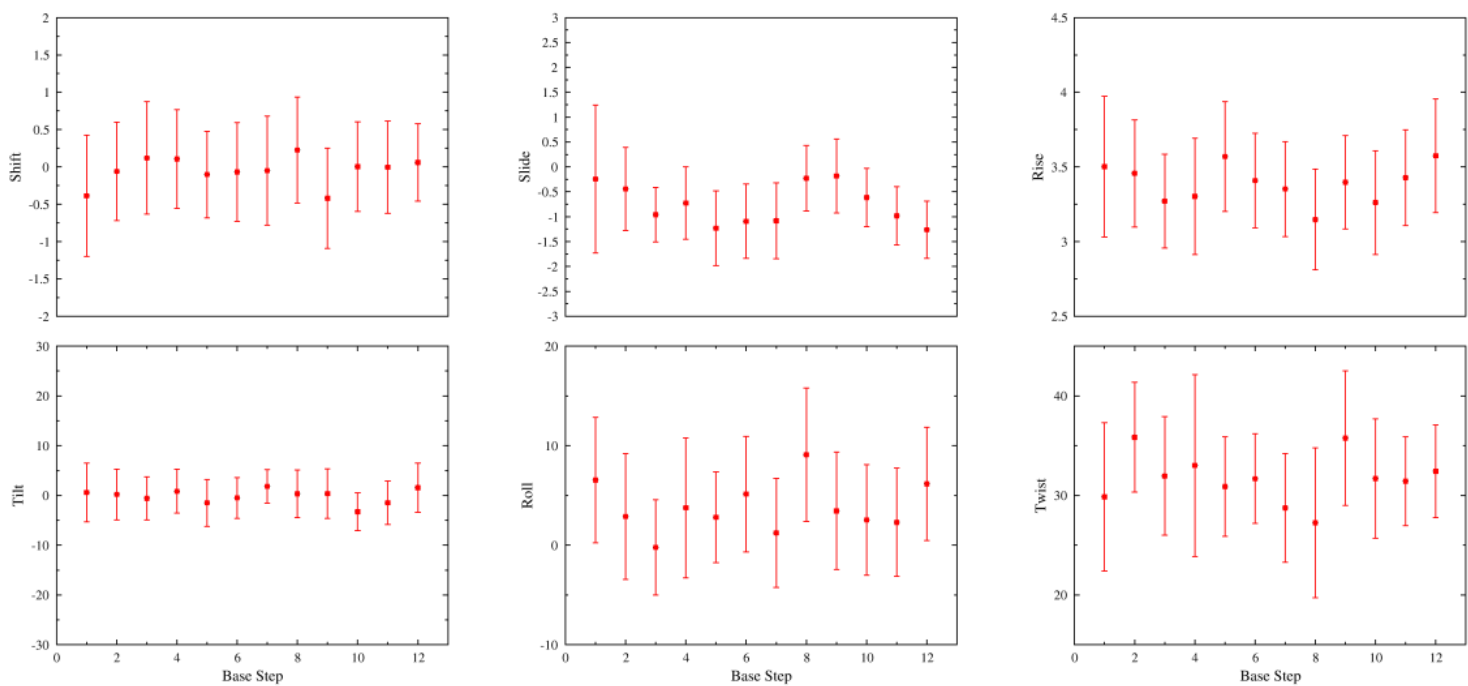

Figure S6. Average base step parameters for $\mathrm{HOCH}_{2}-\mathrm{C}$ adducted DNA with the lesion paired opposite $\mathrm{G}$ and the bulky moiety directed away from the lesion Watson-Crick face.

a)

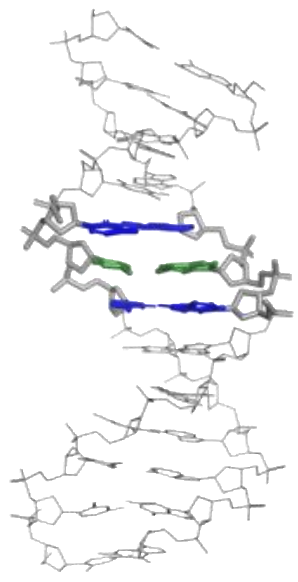

b)

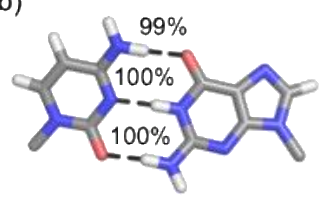

$-134.8 \pm 10.5 \mathrm{~kJ} / \mathrm{mol}$

$\angle\left(\mathrm{N} 1 \mathrm{C} 1^{\prime} \mathrm{C} 1^{\prime}\right)=55.5 \pm 3.4^{\circ}$

$R\left(C 1^{\prime} \cdots C 1^{\prime}\right)=10.713 \pm 0.170 \AA$

Interplanar angle $=14.1 \pm 6.1^{\circ}$

Figure S7. a) Representative structure and b) C:G base-pair hydrogen-bonding geometry (with hydrogenbonding occupancies, energetics and key geometrical information) across the MD simulation trajectory for undamaged DNA. 

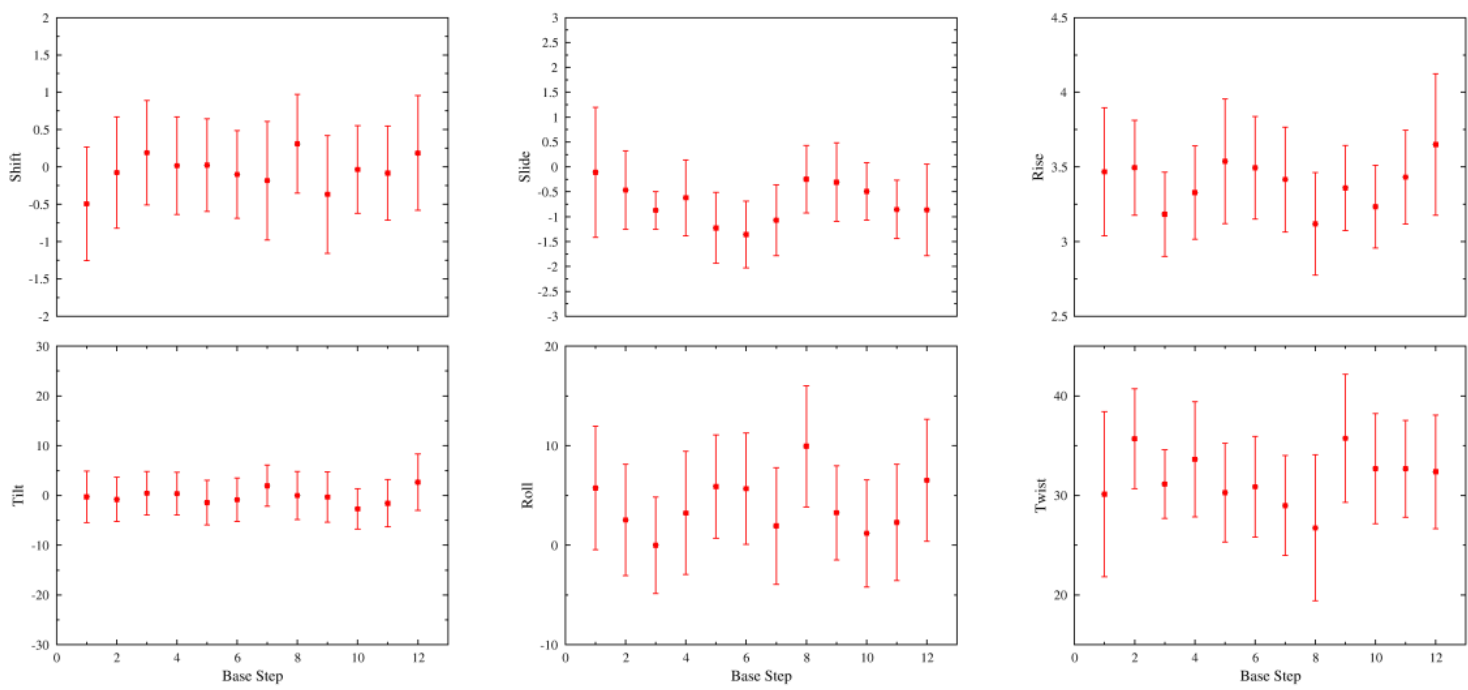

Figure S8. Average base pair parameters for natural DNA containing C paired opposite G.
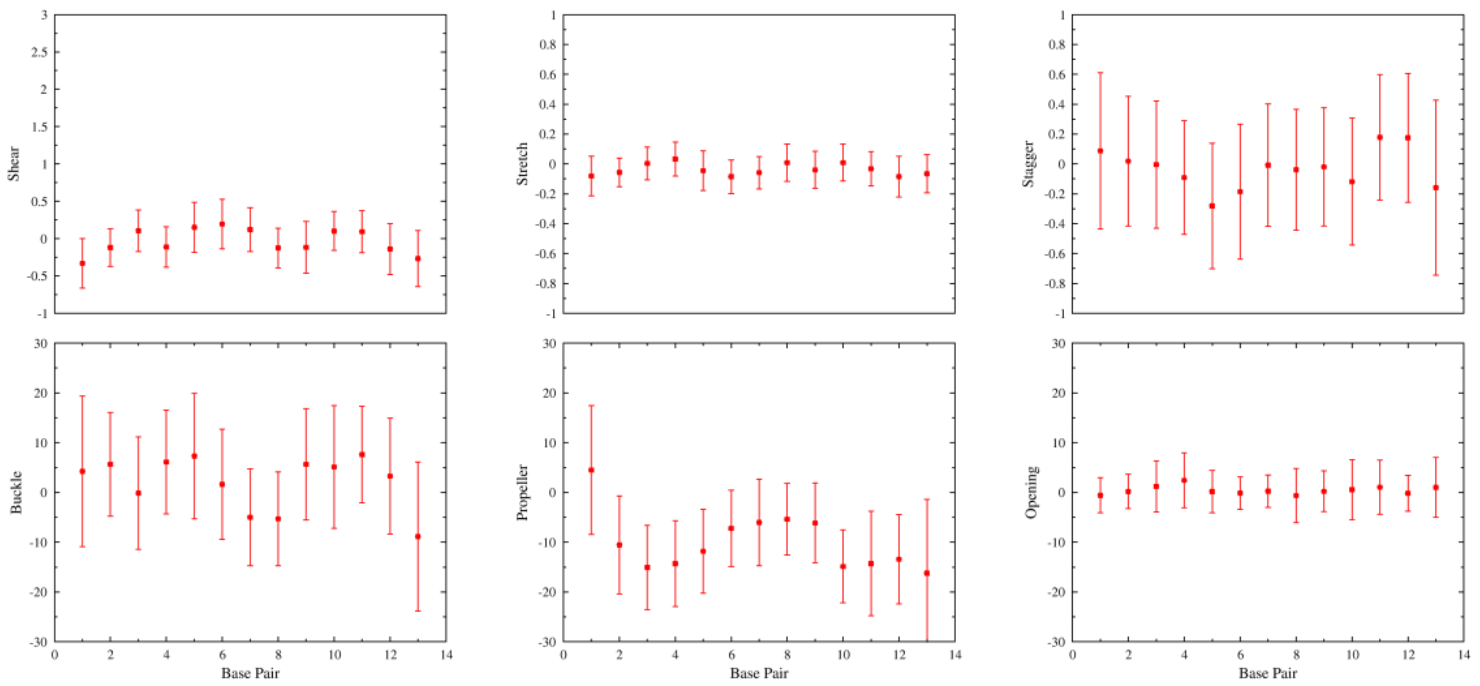

Figure S9. Average base step parameters for natural DNA containing C paired opposite G. 
a)

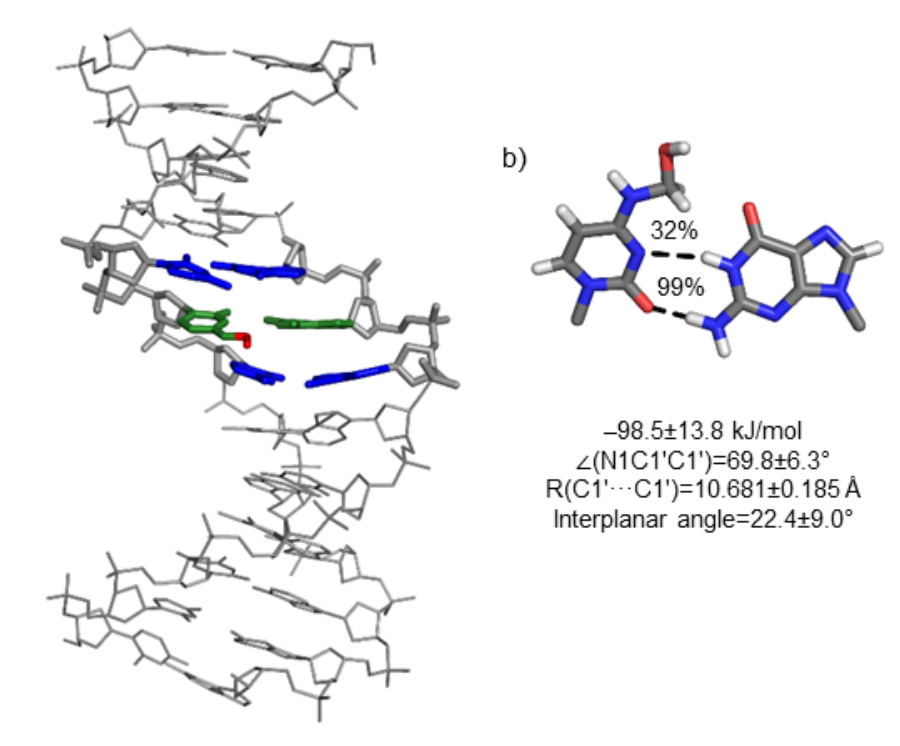

c)

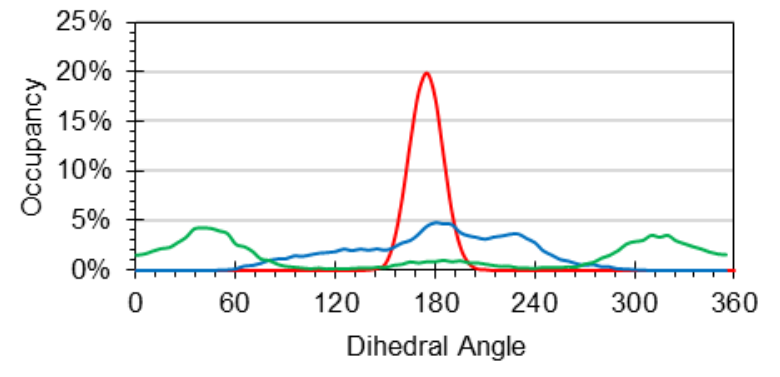

Figure S10. a) Representative structure, b) $\mathrm{HOCH}_{2}-\mathrm{C}$ :G base-pair hydrogen-bonding geometry (with hydrogen-bonding occupancies, energetics and key geometrical information), and c) $\alpha^{\prime}$ (red), $\beta^{\prime}$ (blue) and $\gamma^{\prime}$ (green) dihedral angle distributions across the MD simulation trajectory for $\mathrm{HOCH}_{2}-\mathrm{C}$ adducted DNA when the bulky moiety is directed toward the lesion Watson-Crick face. 
a)
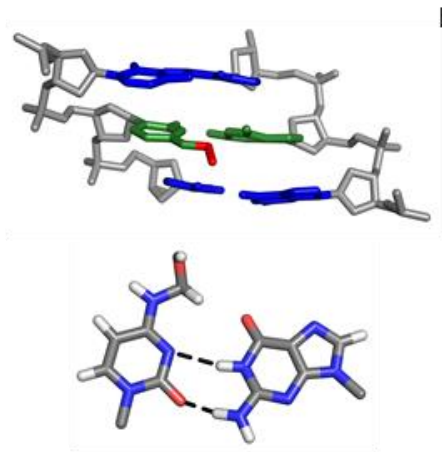

b)

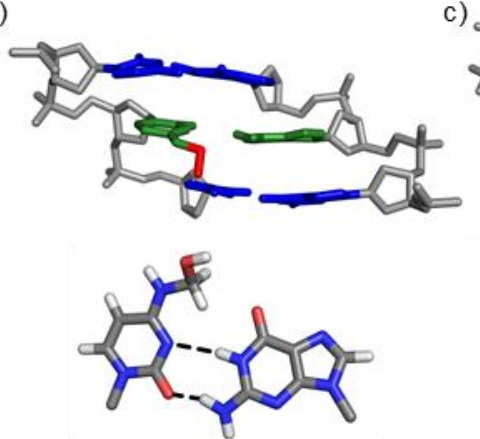

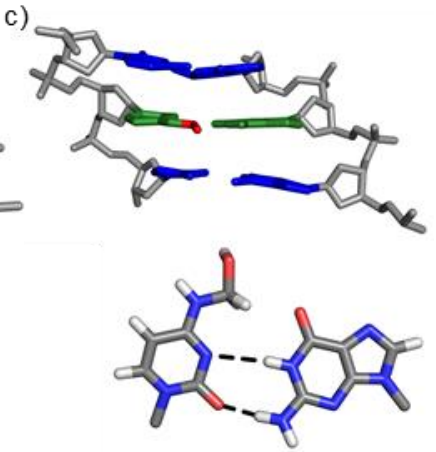

Figure S11. MD representative structures of the three $\gamma^{\prime}$ orientations adopted by the $\mathrm{HOCH}_{2}-\mathrm{C}$ lesion with the bulky moiety directed toward the lesion Watson-Crick face when paired opposite $\mathrm{G}$, with $\gamma^{\prime}$ approximately equal to a) $40^{\circ}$ b) $180^{\circ}$ and c) $320^{\circ}$.
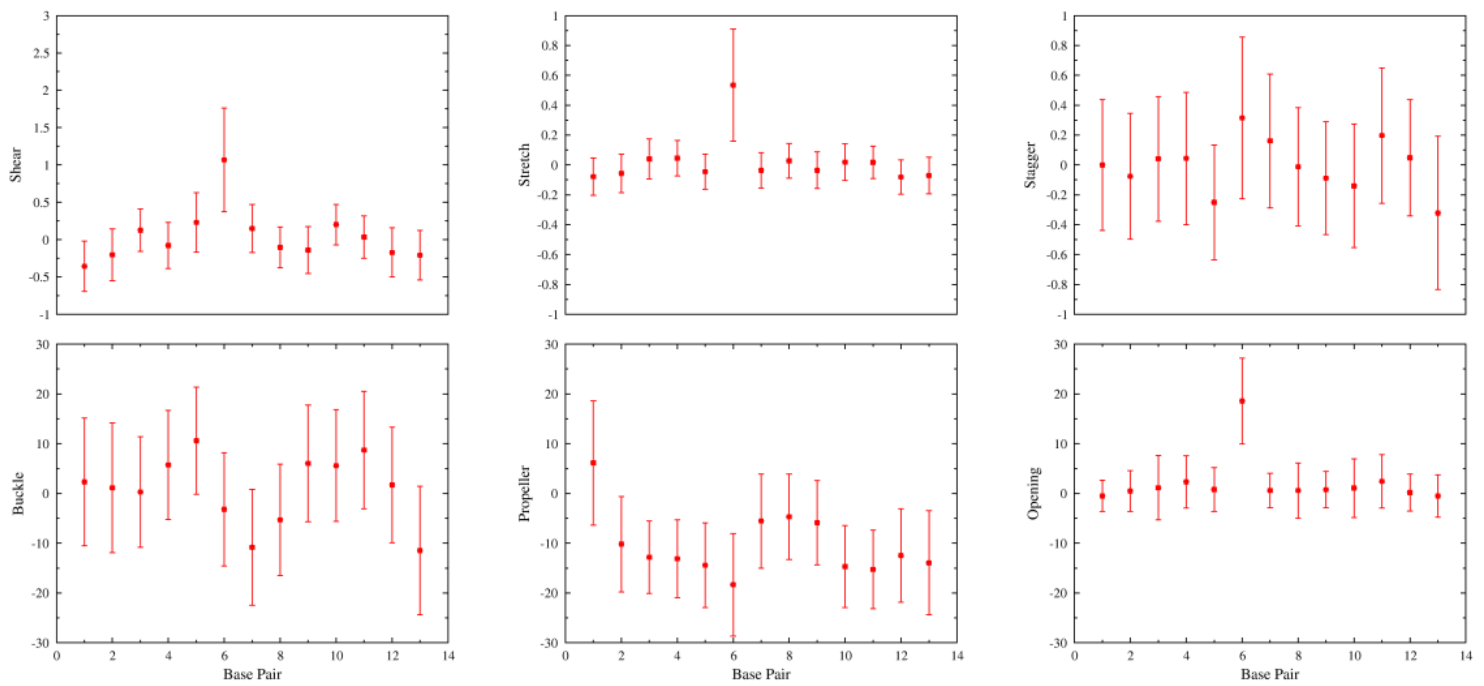

Figure S12. Average base pair parameters for $\mathrm{HOCH}_{2}-\mathrm{C}$ adducted DNA with the lesion paired opposite $\mathrm{G}$ and the bulky moiety directed toward the lesion Watson-Crick face. 

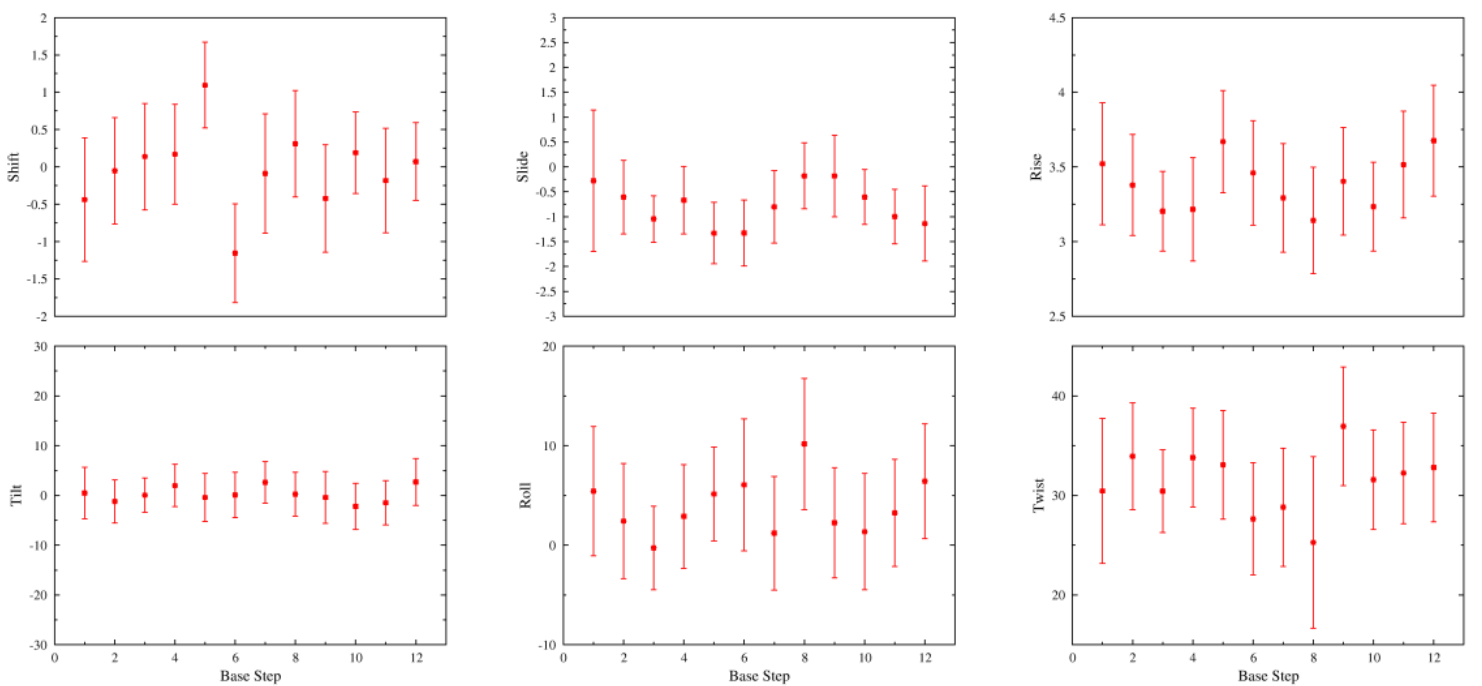

Figure S13. Average base step parameters for $\mathrm{HOCH}_{2}-\mathrm{C}$ adducted DNA with the lesion paired opposite $\mathrm{G}$ and the bulky moiety directed toward the lesion Watson-Crick face.

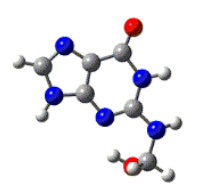

$0.0 \mathrm{~kJ} / \mathrm{mol}$ $\alpha^{\prime}:-176.7^{\circ}$

$\beta^{\prime}: 61.6^{\circ}$

$\gamma^{\prime}:-67.3^{\circ}$

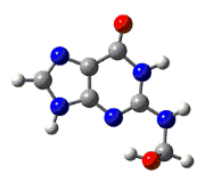

$0.0 \mathrm{~kJ} / \mathrm{mol}$

$\alpha^{\prime}: 176.6^{\circ}$

$\beta^{\prime}:-61.6^{\circ}$

$\gamma^{\prime}: 67.3^{\circ}$

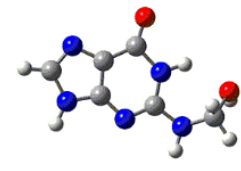

$5.0 \mathrm{~kJ} / \mathrm{mol}$ $\alpha^{\prime} 29.8^{\circ}$ $\beta^{\prime}:-71.8^{\circ}$ $\gamma^{\prime}:-54.9^{\circ}$

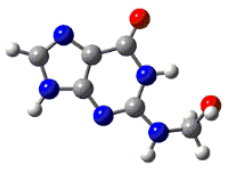

$5.0 \mathrm{~kJ} / \mathrm{mol}$ $\alpha^{\prime}:-29.8^{\circ}$ $\beta^{\prime}: 71.8^{\circ}$ $\gamma^{\prime}: 54.9^{\circ}$

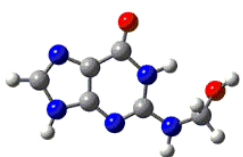

$11.6 \mathrm{~kJ} / \mathrm{mol}$ $\alpha^{\prime}: 28.4^{\circ}$ $\beta^{\prime}:-74.1^{\circ}$ $\gamma^{\prime}: 165.2^{\circ}$

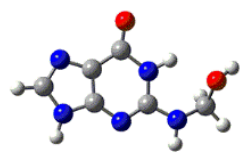

$11.6 \mathrm{~kJ} / \mathrm{mol}$ $\alpha^{\prime}:-28.5^{\circ}$ $\beta^{\prime}: 74.1^{\circ}$ $\gamma^{\prime}:-165.2^{\circ}$

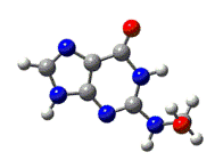

$11.8 \mathrm{~kJ} / \mathrm{mol}$ $\alpha^{\prime}: 34.1^{\circ}$ $\beta^{\prime}: 68.1^{\circ}$ $\gamma^{\prime}:-69.5^{\circ}$

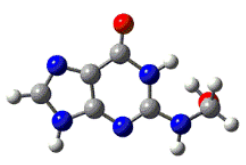

$11.8 \mathrm{~kJ} / \mathrm{mol}$

$\alpha^{\prime}:-34.1^{\circ}$

$\beta^{\prime}:-68.1^{\circ}$

$\gamma^{\prime}: 69.5^{\circ}$

Figure S14. B3LYP-D3(BJ)/6-311+G(2df,2p)//B3LYP/6-31G(d,p) structures for the $\mathrm{HOCH}_{2}$-G nucleobase adduct. Key structural features (deg.) and relative energies $(\mathrm{kJ} / \mathrm{mol}$ ) provided. See Figure 1 in the main text for definitions of dihedral angles. 


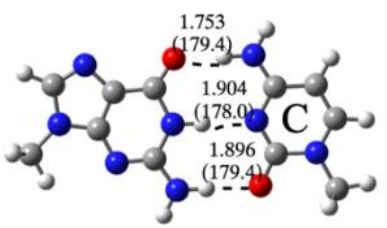

$-117.0 \mathrm{~kJ} / \mathrm{mol}$ $\angle\left(\mathrm{N}^{\prime} \mathrm{C} 1^{\prime} \mathrm{C} 1^{\prime}\right)=53.4^{\circ}$ $R\left(C 1^{\prime} \cdots C 1^{\prime}\right)=10.761 \AA$

Interplanar angle $=1.2^{\circ}$

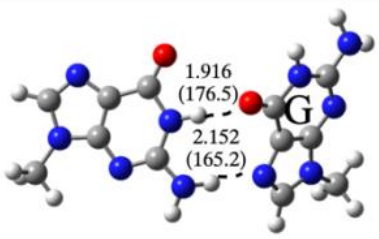

$-60.9 \mathrm{~kJ} / \mathrm{mol}$ $\angle\left(\mathrm{N} 9 \mathrm{C} 1^{\prime} \mathrm{C} 1^{\prime}\right)=58.4^{\circ}$ $R\left(C 1^{\prime} \cdots C 1^{\prime}\right)=10.751 \AA$ Interplanar angle $=64.3^{\circ}$

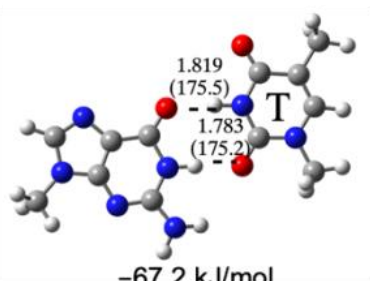

$-67.2 \mathrm{~kJ} / \mathrm{mo}$ $\angle\left(\mathrm{N} 9 \mathrm{C} 1^{\prime} \mathrm{C} 1^{\prime}\right)=42.9^{\circ}$ $R\left(C 1^{\prime} \cdots C 1^{\prime}\right)=10.445 \AA$ Interplanar angle $=2.6^{\circ}$

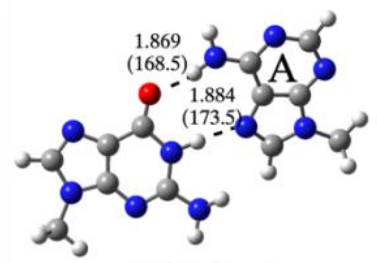

$-67.1 \mathrm{~kJ} / \mathrm{mol}$ $\angle\left(\mathrm{N} 9 \mathrm{C} 1^{\prime} \mathrm{C} 1^{\prime}\right)=52.3^{\circ}$

$R\left(C 1^{\prime} \cdots C 1^{\prime}\right)=10.967 \AA$ Interplanar angle $=23.9^{\circ}$
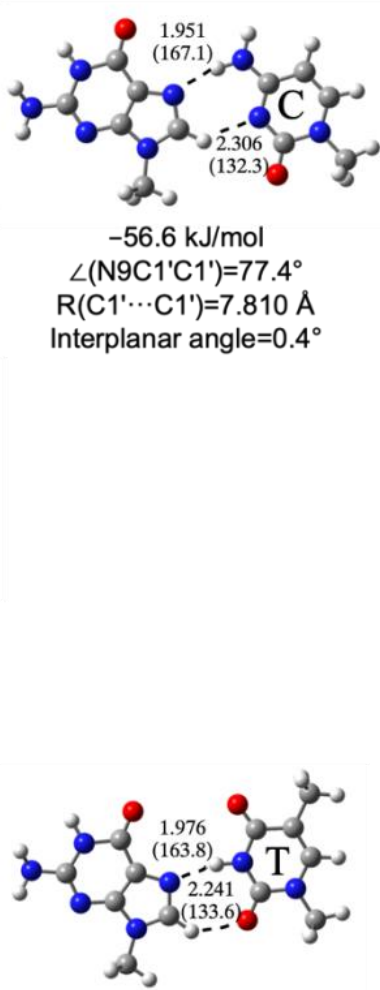

$-36.8 \mathrm{~kJ} / \mathrm{mol}$ $\angle\left(\mathrm{N}^{\prime} \mathrm{C} 1^{\prime} \mathrm{C} 1^{\prime}\right)=61.1^{\circ}$ $R\left(C 1^{\prime} \cdots C 1^{\prime}\right)=7.648 \AA$ Interplanar angle $=1.6^{\circ}$

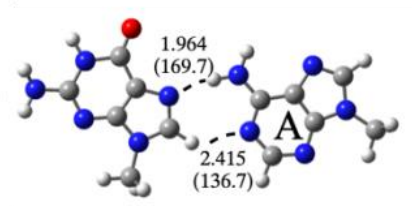

$-41.2 \mathrm{~kJ} / \mathrm{mol}$

$$
\begin{gathered}
\angle\left(\mathrm{N} 9 \mathrm{C} 1^{\prime} \mathrm{C} 1^{\prime}\right)=65.6^{\circ} \\
\mathrm{R}\left(\mathrm{C} 1^{\prime} \cdots \mathrm{C} 1^{\prime}\right)=10.219 \AA \\
\text { Interplanar angle }=0.2^{\circ}
\end{gathered}
$$

Figure S15. DFT structures (distances in $\AA$ and angles in deg.) and binding energies ( $\mathrm{kJ} / \mathrm{mol})$ for base pairs between the Watson-Crick (left) or Hoogsteen (right) face of $G$ and the canonical nucleobases. 


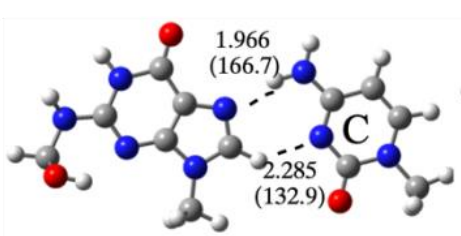

$-56.9 \mathrm{~kJ} / \mathrm{mol}$ $\angle\left(\mathrm{N} 9 \mathrm{C} 1^{\prime} \mathrm{C} 1^{\prime}\right)=78.1^{\circ}$

$\mathrm{R}\left(\mathrm{C} 1^{\prime} \cdots \mathrm{C} 1^{\prime}\right)=7.762 \AA$

Interplanar angle $=0.9^{\circ}$

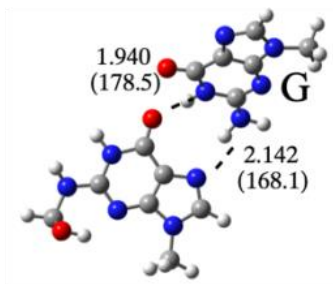

$-57.7 \mathrm{~kJ} / \mathrm{mol}$ $\angle\left(\mathrm{N}^{\prime} \mathrm{C} 1^{\prime} \mathrm{C} 1^{\prime}\right)=35.4^{\circ}$ $R\left(C 1^{\prime} \cdots C 1^{\prime}\right)=11.027 \AA$ Interplanar angle $=56.2^{\circ}$

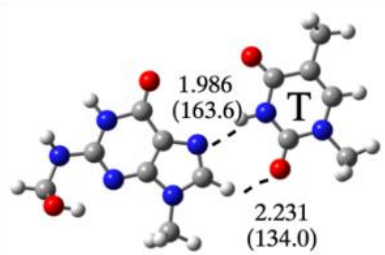

$-36.4 \mathrm{~kJ} / \mathrm{mol}$ $\angle\left(\mathrm{N} 9 \mathrm{C} 1^{\prime} \mathrm{C} 1^{\prime}\right)=61.5^{\circ}$ $R\left(C 1^{\prime} \cdots C 1^{\prime}\right)=7.632 \AA$ Interplanar angle $=0.8^{\circ}$

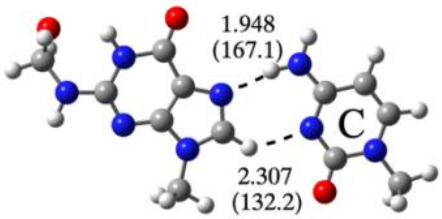

$-57.7 \mathrm{~kJ} / \mathrm{mol}$ $\angle\left(\mathrm{N}^{\circ} 1^{\prime} \mathrm{C} 1^{\prime}\right)=77.4^{\circ}$ $\mathrm{R}\left(\mathrm{C} 1^{\prime} \cdots \mathrm{C}^{\prime} 1^{\prime}\right)=7.814 \AA$ Interplanar angle $=0.6^{\circ}$

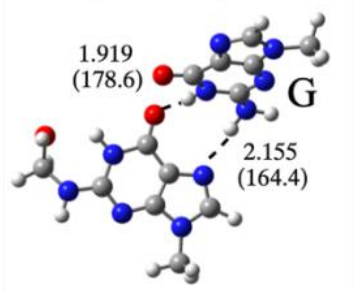

$-61.4 \mathrm{~kJ} / \mathrm{mol}$ $\angle\left(\mathrm{N} 9 \mathrm{C} 1^{\prime} \mathrm{C} 1^{\prime}\right)=39.0^{\circ}$ $R\left(C 1^{\prime} \cdots C 1^{\prime}\right)=10.709 \AA$ Interplanar angle $=66.0^{\circ}$

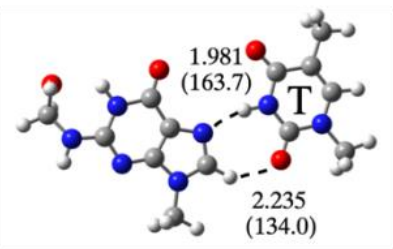

$-37.0 \mathrm{~kJ} / \mathrm{mol}$ $\angle\left(\mathrm{N} 9 \mathrm{C} 1^{\prime} \mathrm{C} 1^{\prime}\right)=61.3^{\circ}$

$\mathrm{R}\left(\mathrm{C} 1^{\prime} \cdots \mathrm{C} 1^{\prime}\right)=7.636 \AA$

Interplanar angle $=2.3^{\circ}$
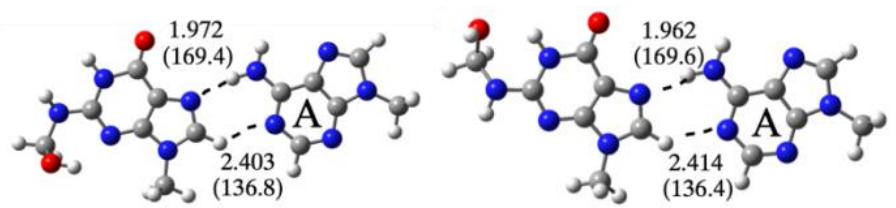

$-41.3 \mathrm{~kJ} / \mathrm{mol}$ $\angle\left(\mathrm{N} 9 \mathrm{C} 1^{\prime} \mathrm{C} 1^{\prime}\right)=66.0^{\circ}$ $R\left(C 1^{\prime} \cdots C 1^{\prime}\right)=10.915 \AA$ Interplanar angle $=1.3^{\circ}$

$-42.4 \mathrm{~kJ} / \mathrm{mol}$ $\angle\left(\mathrm{N} 9 \mathrm{C} 1^{\prime} \mathrm{C} 1^{\prime}\right)=65.5^{\circ}$

$R\left(C 1^{\prime} \cdots C 1^{\prime}\right)=10.217 \AA$

Interplanar angle $=0.8^{\circ}$

Figure S16. DFT structures (distances in $\AA$ and angles in deg.) and binding energies $(\mathrm{kJ} / \mathrm{mol})$ for base pairs between the Hoogsteen face of $\mathrm{HOCH}_{2}-\mathrm{G}$ and the canonical nucleobases when the bulky moiety is directed away (left) or toward (right) the lesion Watson-Crick face. 


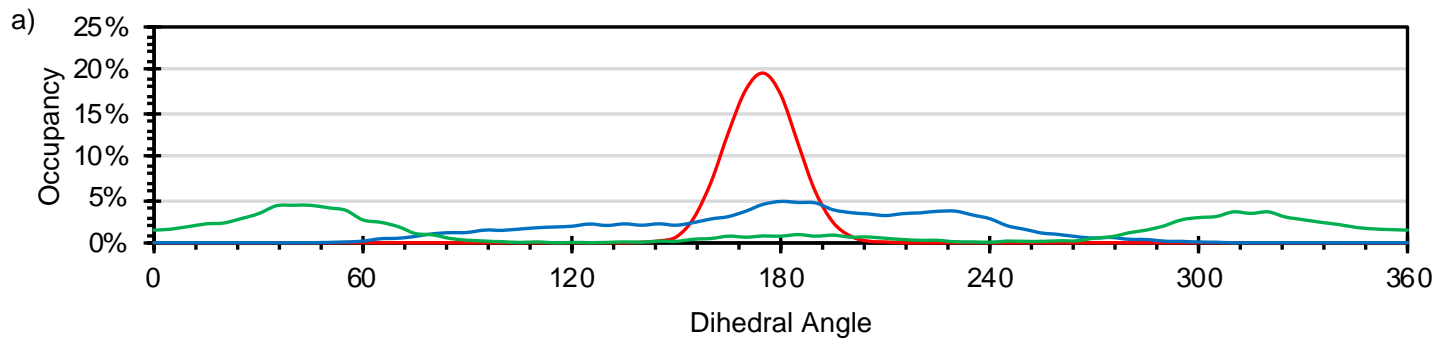

b)
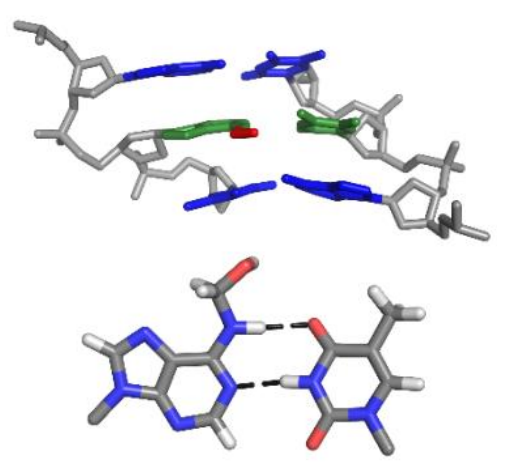

c)

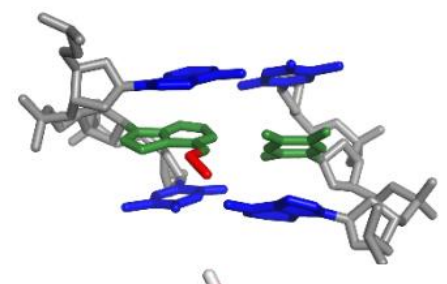

d)

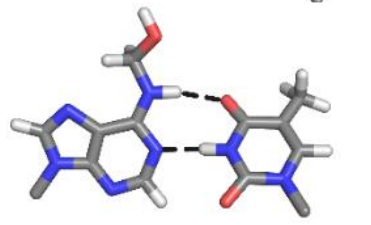

Figure S17. a) $\alpha^{\prime}$ (red), $\beta^{\prime}$ (blue) and $\gamma^{\prime}$ (green) dihedral angle distributions and MD representative structures of the three $\gamma^{\prime}$ orientations adopted by the $\mathrm{HOCH}_{2}$-G lesion with the bulky moiety directed away from the lesion Watson-Crick face when paired opposite $G$, with $\gamma^{\prime}$ approximately equal to b) $30^{\circ}$, c) $180^{\circ}$ and d) $330^{\circ}$.
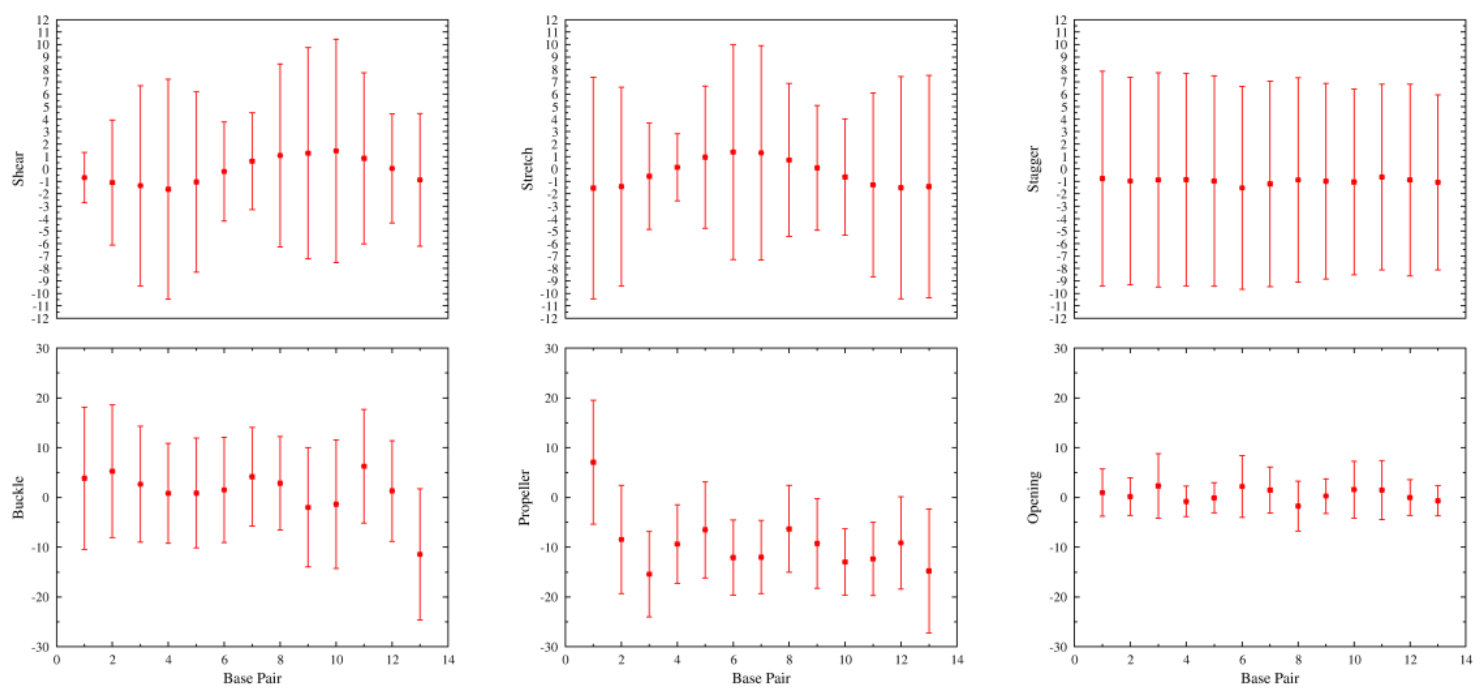

Figure S18. Average base pair parameters for $\mathrm{HOCH}_{2}-\mathrm{G}$ adducted DNA with the lesion paired opposite $\mathrm{C}$ and the bulky moiety directed away from the lesion Watson-Crick face. 

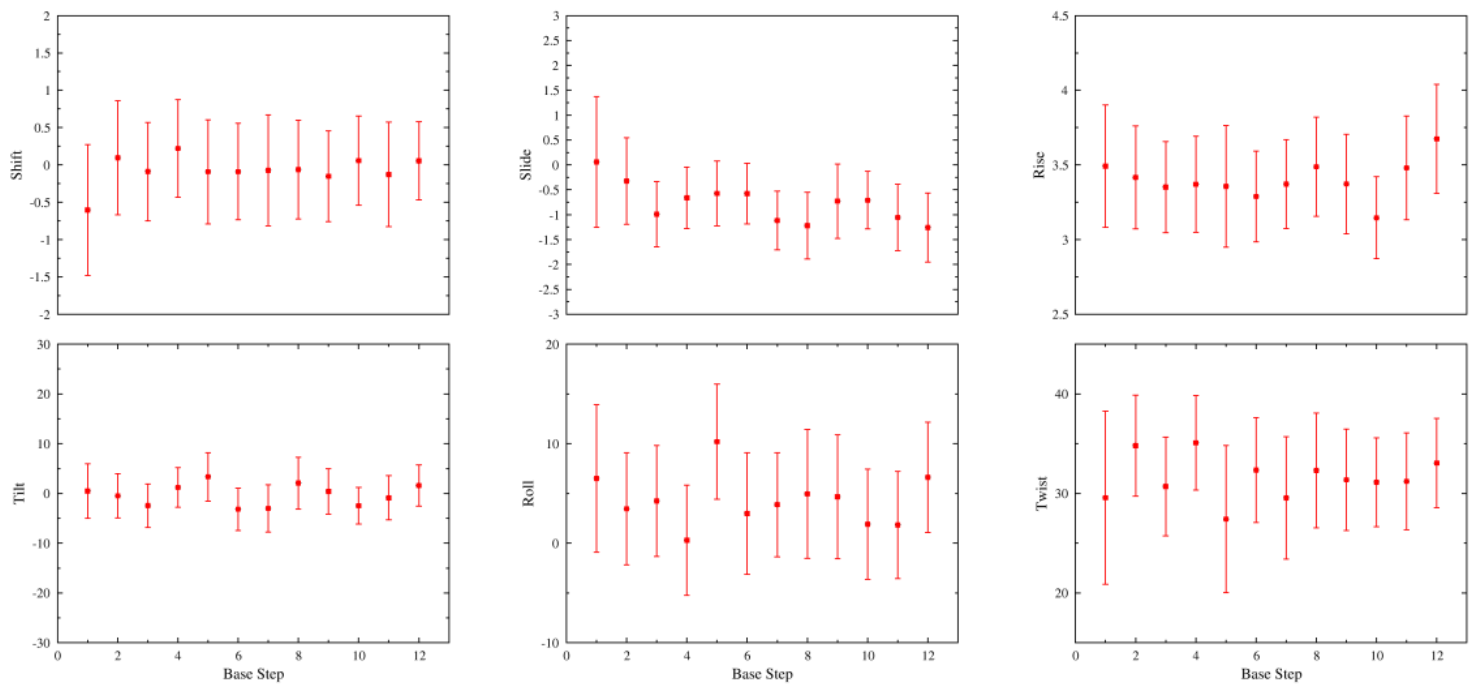

Figure S19. Average base step parameters for $\mathrm{HOCH}_{2}-\mathrm{G}$ adducted DNA with the lesion paired opposite $\mathrm{C}$ and the bulky moiety directed away from the lesion Watson-Crick face.

a)

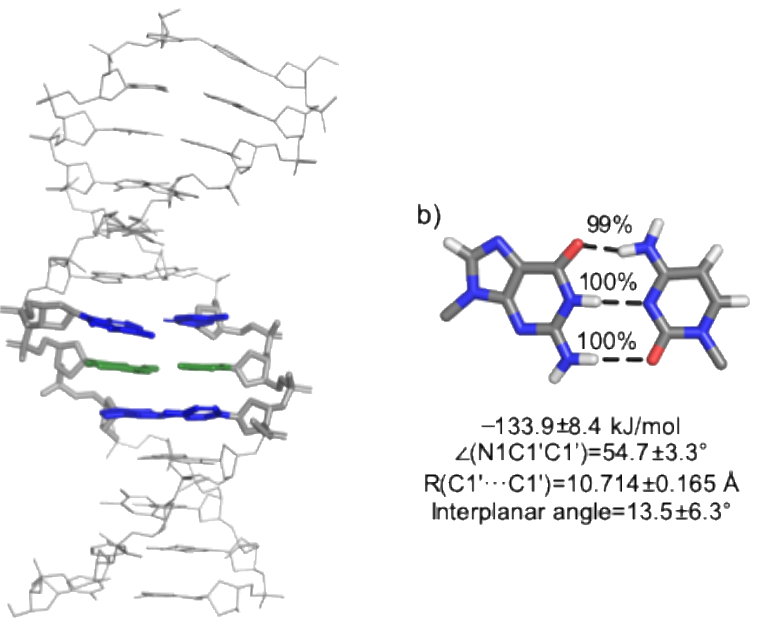

Figure S20. a) Representative structure and b) G:C base-pair hydrogen-bonding geometry (with hydrogen-bonding occupancies, energetics and key geometrical information) across the MD simulation trajectory for undamaged DNA. 

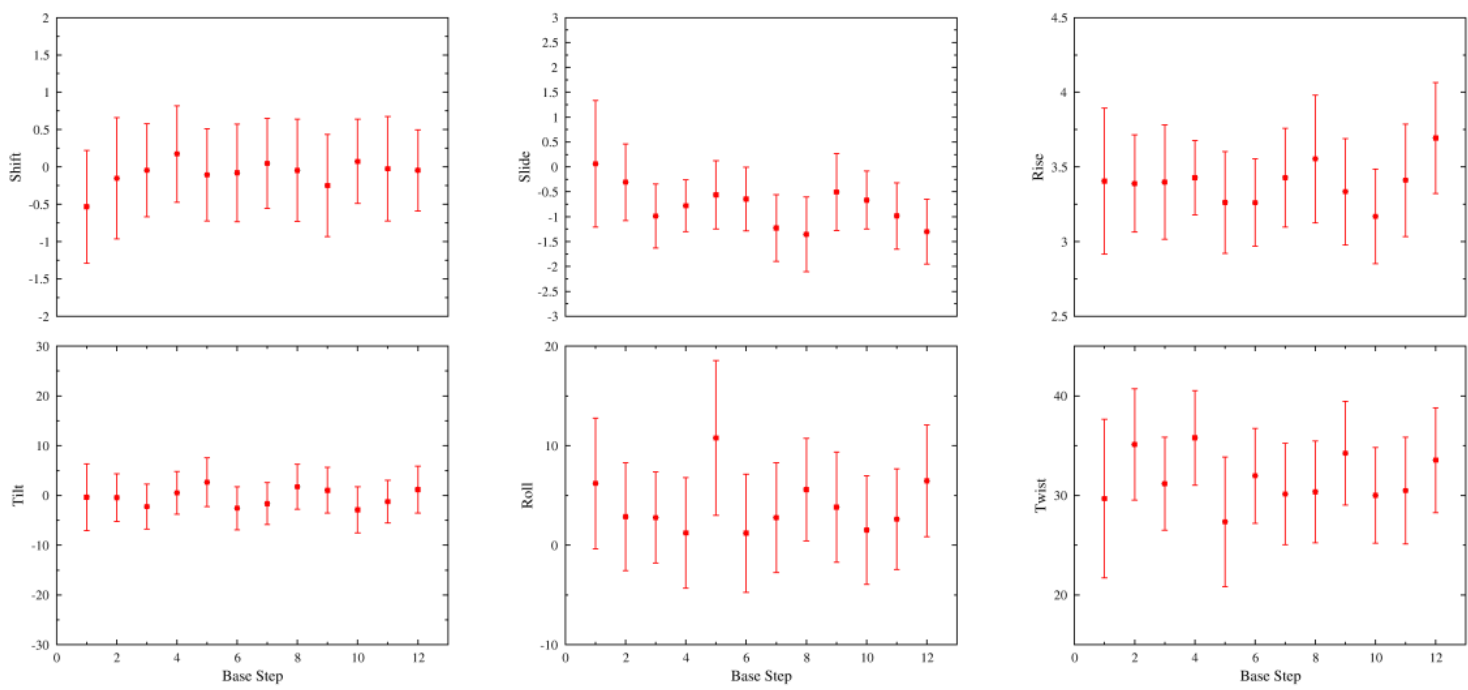

Figure S21. Average base pair parameters for natural DNA containing G paired opposite C.
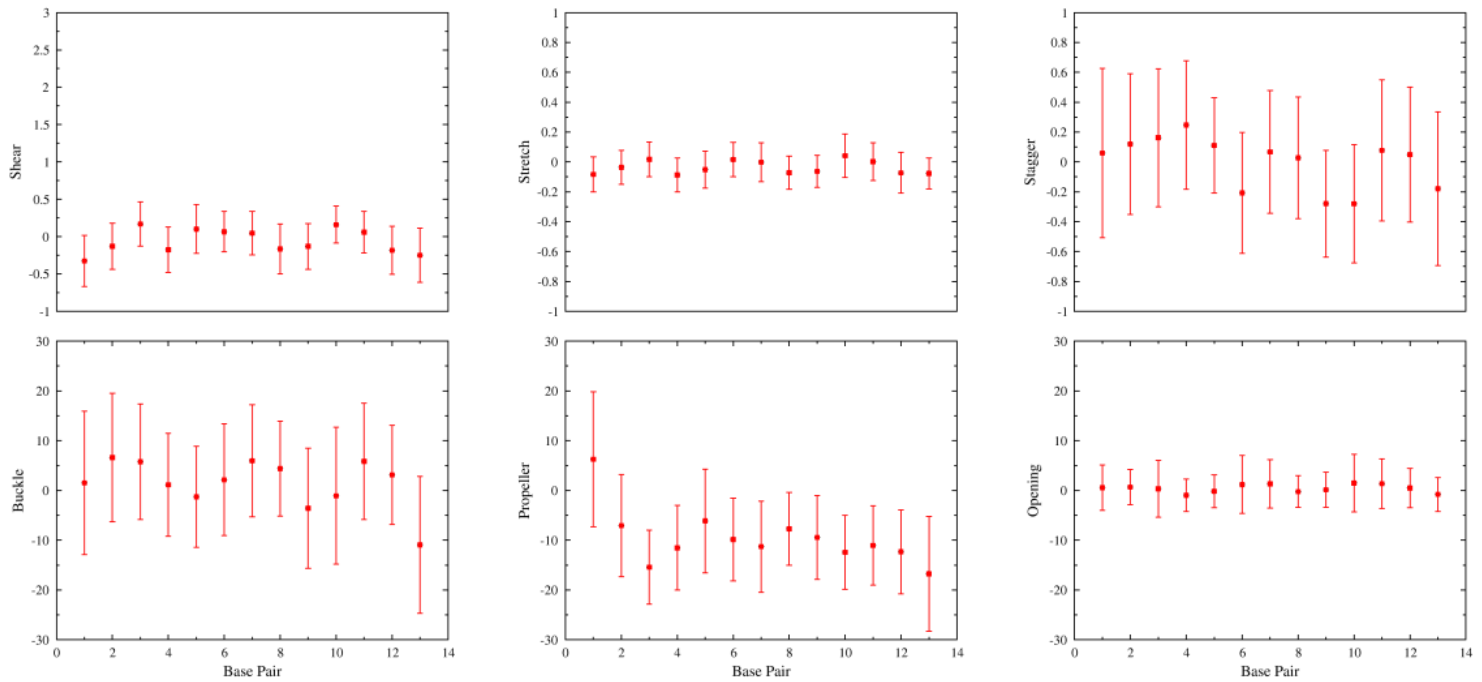

Figure S22. Average base step parameters for natural DNA containing G paired opposite C. 
a)

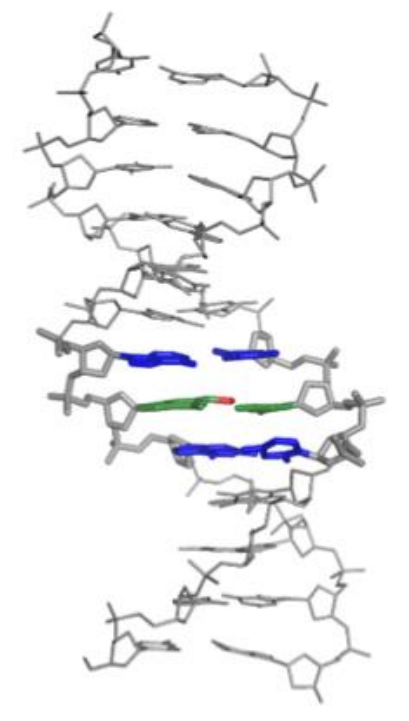

b)

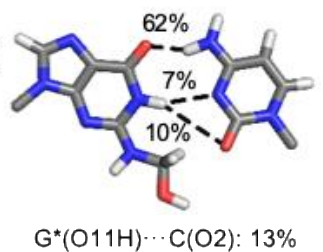

$\mathrm{G}^{\star}(\mathrm{O} 11 \mathrm{H}) \cdots \mathrm{C}(\mathrm{O} 2): 13 \%$
$\mathrm{G}^{\star}(\mathrm{O} 11 \mathrm{H}) \cdots \mathrm{T} 20\left(\mathrm{O} 4^{\prime}\right): 13 \%$

$\mathrm{G}^{*}(\mathrm{O} 11 \mathrm{H}) \cdots \mathrm{C}\left(\mathrm{O}^{\prime}\right): 9 \%$

$\mathrm{G}^{\star}(\mathrm{O} 11 \mathrm{H}) \cdots \mathrm{G} 9(\mathrm{~N} 3): 7 \%$

$-95.4 \pm 26.4 \mathrm{~kJ} / \mathrm{mol}$

$\angle\left(\mathrm{N} 1 \mathrm{C} 1^{\prime} \mathrm{C} 1^{\prime}\right)=49.7 \pm 9.2^{\circ}$

$\mathrm{R}\left(\mathrm{C} 1^{\prime} \cdots \mathrm{C} 1^{\prime}\right)=11.647 \pm 0.730 \mathrm{~A}$

Interplanar angle $=28.9 \pm 25.6^{\circ}$

c)

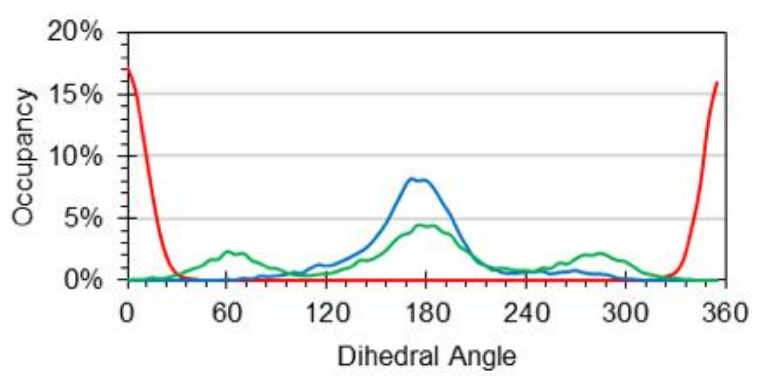

Figure S23. a) Representative structure, b) $\mathrm{HOCH}_{2}-\mathrm{G}: \mathrm{C}$ base-pair hydrogen-bonding geometry (with hydrogen-bonding occupancies, energetics and key geometrical information), and c) $\alpha^{\prime}$ (red), $\beta^{\prime}$ (blue) and $\gamma^{\prime}$ (green) dihedral angle distributions across the MD simulation trajectory for $\mathrm{HOCH}_{2}-\mathrm{G}$ adducted DNA when the bulky moiety is directed toward the lesion Watson-Crick face. 
a)

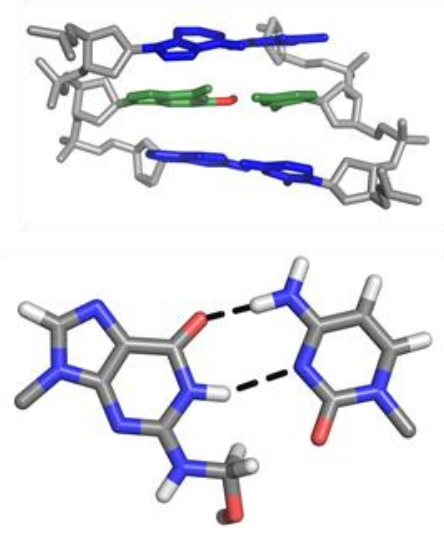

b)

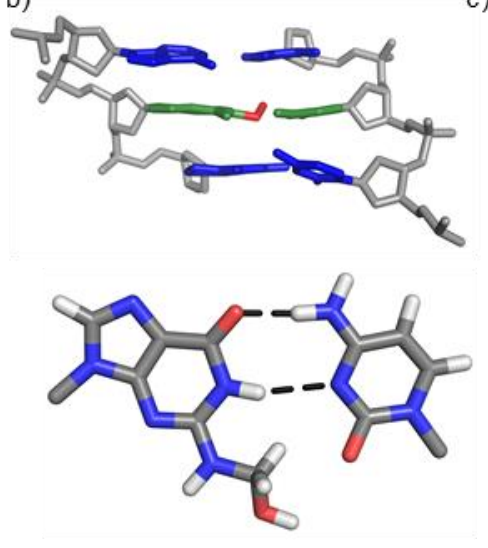

c)

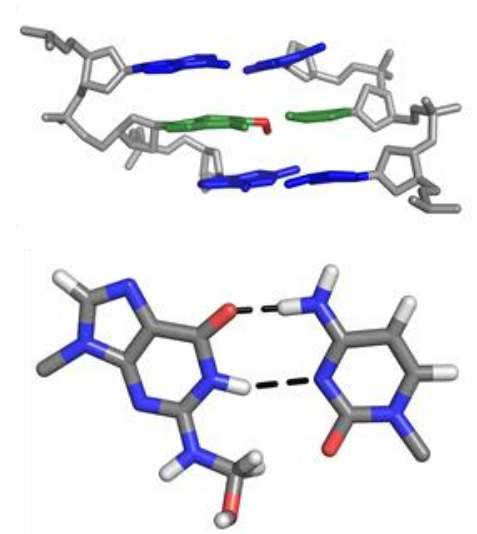

Figure S24. MD representative structures of the three $\gamma^{\prime}$ orientations adopted by the $\mathrm{HOCH}_{2}$-G lesion with the bulky moiety directed toward the lesion Watson-Crick face when paired opposite $\mathrm{C}$, with $\gamma^{\prime}$ approximately equal to a) $70^{\circ}$ b) $180^{\circ}$ and c) $290^{\circ}$.
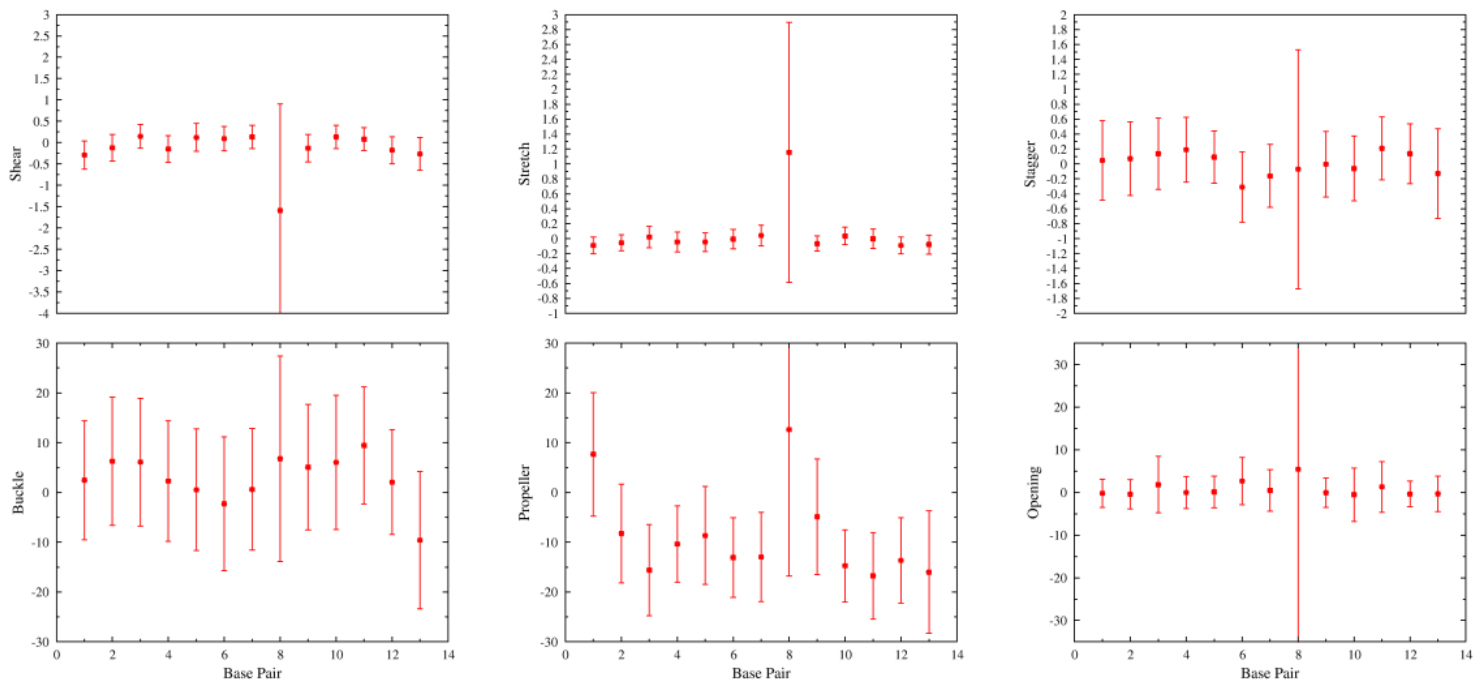

Figure S25. Average base pair parameters for $\mathrm{HOCH}_{2}-\mathrm{G}$ adducted DNA with the lesion paired opposite $\mathrm{C}$ and the bulky moiety directed toward the lesion Watson-Crick face. 

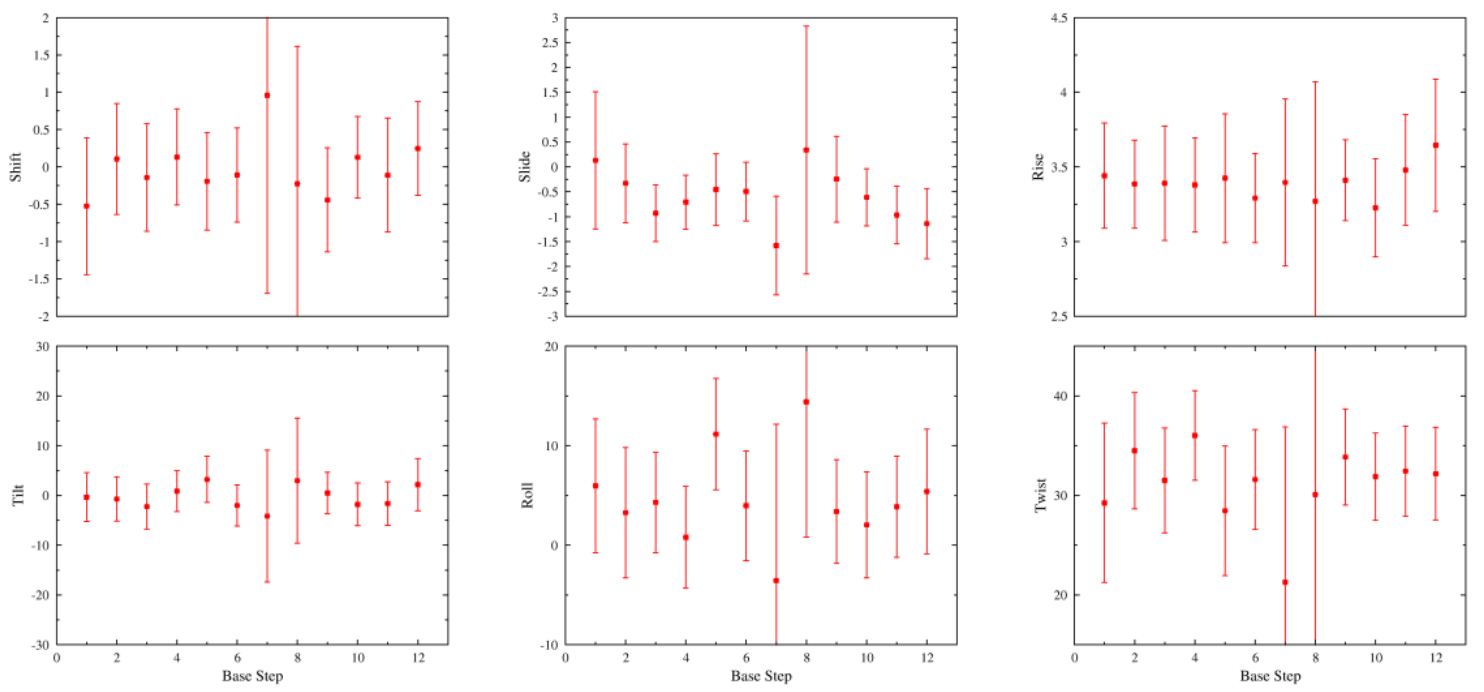

Figure S26. Average base step parameters for $\mathrm{HOCH}_{2}-\mathrm{G}$ adducted DNA with the lesion paired opposite $\mathrm{C}$ and the bulky moiety directed toward the lesion Watson-Crick face.

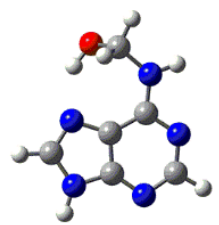

$0.0 \mathrm{~kJ} / \mathrm{mol}$

$\alpha^{\prime}:-176.9^{\circ}$

$\beta^{\prime}:-66.1^{\circ}$

$\gamma^{\prime}: 80.4^{\circ}$

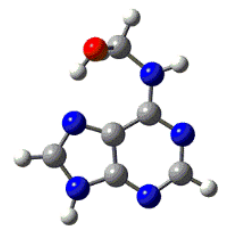

$0.0 \mathrm{~kJ} / \mathrm{mol}$

$\alpha^{\prime}: 176.9^{\circ}$

$\beta^{\prime}: 66.1^{\circ}$

$\gamma^{\prime}:-80.4^{\circ}$

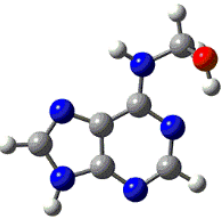

$3.3 \mathrm{~kJ} / \mathrm{mol}$

$\alpha^{\prime}:-4.4^{\circ}$

$\beta^{\prime}:-60.7^{\circ}$

$\gamma^{\prime}: 67.6^{\circ}$

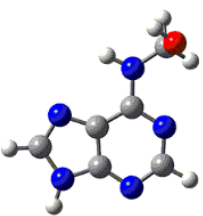

$16.5 \mathrm{~kJ} / \mathrm{mol}$

$\alpha^{\prime}:-12.8^{\circ}$

$\beta^{\prime}:-81.6^{\circ}$

$\gamma^{\prime}:-66.1^{\circ}$

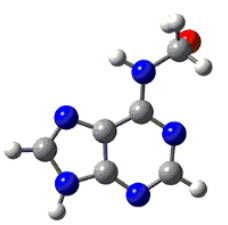

$16.5 \mathrm{~kJ} / \mathrm{mol}$

$\alpha^{\prime}: 12.9^{\circ}$

$\beta^{\prime}: 81.5^{\circ}$

$\gamma^{\prime}: 66.1^{\circ}$

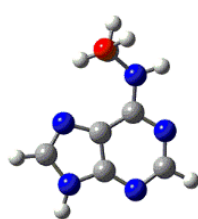

$19.1 \mathrm{~kJ} / \mathrm{mol}$

$\alpha^{\prime}:-159.1^{\circ}$

$\beta^{\prime}: 72.7^{\circ}$

$\gamma^{\prime}: 65.4^{\circ}$

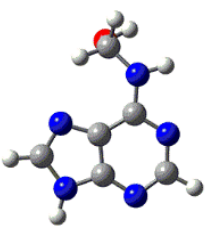

$19.1 \mathrm{~kJ} / \mathrm{mol}$

$\alpha^{\prime}: 159.1^{\circ}$

$\beta^{\prime}:-72.7^{\circ}$

$\gamma^{\prime}:-65.4^{\circ}$

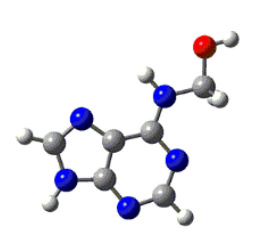

$22.5 \mathrm{~kJ} / \mathrm{mol}$

$\alpha^{\prime}: 0.0^{\circ}$

$\beta^{\prime}: 180.0^{\circ}$

$\gamma^{\prime}: 179.9^{\circ}$

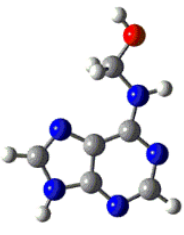

$26.9 \mathrm{~kJ} / \mathrm{mol}$

$\alpha^{\prime}: 180.0^{\circ}$

$\beta^{\prime}: 180.0^{\circ}$

$\gamma^{\prime}: 180.0^{\circ}$

Figure S27. B3LYP-D3(BJ)/6-311+G(2df,2p)//B3LYP/6-31G(d,p) structures for the $\mathrm{HOCH}_{2}-\mathrm{A}$ nucleobase adduct. Key structural features (deg.) and relative energies $(\mathrm{kJ} / \mathrm{mol}$ ) provided. See Figure 1 in the main text for definitions of dihedral angles. 


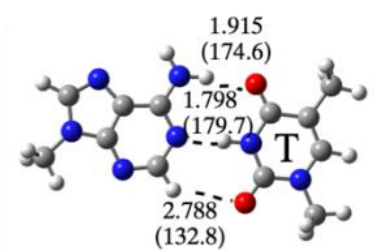

$-63.2 \mathrm{~kJ} / \mathrm{mol}$ $\angle\left(\mathrm{N} 9 \mathrm{C} 1^{\prime} \mathrm{C} 1^{\prime}\right)=55.2^{\circ}$ $R\left(C 1^{\prime} \cdots C 1^{\prime}\right)=10.574 \AA$ Interplanar angle $=0.0^{\circ}$
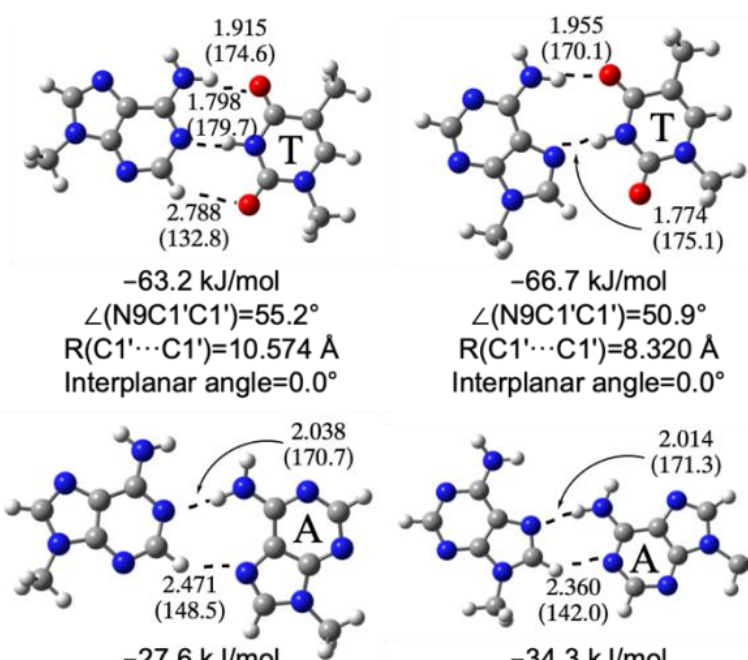

$-27.6 \mathrm{~kJ} / \mathrm{mol}$ $\angle\left(\mathrm{N}^{\prime} \mathrm{C} 1^{\prime} \mathrm{C} 1^{\prime}\right)=73.0^{\circ}$ $R\left(C 1^{\prime} \cdots C 1^{\prime}\right)=10.682 \AA$ Interplanar angle $=21.3^{\circ}$

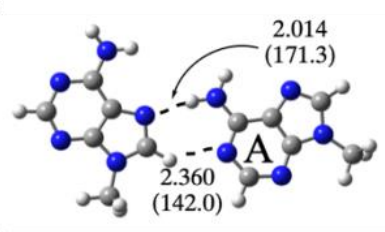

$-34.3 \mathrm{~kJ} / \mathrm{mol}$ $\angle\left(\mathrm{N}^{\prime} \mathrm{C} 1^{\prime} \mathrm{C} 1^{\prime}\right)=68.4^{\circ}$ $R\left(C 1^{\prime} \cdots C 1^{\prime}\right)=10.100 \AA$ Interplanar angle $=4.0^{\circ}$
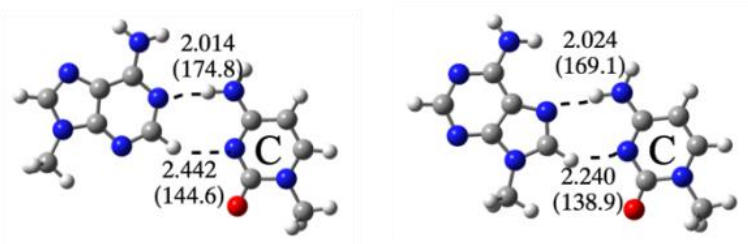

$-30.2 \mathrm{~kJ} / \mathrm{mol}$ $\angle\left(\mathrm{N} 9 \mathrm{C} 1^{\prime} \mathrm{C} 1^{\prime}\right)=75.1^{\circ}$ $R\left(C 1^{\prime} \cdots C 1^{\prime}\right)=10.402 \AA$ Interplanar angle $=15.3^{\circ}$

$-46.0 \mathrm{~kJ} / \mathrm{mol}$ $\angle\left(\mathrm{N} 9 \mathrm{C} 1^{\prime} \mathrm{C} 1^{\prime}\right)=54.4^{\circ}$ $R\left(C 1^{\prime} \cdots C 1^{\prime}\right)=7.626 \AA$ Interplanar angle $=8.4^{\circ}$
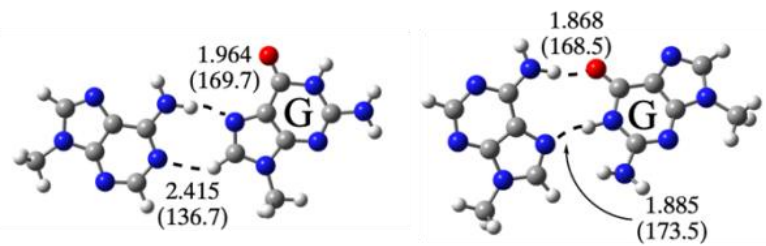

$-41.2 \mathrm{~kJ} / \mathrm{mol}$ $\angle\left(\mathrm{N} 9 \mathrm{C} 1^{\prime} \mathrm{C} 1^{\prime}\right)=44.4^{\circ}$ $R\left(C 1^{\prime} \cdots C 1^{\prime}\right)=10.219 \AA$ Interplanar angle $=0.2^{\circ}$

$-67.2 \mathrm{~kJ} / \mathrm{mol}$ $\angle\left(\mathrm{N} 9 \mathrm{C} 1^{\prime} \mathrm{C} 1^{\prime}\right)=38.8^{\circ}$ $R\left(C 1^{\prime} \cdots C 1^{\prime}\right)=10.970 \AA$ Interplanar angle $=23.9^{\circ}$

Figure S28. DFT structures (distances in $\AA$ and angles in deg.) and binding energies ( $\mathrm{kJ} / \mathrm{mol}$ ) for base pairs between the Watson-Crick (left) or Hoogsteen (right) face of $A$ and the canonical nucleobases. 

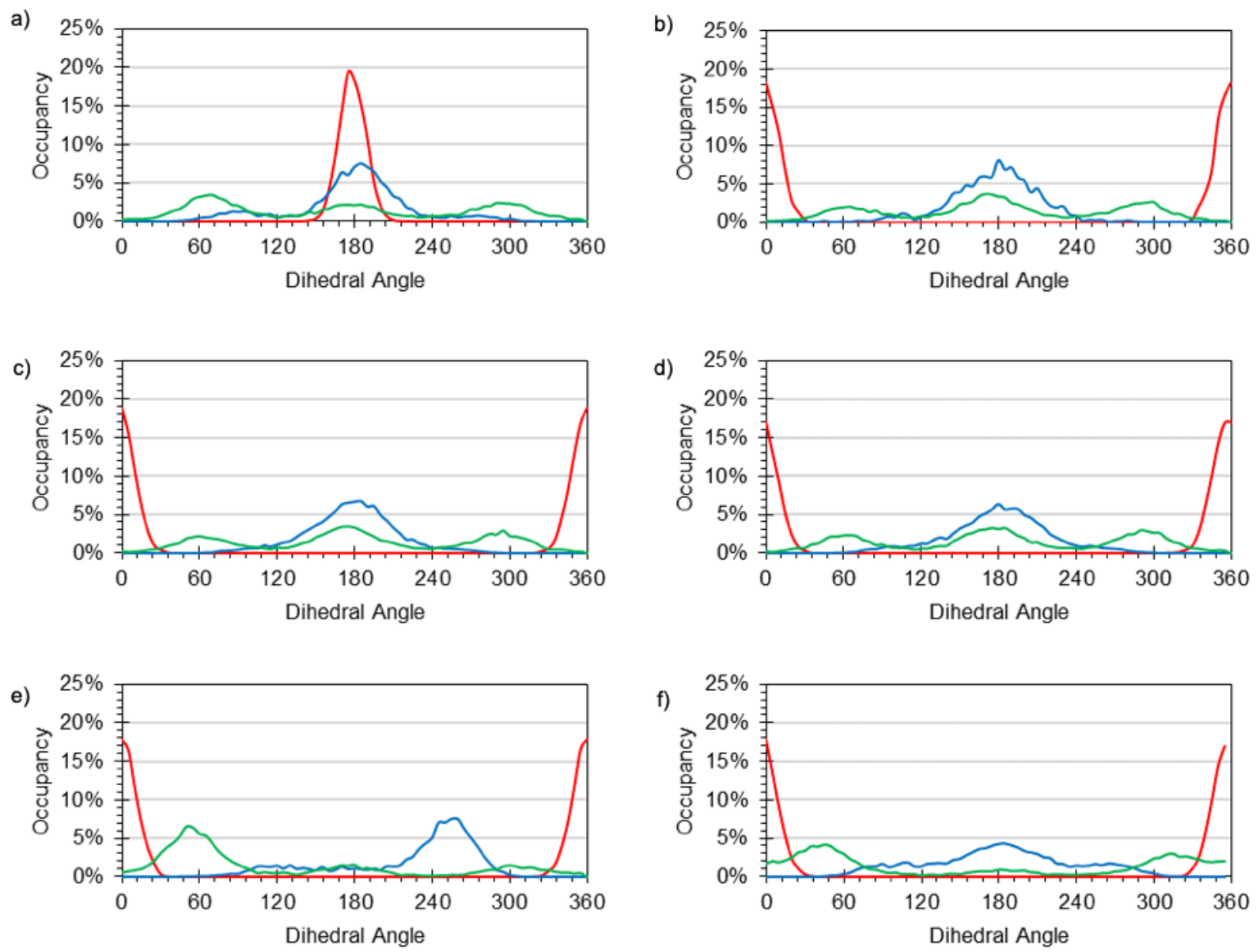

Figure S29. Dihedral distributions of $\alpha^{\prime}$ (red), $\beta^{\prime}$ (blue) and $\gamma^{\prime}$ (green) across MD simulations for $\mathrm{HOCH}_{2}-\mathrm{A}$ adducted DNA, when either (1) the bulky moiety is directed away from the lesion Watson-Crick face and anti $\mathrm{HOCH}_{2}-\mathrm{A}$ is paired opposite $\mathrm{T}$ (a) or (2) the bulky moiety is directed towards the lesion Watson-Crick face and anti $\mathrm{HOCH}_{2}-\mathrm{A}$ is paired opposite $\mathrm{T}$ (b), $\mathrm{C}$ (c) or $\mathrm{A}$ (d) or syn $\mathrm{HOCH}_{2}-\mathrm{A}$ is paired opposite $\mathrm{A}$ (e) or $\mathrm{G}$ (f). 
a)

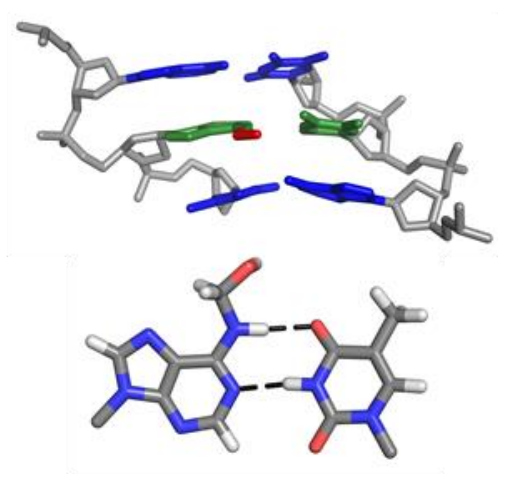

b)

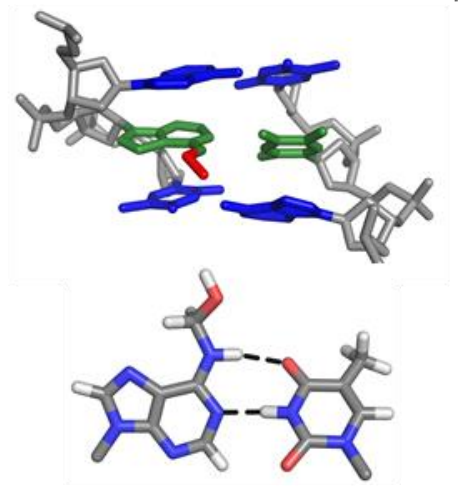

c)

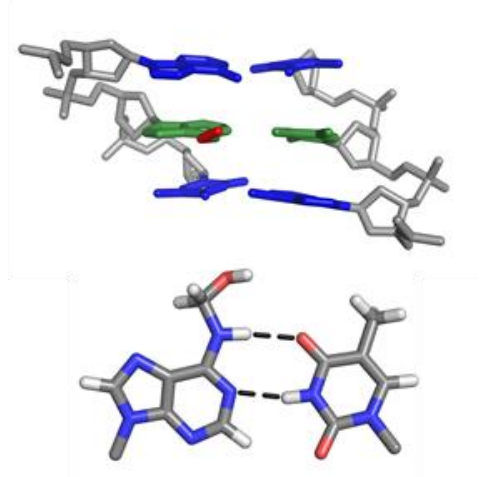

Figure S30. MD representative structures of the three $\gamma^{\prime}$ orientations adopted by the $\mathrm{HOCH}_{2}-\mathrm{A}$ lesion with the bulky moiety directed away from the lesion Watson-Crick face when paired opposite $T$, with $\gamma^{\prime}$ approximately equal to a) $60^{\circ}$ b) $180^{\circ}$ and c) $300^{\circ}$.
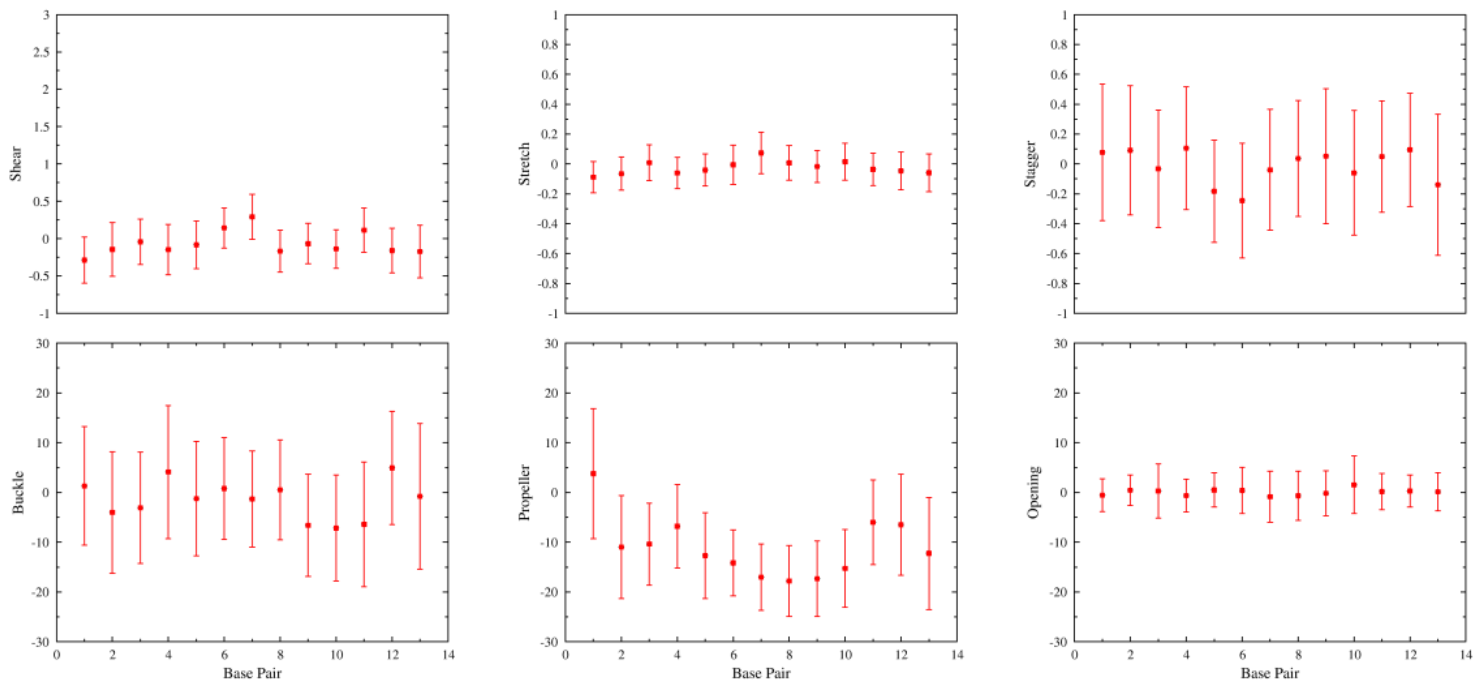

Figure S31. Average base pair parameters for $\mathrm{HOCH}_{2}-\mathrm{A}$ adducted DNA with the lesion paired opposite $\mathrm{T}$ and the bulky moiety directed away from the lesion Watson-Crick face. 

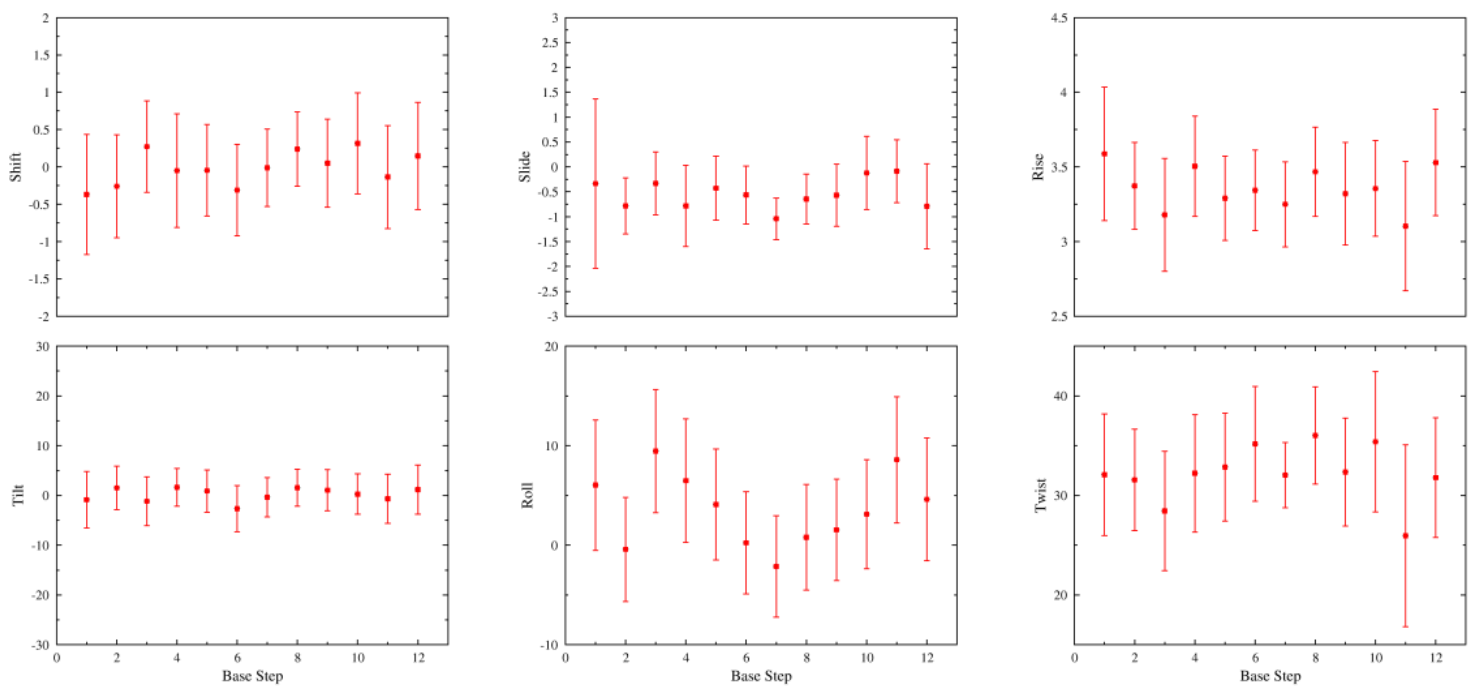

Figure S32. Average base step parameters for $\mathrm{HOCH}_{2}-\mathrm{A}$ adducted DNA with the lesion paired opposite $\mathrm{T}$ and the bulky moiety directed away from the lesion Watson-Crick face.

a)

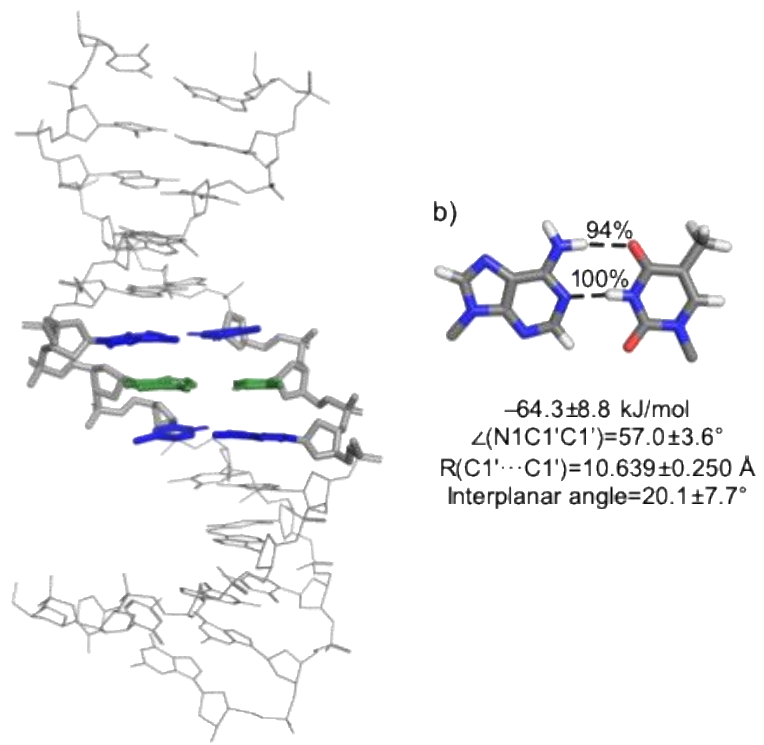

Figure S33. a) Representative structure, and b) A:T base-pair hydrogen-bonding geometry (with hydrogen-bonding occupancies, energetics and key geometrical information) across the MD simulation trajectory for undamaged DNA. 

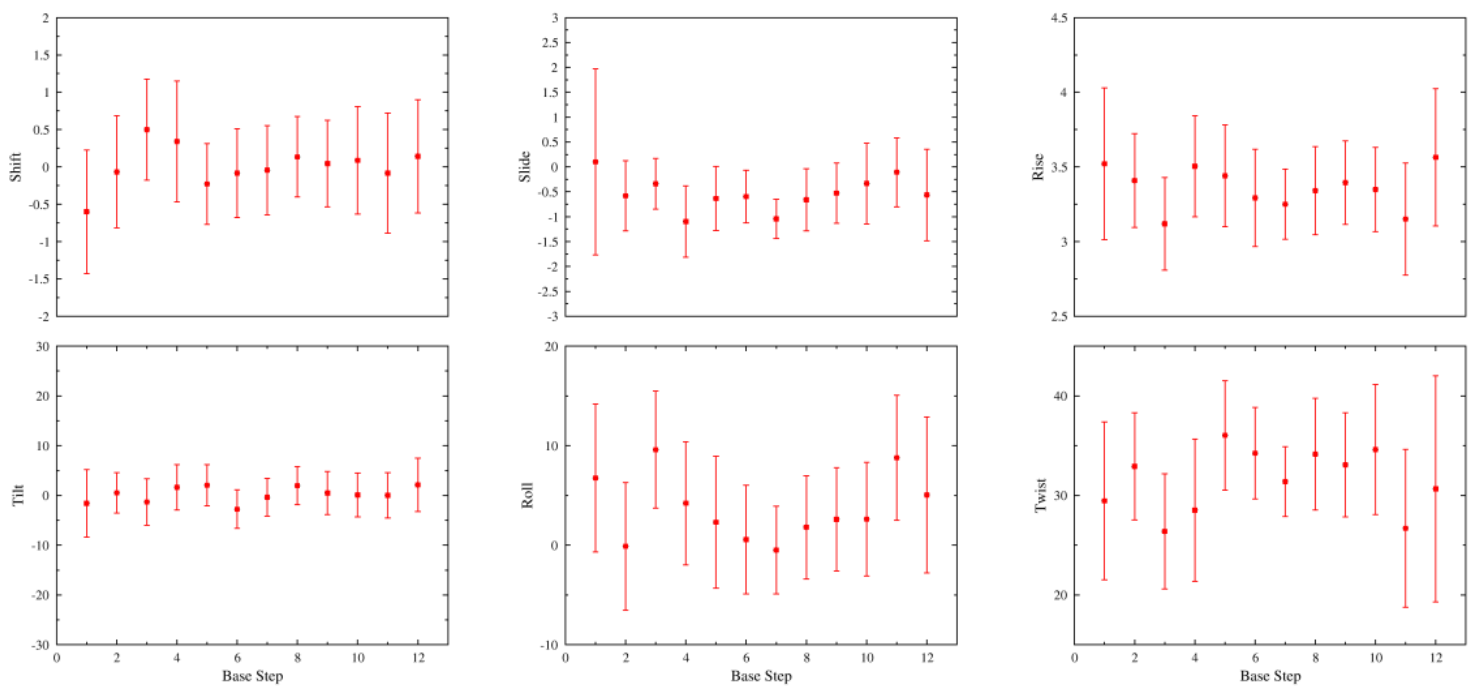

Figure S34. Average base pair parameters for natural DNA containing A paired opposite T.
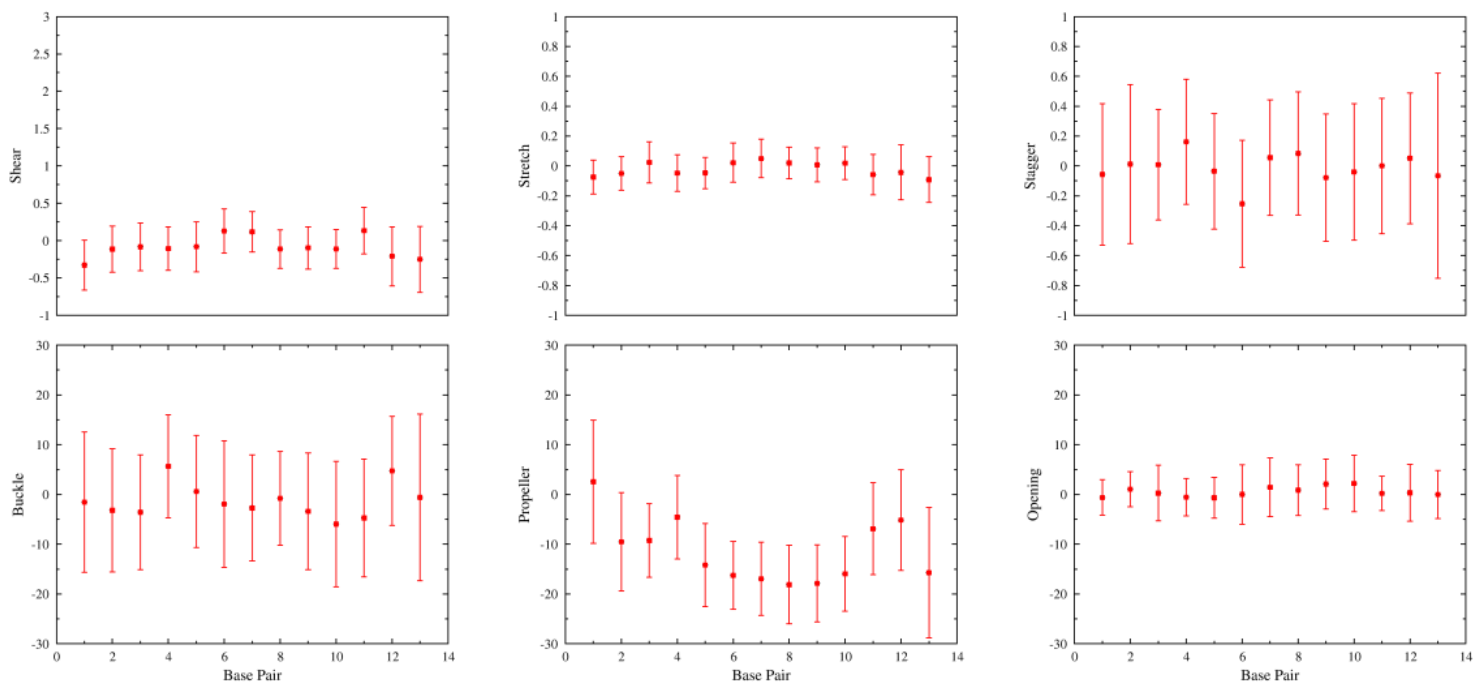

Figure S35. Average base step parameters for natural DNA containing A paired opposite T. 
a)
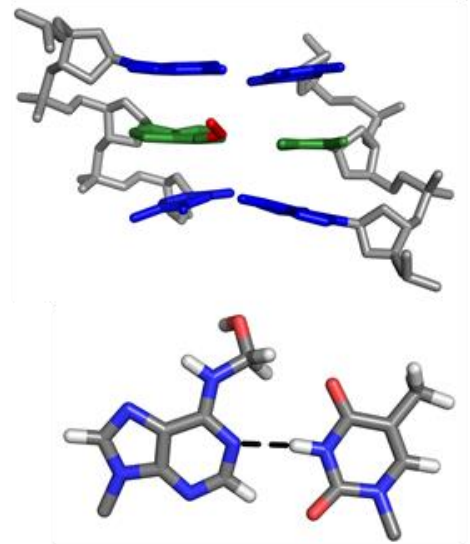

b)
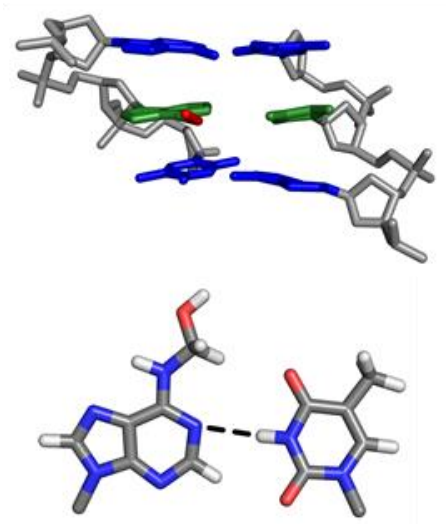

c)
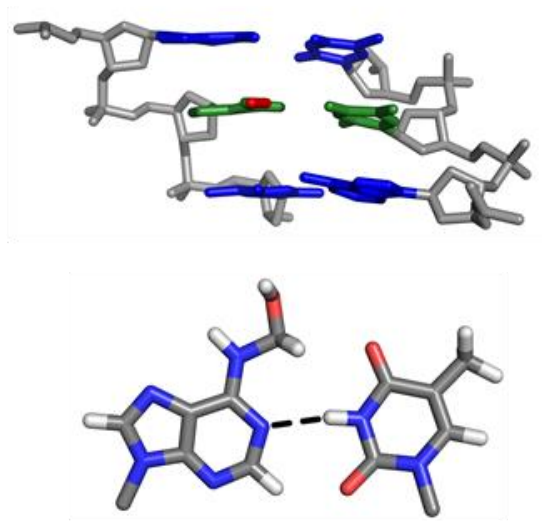

Figure S36. MD representative structures of the three $\gamma^{\prime}$ orientations adopted by the $\mathrm{HOCH}_{2}-\mathrm{A}$ lesion with the bulky moiety directed toward the lesion Watson-Crick face when paired opposite $\mathrm{T}$, with $\gamma^{\prime}$ approximately equal to a) $\left.60^{\circ} \mathrm{b}\right) 180^{\circ}$ and c) $300^{\circ}$.
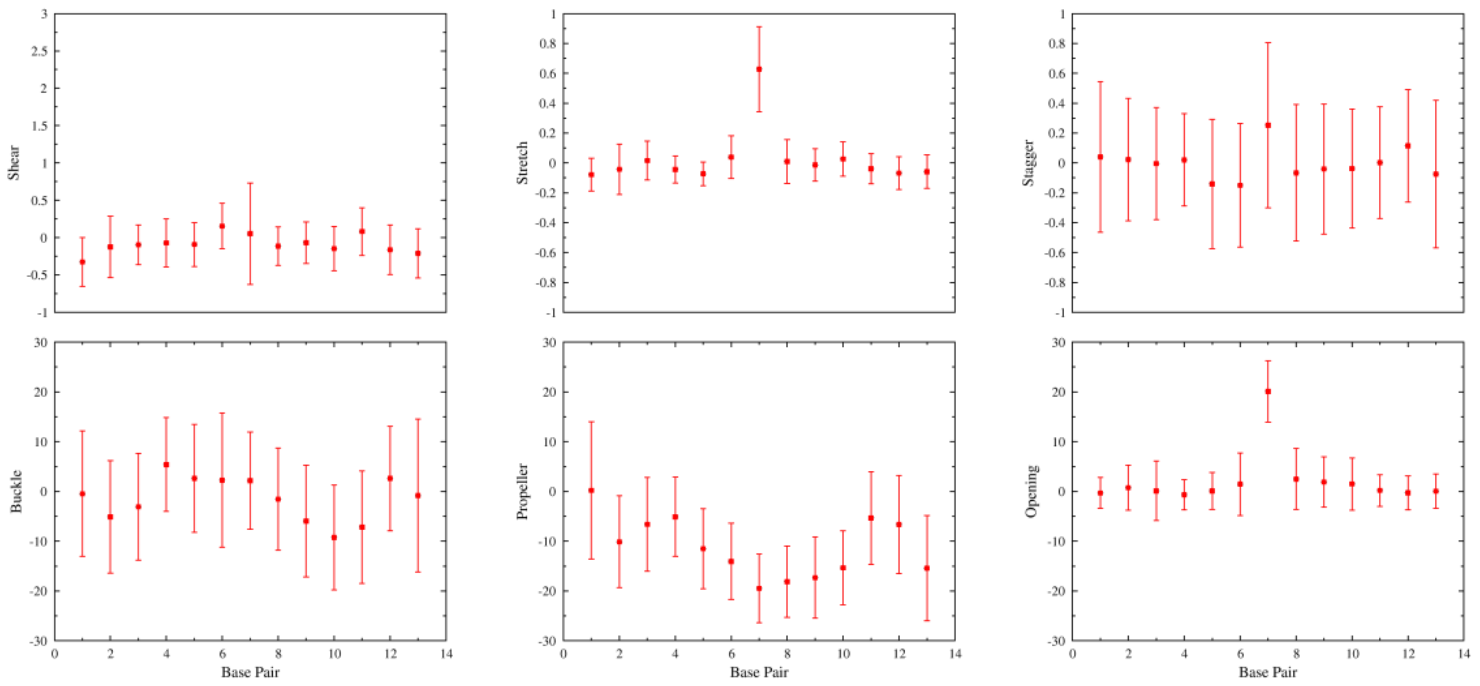

Figure S37. Average base pair parameters for $\mathrm{HOCH}_{2}-\mathrm{A}$ adducted DNA with the lesion paired opposite $\mathrm{T}$ and the bulky moiety directed toward the lesion Watson-Crick face. 

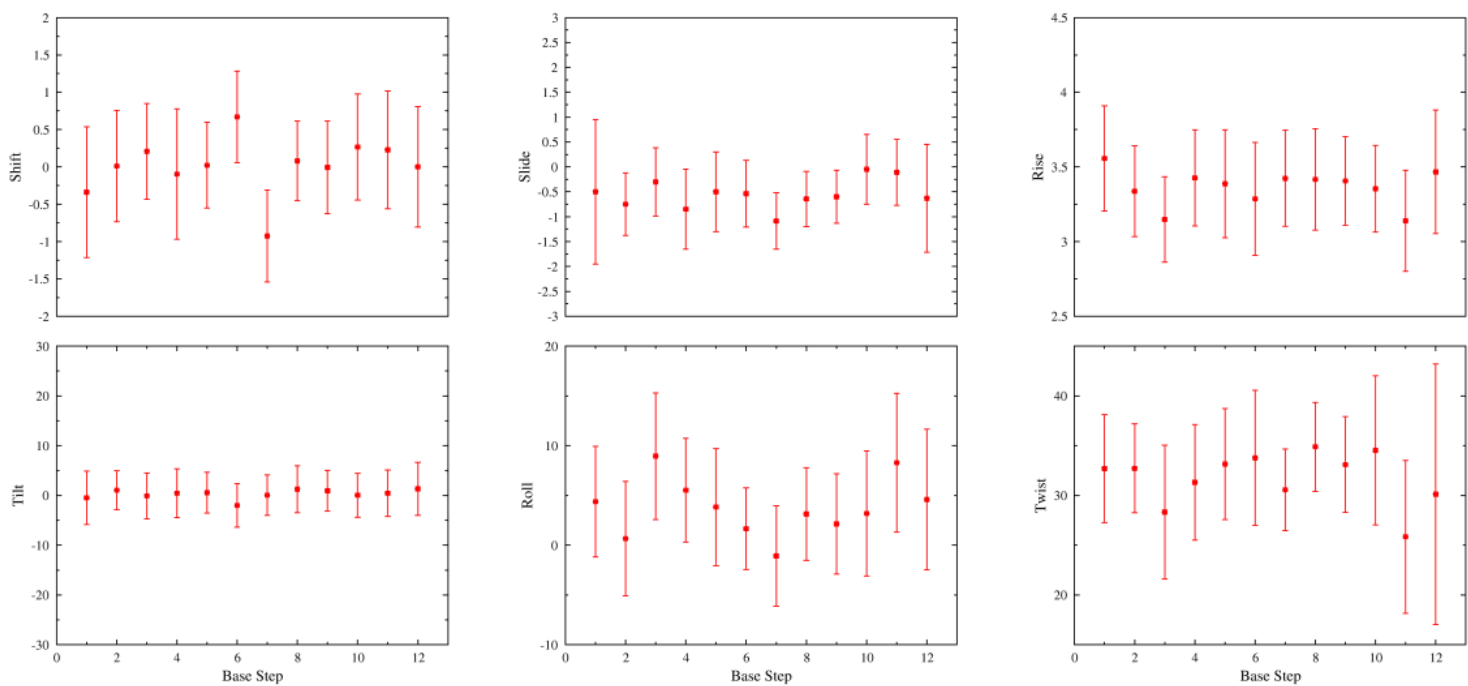

Figure S38. Average base step parameters for $\mathrm{HOCH}_{2}-\mathrm{A}$ adducted DNA with the lesion paired opposite T and the bulky moiety directed toward the lesion Watson-Crick face.

a)
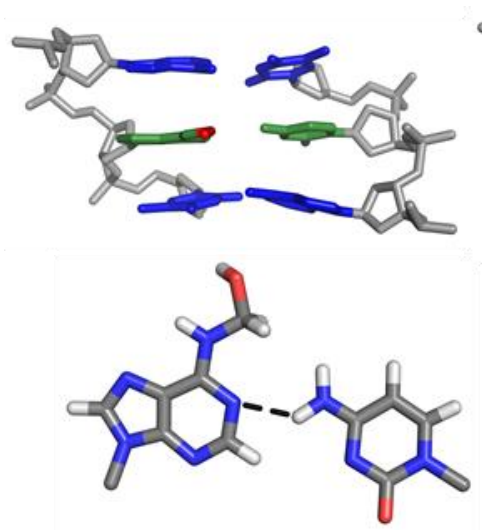

b)
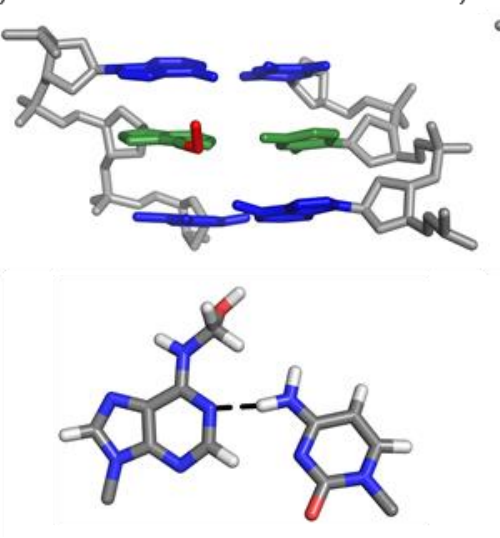

c)

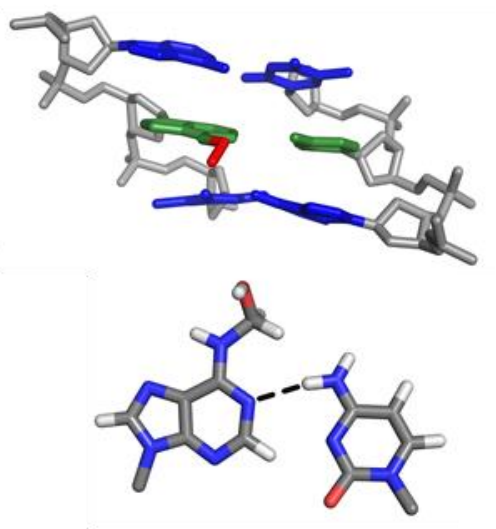

Figure S39. MD representative structures of the three $\gamma^{\prime}$ orientations adopted by the $\mathrm{HOCH}_{2}-\mathrm{A}$ lesion with the bulky moiety directed toward the lesion Watson-Crick face when paired opposite $\mathrm{C}$, with $\gamma^{\prime}$ approximately equal to a) $60^{\circ}$ b) $180^{\circ}$ and c) $300^{\circ}$. 

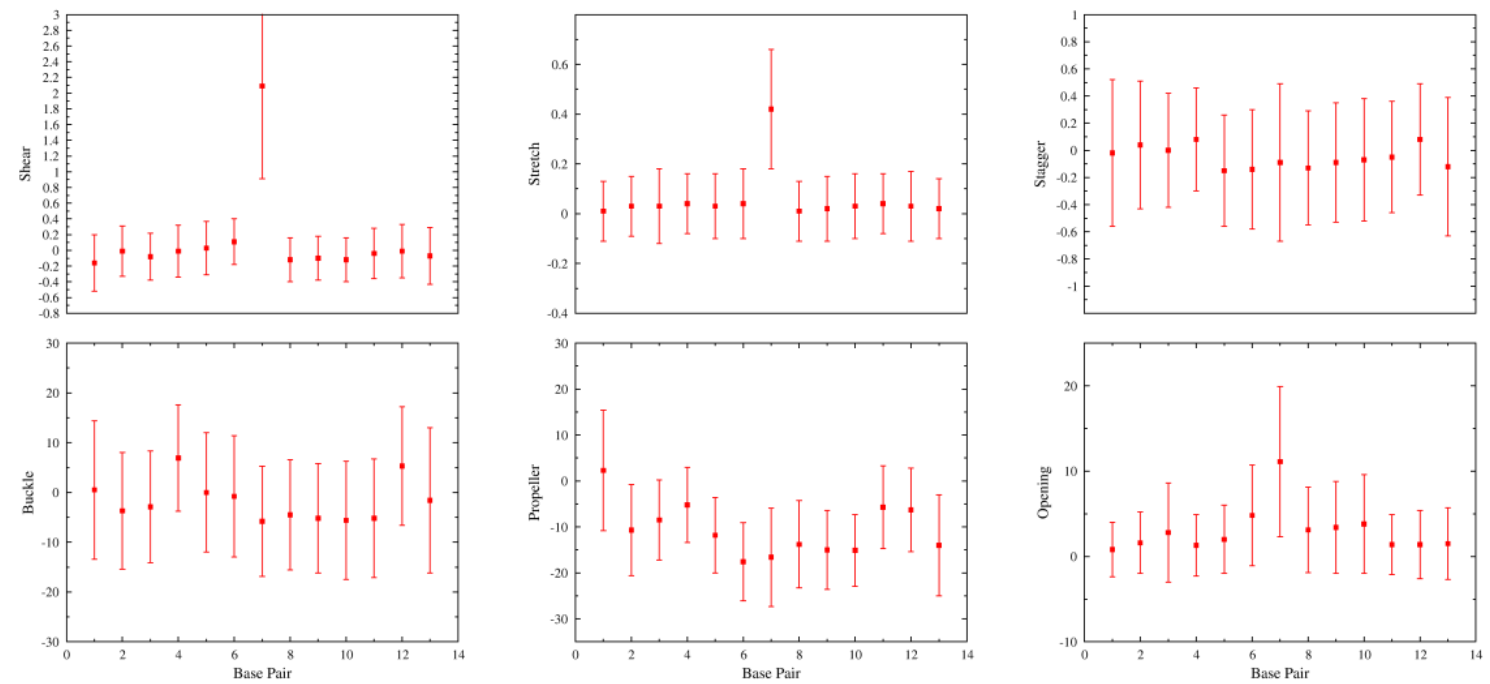

Figure S40. Average base pair parameters for anti $\mathrm{HOCH}_{2}-\mathrm{A}$ adducted DNA with the lesion paired opposite $\mathrm{C}$ and the bulky moiety toward the lesion Watson-Crick face.
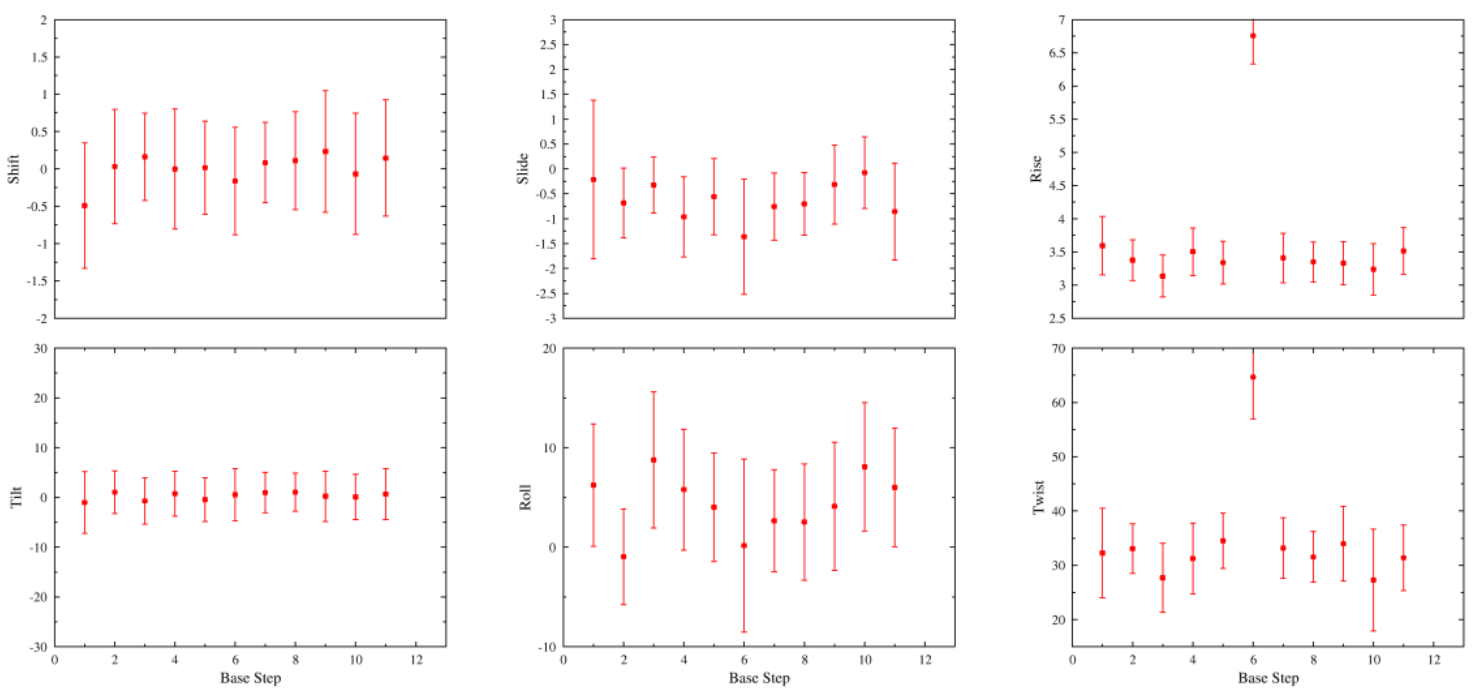

Figure S41. Average base step parameters for anti $\mathrm{HOCH}_{2}-\mathrm{A}$ adducted DNA with the lesion paired opposite $\mathrm{C}$ and the bulky moiety directed toward the lesion Watson-Crick face. 
a)

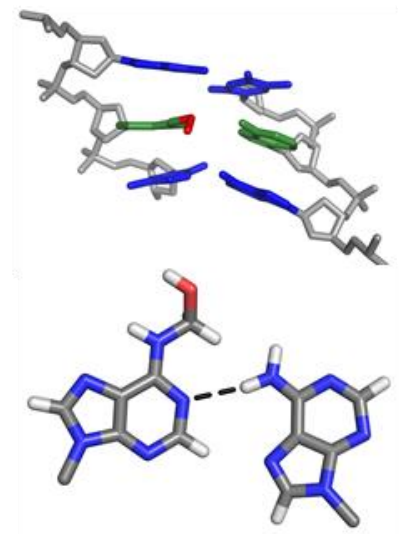

b)

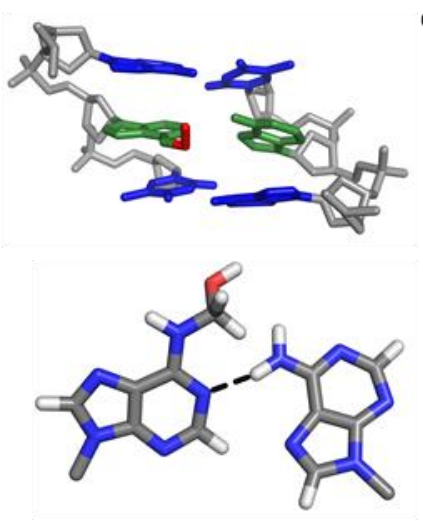

c)
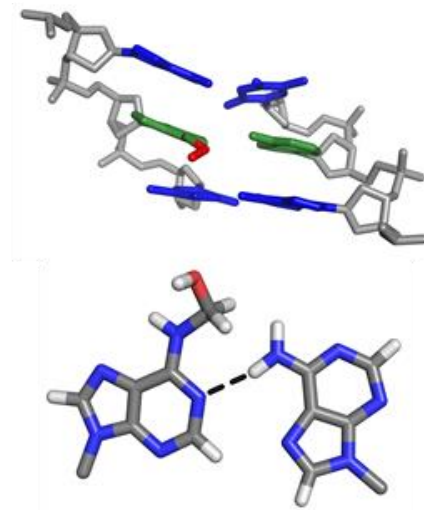

Figure S42. MD representative structures of the three $\gamma^{\prime}$ orientations adopted by the anti $\mathrm{HOCH}_{2}-\mathrm{A}$ lesion with the bulky moiety directed toward the lesion Watson-Crick face when paired opposite $A$, with $\gamma^{\prime}$ approximately equal to a) $120^{\circ}$ b) $180^{\circ}$ and c) $240^{\circ}$.
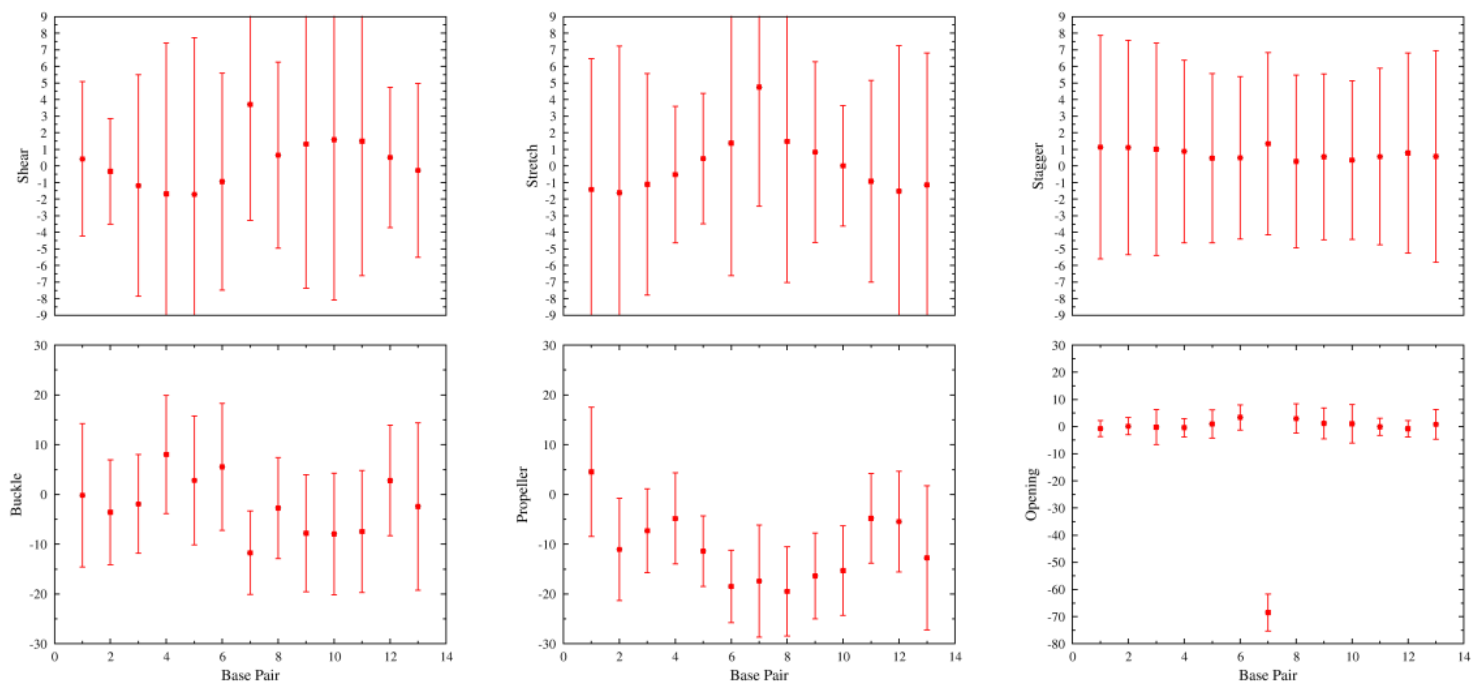

Figure S43. Average base pair parameters for anti $\mathrm{HOCH}_{2}-\mathrm{A}$ adducted DNA with the lesion paired opposite $A$ and the bulky moiety directed toward the lesion Watson-Crick face. 

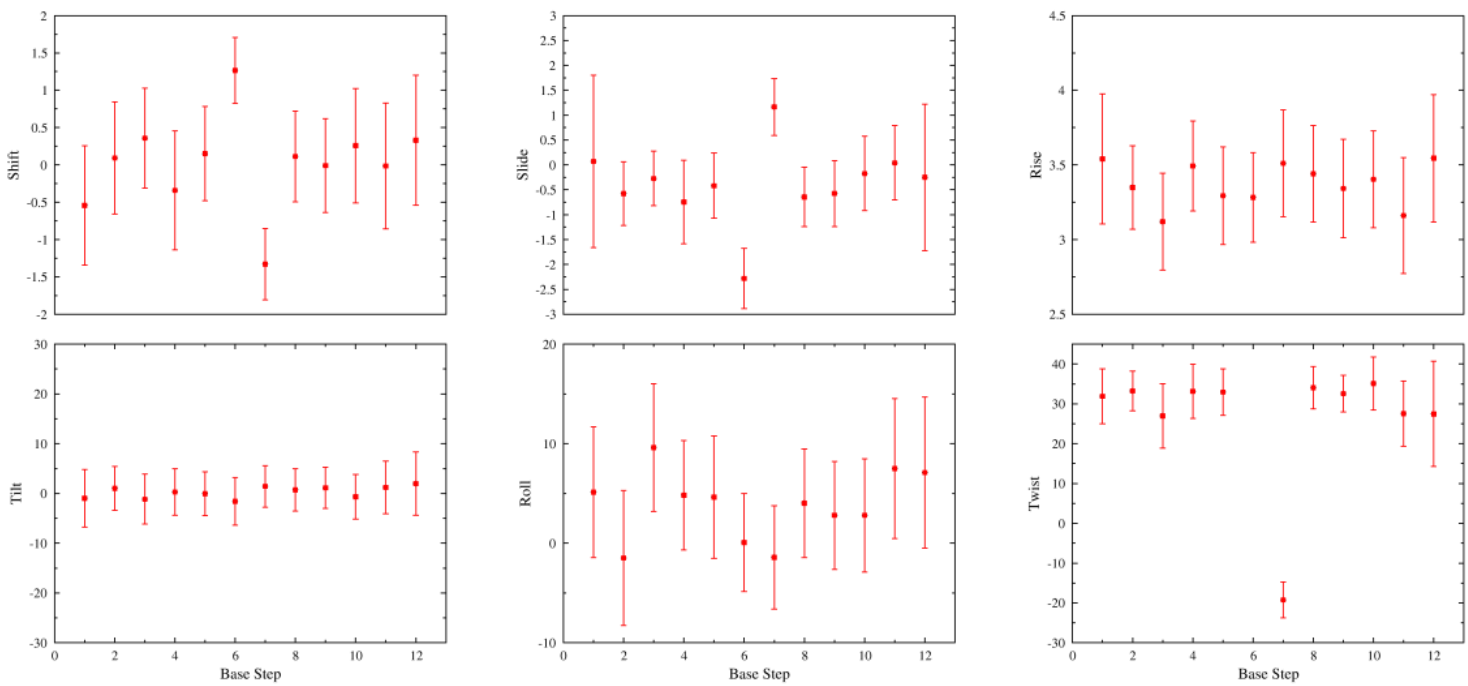

Figure S44. Average base step parameters for anti $\mathrm{HOCH}_{2}-\mathrm{A}$ adducted DNA with the lesion paired opposite $A$ and the bulky moiety directed toward the lesion Watson-Crick face.

a)

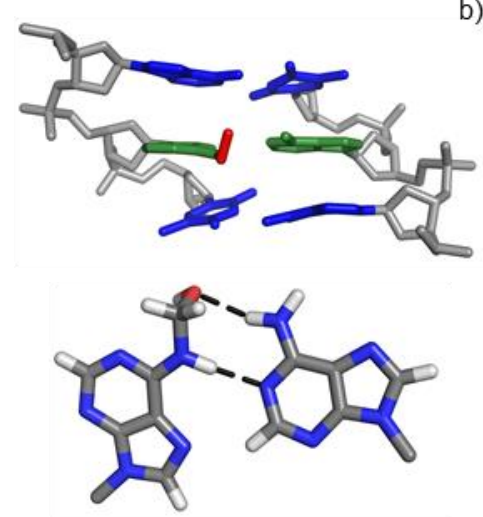

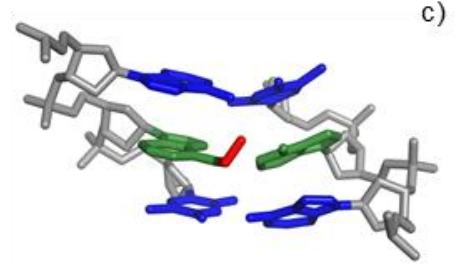

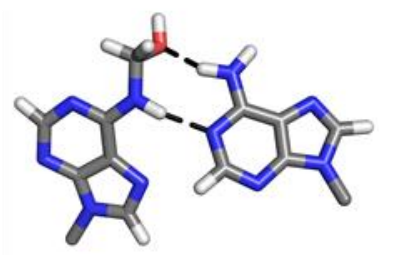

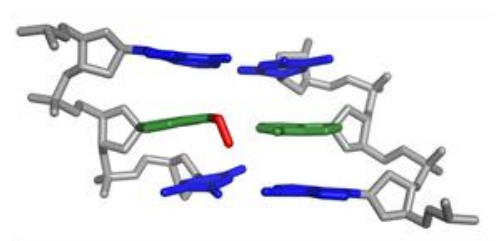

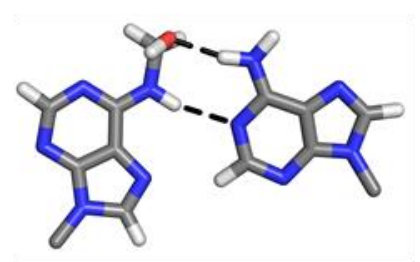

Figure S45. MD representative structures of the three $\gamma^{\prime}$ orientations adopted by the syn $\mathrm{HOCH}_{2}-\mathrm{A}$ lesion with the bulky moiety directed toward the lesion Watson-Crick face when paired opposite $A$, with $\gamma^{\prime}$ approximately equal to a) $60^{\circ}$ b) $180^{\circ}$ and c) $300^{\circ}$. 

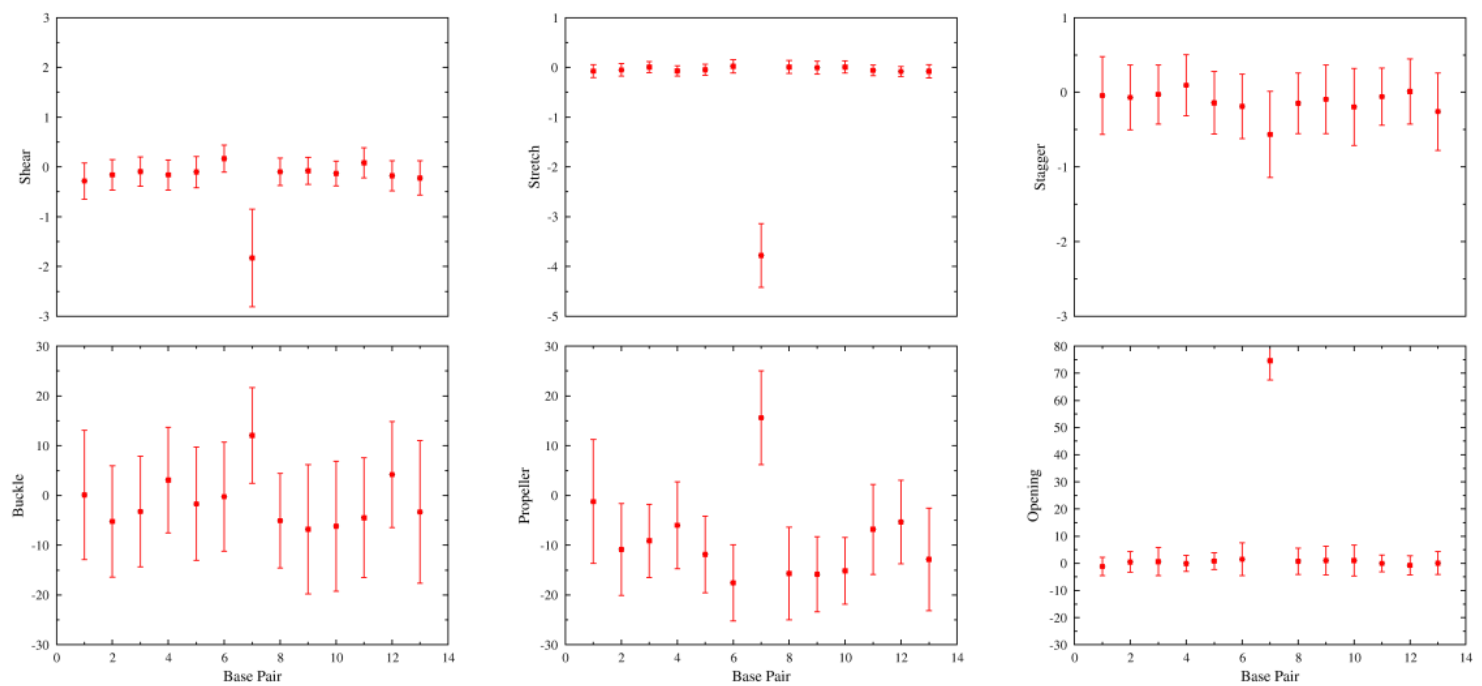

Figure S46. Average base pair parameters for syn $\mathrm{HOCH}_{2}-\mathrm{A}$ adducted DNA with the lesion paired opposite $A$ and the bulky moiety directed toward the lesion Watson-Crick face.
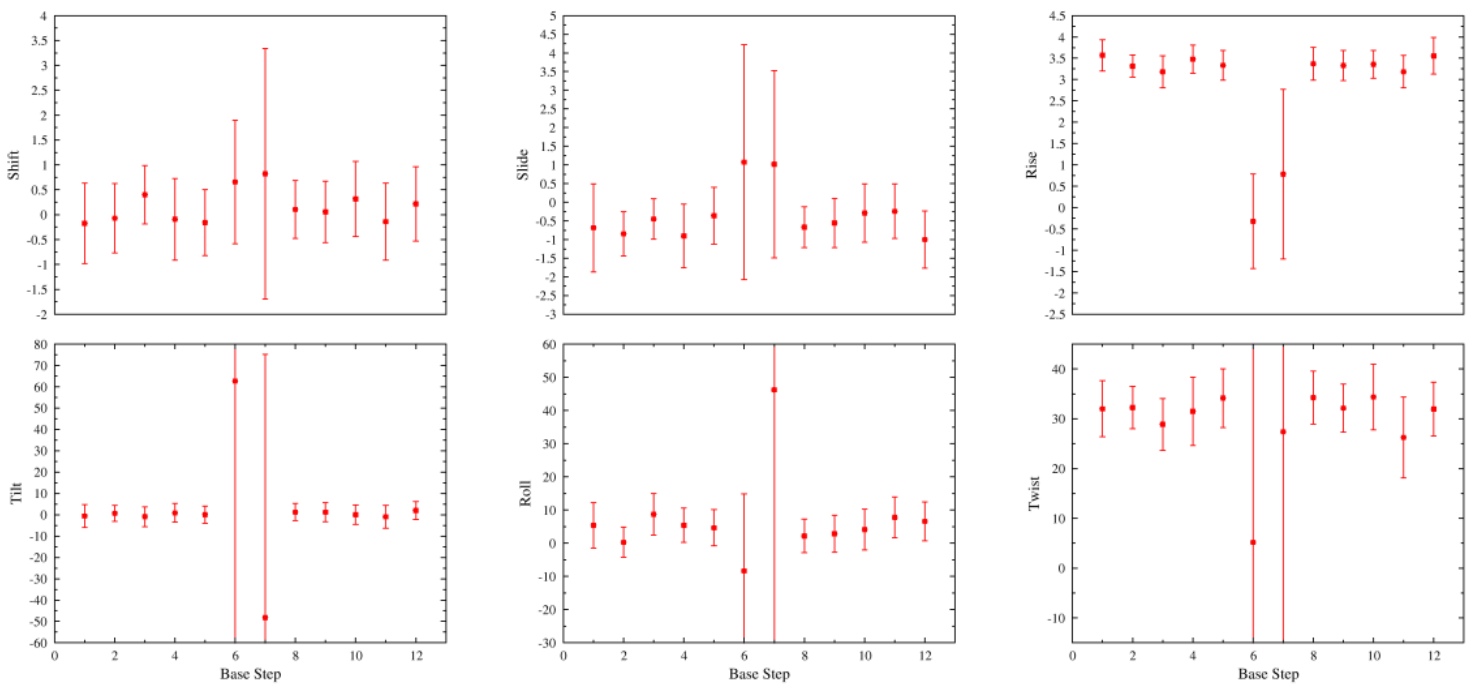

Figure S47. Average base step parameters for syn $\mathrm{HOCH}_{2}-\mathrm{A}$ adducted DNA with the lesion paired opposite $A$ and the bulky moiety directed toward the lesion Watson-Crick face. 
a)
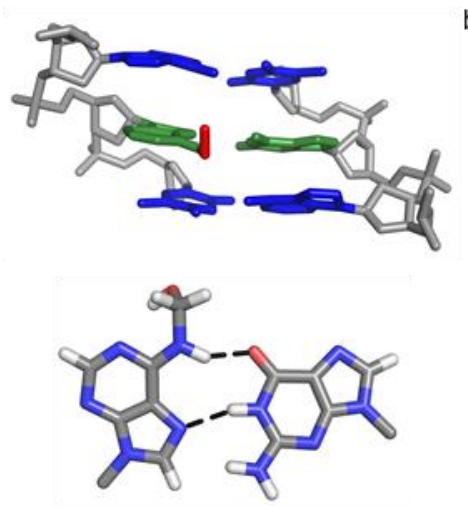
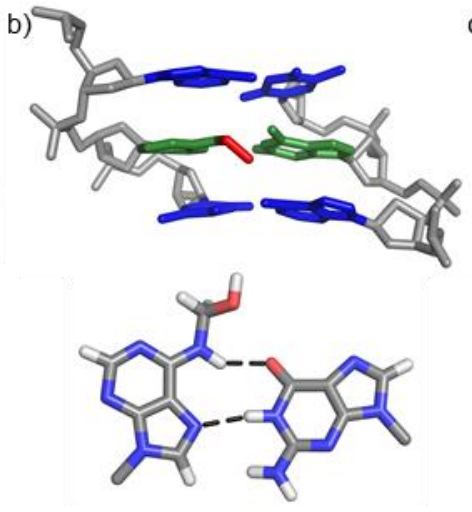

c)

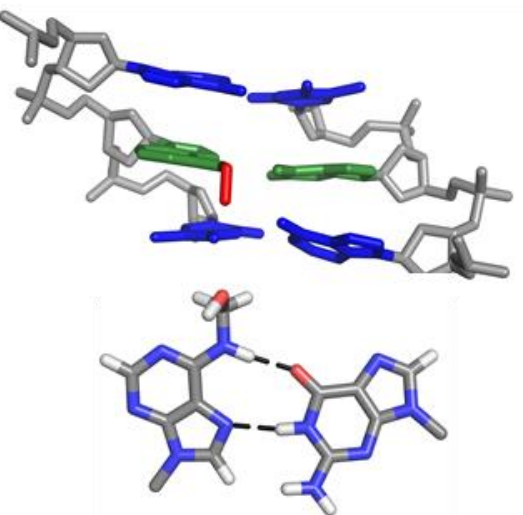

Figure S48. MD representative structures of the three $\gamma^{\prime}$ orientations adopted by the syn $\mathrm{HOCH}_{2}-\mathrm{A}$ lesion with the bulky moiety directed toward the lesion Watson-Crick face when paired opposite $\mathrm{G}$, with $\gamma^{\prime}$ approximately equal to a) $50^{\circ}$ b) $180^{\circ}$ and c) $310^{\circ}$.
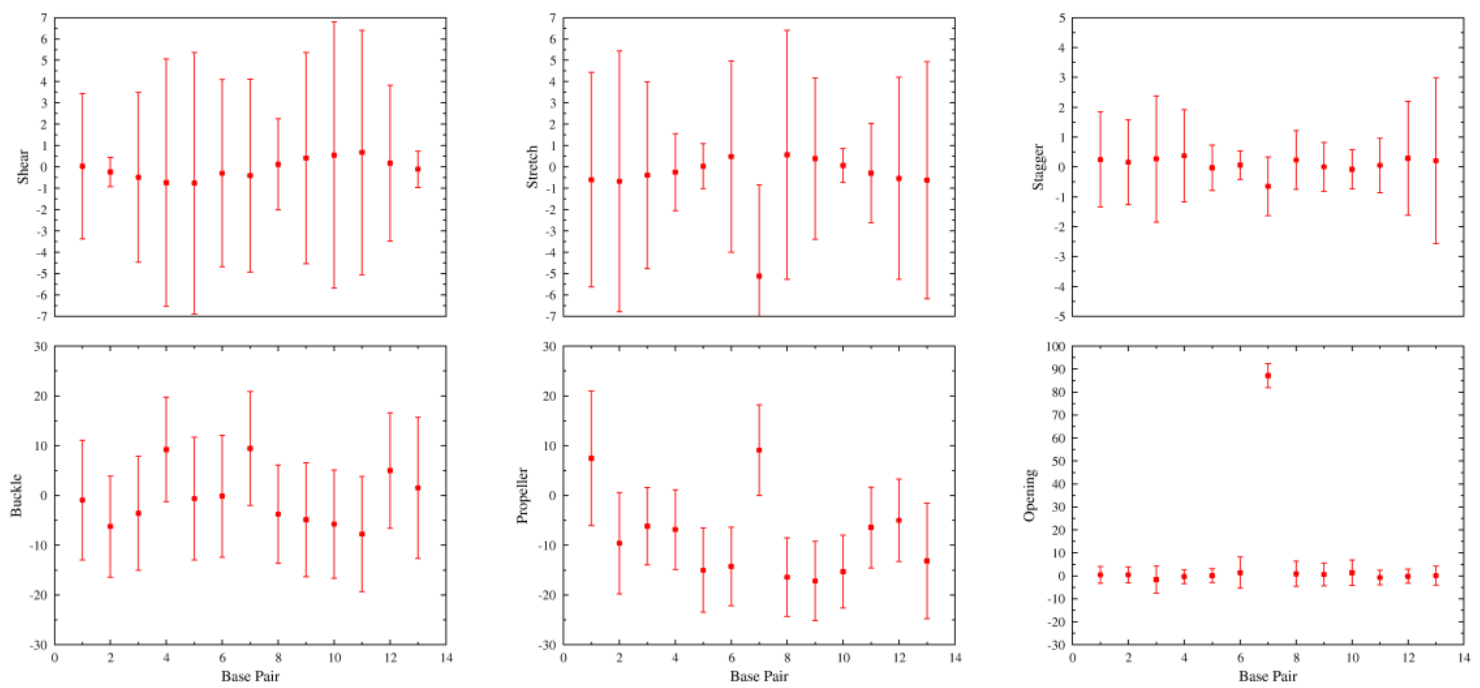

Figure S49. Average base pair parameters for syn $\mathrm{HOCH}_{2}-\mathrm{A}$ adducted DNA with the lesion paired opposite $\mathrm{G}$ and the bulky moiety directed toward the lesion Watson-Crick face. 

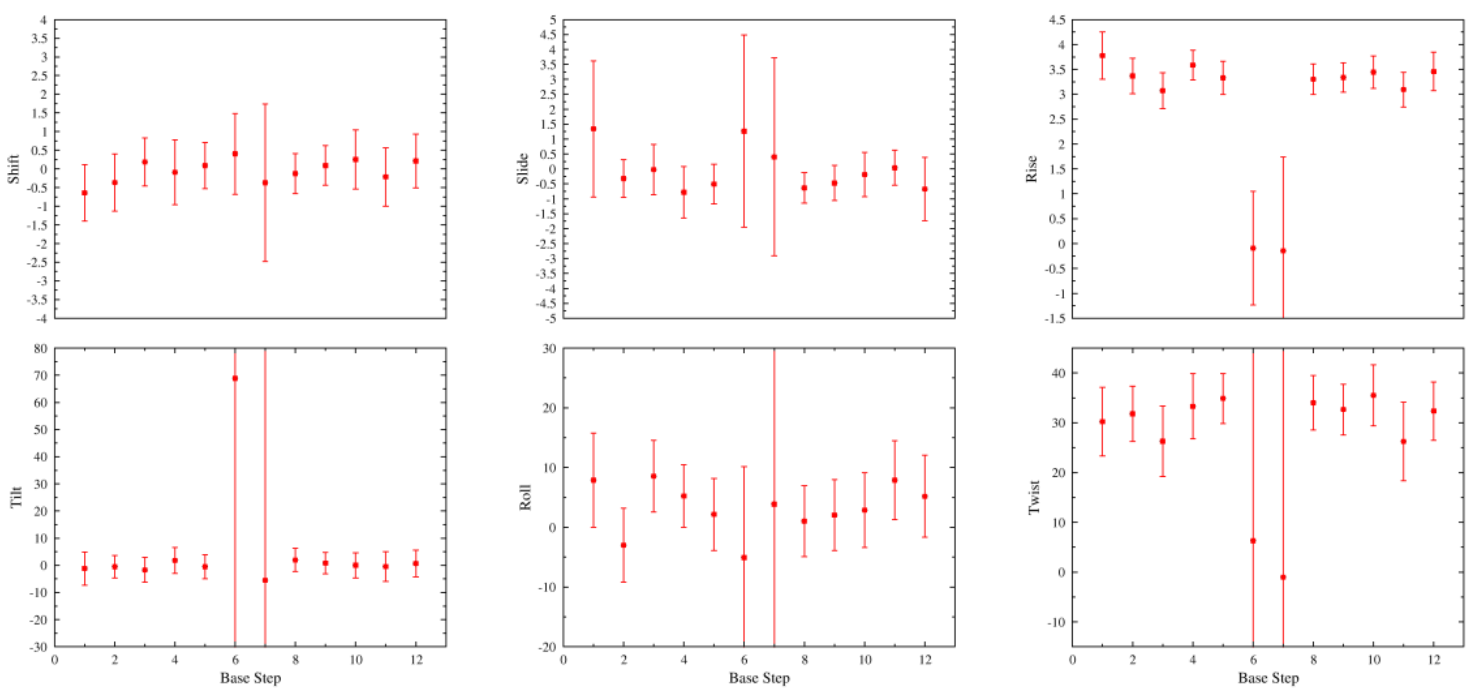

Figure S50. Average base step parameters for syn $\mathrm{HOCH}_{2}-\mathrm{A}$ adducted DNA with the lesion paired opposite $\mathrm{G}$ and the bulky moiety directed toward the lesion Watson-Crick face. 
Table S1. Charges and atom types for the $\mathrm{HOCH}_{2}-\mathrm{C}$ lesion.

\begin{tabular}{ccc}
\hline Atom Name & Atom Type & Charge \\
\hline N1 & NA & -0.0631 \\
C6 & CM & 0.0098 \\
H6 & H4 & 0.2092 \\
C5 & CM & -0.5178 \\
H5 & HA & 0.1824 \\
C4 & CA & 0.7878 \\
N4 & N2 & -0.7374 \\
H4 & H & 0.3783 \\
N3 & NC & -0.7462 \\
C2 & $\mathrm{C}$ & 0.7908 \\
O2 & $\mathrm{O}$ & -0.6325 \\
C7 & CT & 0.4265 \\
H71 & H2 & 0.0216 \\
H72 & H2 & 0.0216 \\
O8 & OH & -0.6159 \\
H8 & HO & 0.3877 \\
H1 & H & 0.0972 \\
\hline
\end{tabular}

Table S2. Charges and atom types for the $\mathrm{HOCH}_{2}-\mathrm{G}$ lesion.

\begin{tabular}{ccc}
\hline Atom Name & Atom Type & Charge \\
\hline N9 & NA & -0.0608 \\
N1 & NA & -0.5008 \\
H1 & H & 0.32 \\
C2 & CA & 0.5308 \\
N2 & N2 & -0.5788 \\
H2 & H & 0.3699 \\
N3 & NC & -0.4792 \\
C4 & CB & 0.2031 \\
C5 & CB & 0.1117 \\
C6 & C & 0.571 \\
O6 & O & -0.5547 \\
N7 & NB & -0.5479 \\
C8 & CK & 0.1427 \\
H8 & H5 & 0.1604 \\
C10 & CT & 0.2412 \\
H101 & H2 & 0.0901 \\
H102 & H2 & 0.0901 \\
O11 & OH & -0.6455 \\
H11 & HO & 0.424 \\
H9 & H5 & 0.1127 \\
\hline
\end{tabular}


Table S3. Charges and atom types for the $\mathrm{HOCH}_{2}-\mathrm{A}$ lesion.

\begin{tabular}{ccc}
\hline Atom Name & Atom Type & Charge \\
\hline N9 & NA & -0.2497 \\
C8 & CK & 0.2831 \\
H8 & H5 & 0.1428 \\
N7 & NB & -0.6467 \\
C5 & CB & 0.0437 \\
C6 & CA & 0.5224 \\
N6 & N2 & -0.6108 \\
H6 & H & 0.4081 \\
N1 & NC & -0.5837 \\
C2 & CQ & 0.3755 \\
H2 & H5 & 0.0826 \\
N3 & NC & -0.595 \\
C4 & CB & 0.5131 \\
C10 & CT & 0.2262 \\
H101 & H2 & 0.0707 \\
H102 & H2 & 0.0707 \\
O11 & OH & -0.5778 \\
H11 & HO & 0.3682 \\
H9 & H5 & 0.1566 \\
\hline
\end{tabular}

Table S4. Heavy atom rmsd ( $\AA$ ) with respect to the representative structure for Trial $1 .^{\mathrm{a}}$

\begin{tabular}{|c|c|c|c|c|c|c|}
\hline & \multicolumn{2}{|c|}{ Trial 1} & \multicolumn{2}{|c|}{ Trial 2} & \multicolumn{2}{|c|}{ Trial 3} \\
\hline & Helix & Trimer & Helix & Trimer & Helix & Trimer \\
\hline $\mathrm{HOCH}_{2}-\mathrm{C}: \mathrm{G}$ & $2.054 \pm 0.483$ & $1.012 \pm 0.183$ & $2.044 \pm 0.451$ & $1.019 \pm 0.198$ & $2.017 \pm 0.450$ & $1.001 \pm 0.180$ \\
\hline $\mathrm{HOCH}_{2}-\mathrm{C}: \mathrm{G}$ rotated ${ }^{\mathrm{b}}$ & $1.928 \pm 0.400$ & $0.910 \pm 0.201$ & $2.045 \pm 0.450$ & $0.973 \pm 0.245$ & $2.049 \pm 0.440$ & $0.932 \pm 0.217$ \\
\hline $\mathrm{HOCH}_{2}-\mathrm{G}: \mathrm{C}$ & $1.913 \pm 0.370$ & $0.936 \pm 0.216$ & $1.961 \pm 0.382$ & $0.921 \pm 0.220$ & $1.930 \pm 0.365$ & $0.928 \pm 0.222$ \\
\hline $\mathrm{HOCH}_{2}-\mathrm{G}: \mathrm{C}$ rotated ${ }^{b}$ & $2.438 \pm 0.572$ & $1.616 \pm 0.969$ & $2.335 \pm 0.511$ & $1.315 \pm 0.783$ & $2.194 \pm 0.491$ & $0.992 \pm 0.318$ \\
\hline $\mathrm{HOCH}_{2}-\mathrm{A}: \mathrm{T}$ & $2.259 \pm 0.467$ & $1.118 \pm 0.142$ & $2.307 \pm 0.526$ & $1.135 \pm 0.137$ & $2.377 \pm 0.534$ & $1.133 \pm 0.156$ \\
\hline $\mathrm{HOCH}_{2}-\mathrm{A}: \mathrm{T}$ rotated ${ }^{\mathrm{b}}$ & $2.512 \pm 0.450$ & $0.879 \pm 0.206$ & $2.645 \pm 0.529$ & $0.827 \pm 0.180$ & $3.213 \pm 0.544$ & $0.839 \pm 0.197$ \\
\hline $\mathrm{HOCH}_{2}-\mathrm{A}: \mathrm{C}$ rotated ${ }^{\mathrm{b}}$ & $2.001 \pm 0.461$ & $0.989 \pm 0.243$ & $2.131 \pm 0.510$ & $1.038 \pm 0.227$ & $2.035 \pm 0.458$ & $1.000 \pm 0.229$ \\
\hline syn- $\mathrm{HOCH}_{2}-\mathrm{A}: \mathrm{G}$ rotated $^{\mathrm{b}}$ & $2.757 \pm 0.546$ & $1.085 \pm 0.222$ & $2.902 \pm 0.495$ & $1.046 \pm 0.224$ & $3.000 \pm 0.525$ & $1.064 \pm 0.224$ \\
\hline $\mathrm{HOCH}_{2}-\mathrm{A}:$ syn-A rotated & $2.119 \pm 0.386$ & $0.825 \pm 0.177$ & $2.063 \pm 0.346$ & $0.794 \pm 0.154$ & $2.611 \pm 0.398$ & $0.853 \pm 0.207$ \\
\hline syn- $\mathrm{HOCH}_{2}-\mathrm{A}: \mathrm{A}$ rotated ${ }^{b}$ & $2.058 \pm 0.493$ & $1.028 \pm 0.206$ & $2.837 \pm 0.787$ & $0.897 \pm 0.182$ & $2.064 \pm 0.445$ & $0.940 \pm 0.223$ \\
\hline
\end{tabular}

a100 ns adducted MD production simulations. ${ }^{\mathrm{b}}$ Bulky moiety directed toward the lesion Watson-Crick binding face. 
Table S5. Hydrogen-bonding occupancies and geometric features (distances in $\AA$ and angles in deg.) for the lesion, as well as the $5^{\prime}$ and $3^{\prime}$ flanking base pairs, in $\mathrm{HOCH}_{2}-\mathrm{C}$ adducted DNA. ${ }^{a}$

\begin{tabular}{lcccccc}
\hline & \multicolumn{3}{c}{$\mathrm{HOCH}_{2}-\mathrm{C}: \mathrm{G}^{\mathrm{b}}$} & \multicolumn{3}{c}{$\mathrm{HOCH}_{2}$-C:G (rotated) } \\
\cline { 2 - 7 } & Occupancy & Distance & Angle & Occupancy & Distance & Angle \\
\hline G20(N1H)-C7(N3) & $100 \%$ & 2.948 & 165.1 & $100 \%$ & 2.952 & 165.1 \\
G20(N2H)-C7(O2) & $100 \%$ & 2.851 & 163.7 & $100 \%$ & 2.853 & 163.0 \\
G20(O6)-C7(N4H) & $98 \%$ & 2.941 & 161.5 & $98 \%$ & 2.945 & 161.1 \\
G22(O6)-C5(N4H) & $99 \%$ & 2.931 & 161.9 & $98 \%$ & 2.943 & 163.3 \\
G22(N2H)-C5(O2) & $100 \%$ & 2.875 & 163.7 & $100 \%$ & 2.886 & 164.3 \\
G22(N1H)-C5(N3) & $100 \%$ & 2.950 & 165.0 & $100 \%$ & 2.948 & 164.6 \\
G21(N2H)-C*(O2) & $100 \%$ & 2.859 & 163.7 & $99 \%$ & 2.804 & 158.3 \\
G21(N1H)-C*(N3) & $100 \%$ & 2.974 & 164.6 & $31 \%$ & 3.288 & 162.5 \\
G21(O6)-C*(N4H) & $98 \%$ & 2.935 & 162.2 & $\mathrm{NO}^{\mathrm{d}}$ & & \\
G20(O6)-C*(O8H) & $27 \%$ & 2.887 & 156.5 & $7 \%$ & 2.945 & 149.1 \\
$\mathrm{G}_{21}(\mathrm{~N} 1 \mathrm{H})-\mathrm{C}^{*}(\mathrm{O} 2)$ & $24 \%$ & 3.273 & 134.7 & $\mathrm{NO}^{\mathrm{d}}$ & & \\
$\mathrm{G}_{21}(\mathrm{O} 6)-\mathrm{C}^{*}(\mathrm{O} 8 \mathrm{H})$ & $8 \%$ & 3.063 & 143.8 & $\mathrm{NO}^{\mathrm{d}}$ & & \\
\hline
\end{tabular}

aHydrogen-bonding occupancies are based on a distance cutoff of $<3.4 \AA$ and an angle cutoff of

$<120^{\circ}$. Nucleobase numbering starts at 1 on the $5^{\prime}$ side of the damaged strand and continues in the $3^{\prime}$ to $5^{\prime}$ direction in the undamaged complementary strand for the 5'-GGATCC*CTGAAGG sequence

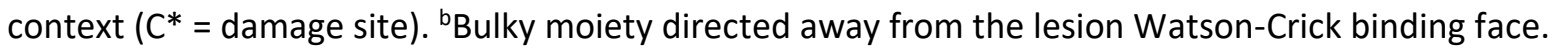
'Bulky moiety directed toward the lesion Watson-Crick binding face. ${ }^{\mathrm{d}}$ Not observed.

Table S6. Hydrogen-bonding occupancies and geometric features (distances in $\AA$ and angles in deg.) for cytosine, as well as the $5^{\prime}$ and $3^{\prime}$ flanking base pairs, in natural DNA with the sequence that mirrors the $\mathrm{HOCH}_{2}-\mathrm{C}$ adducted DNA. ${ }^{a}$

\begin{tabular}{lccc}
\hline & Occupancy & Distance & Angle \\
\hline G20(N1H)-C7(N3) & $100 \%$ & 2.952 & 165.3 \\
G20(N2H)-C7(O2) & $100 \%$ & 2.855 & 163.8 \\
G20(O6)-C7(N4H) & $99 \%$ & 2.934 & 162.4 \\
G22(O6)-C5(N4H) & $98 \%$ & 2.939 & 162.6 \\
G22(N2H)-C5(O2) & $100 \%$ & 2.876 & 163.6 \\
G22(N1H)-C5(N3) & $100 \%$ & 2.953 & 165.0 \\
G21(N2H)-C*(O2) & $100 \%$ & 2.855 & 164.1 \\
G21(N1H)-C*(N3) & $100 \%$ & 2.948 & 165.2 \\
G21(O6)-C*(N4H) & $99 \%$ & 2.933 & 162.7 \\
\hline
\end{tabular}

aHydrogen-bonding occupancies are based on a distance cutoff of $<3.4 \AA$ and an angle cutoff of $<120^{\circ}$. Nucleobase are numbered starting at 1 on the $5^{\prime}$ side of the damaged strand and continues in the $3^{\prime}$ to $5^{\prime}$ direction in the undamaged complementary strand for the $5^{\prime}-$ GGATCC*CTGAAGG sequence context. 
Table S7. Hydrogen-bonding occupancies and geometric features (distances in $\AA$ and angles in deg.) for the lesion, as well as the $5^{\prime}$ and $3^{\prime}$ flanking base pairs, in $\mathrm{HOCH}_{2}-\mathrm{G}$ adducted DNA. ${ }^{\text {a }}$

\begin{tabular}{|c|c|c|c|c|c|c|}
\hline & \multicolumn{3}{|c|}{$\mathrm{HOCH}_{2}-\mathrm{G}: \mathrm{C}^{\mathrm{b}}$} & \multicolumn{3}{|c|}{$\mathrm{HOCH}_{2}-\mathrm{G}: \mathrm{C}$ (rotated)c } \\
\hline & Occupancy & Distance & Angle & Occupancy & Distance & Angle \\
\hline C18(N3)-G9(N1H) & $100 \%$ & 2.955 & 165.5 & $100 \%$ & 2.959 & 164.5 \\
\hline $\mathrm{C} 18(\mathrm{O} 2)-\mathrm{G} 9(\mathrm{~N} 2 \mathrm{H})$ & $100 \%$ & 2.873 & 163.5 & $100 \%$ & 2.873 & 162.1 \\
\hline $\mathrm{C} 18(\mathrm{~N} 4 \mathrm{H})-\mathrm{G} 9(\mathrm{O} 6)$ & $98 \%$ & 2.934 & 162.6 & $98 \%$ & 2.948 & 162.4 \\
\hline T20(N3H)-A7(N1) & $100 \%$ & 2.945 & 164.9 & $99 \%$ & 2.964 & 163.7 \\
\hline $\mathrm{T} 20(\mathrm{O} 4)-\mathrm{A} 7(\mathrm{~N} 6 \mathrm{H})$ & $97 \%$ & 2.965 & 163.2 & $97 \%$ & 2.954 & 161.9 \\
\hline $\mathrm{C} 19(\mathrm{O} 2)-\mathrm{G} *(\mathrm{~N} 2 \mathrm{H})$ & $100 \%$ & 2.868 & 161.9 & $\mathrm{NO}^{\mathrm{d}}$ & & \\
\hline C19(N3)-G*(N1H) & $100 \%$ & 2.976 & 164.7 & $7 \%$ & 3.337 & 156.6 \\
\hline $\mathrm{C} 19(\mathrm{O} 2)-\mathrm{G} *(\mathrm{~N} 1 \mathrm{H})$ & $\mathrm{NO}^{\mathrm{d}}$ & & & $10 \%$ & 2.976 & 160.7 \\
\hline C19(N4H)-G*(O6) & $98 \%$ & 2.923 & 162.2 & $62 \%$ & 2.860 & 159.5 \\
\hline $\mathrm{C} 19(\mathrm{~N} 4 \mathrm{H})-\mathrm{C} 18(\mathrm{OP} 2)$ & $\mathrm{NO}^{\mathrm{d}}$ & & & $22 \%$ & 2.890 & 163.1 \\
\hline G9(N3)-G*(O11H) & $24 \%$ & 2.946 & 161.0 & $7 \%$ & 2.906 & 158.2 \\
\hline $\mathrm{C} 19(\mathrm{O} 2)-\mathrm{G} *(\mathrm{O} 11 \mathrm{H})$ & $21 \%$ & 2.919 & 151.2 & $13 \%$ & 2.837 & 149.4 \\
\hline $\mathrm{T} 20(\mathrm{O} 2)-\mathrm{G}^{*}(\mathrm{O} 11 \mathrm{H})$ & $17 \%$ & 3.267 & 156.9 & $\mathrm{NO}^{\mathrm{d}}$ & & \\
\hline $\mathrm{T} 20\left(\mathrm{O}^{\prime}\right)-\mathrm{G}^{*}(\mathrm{O} 11 \mathrm{H})$ & NOd & & & $13 \%$ & 2.942 & 149.4 \\
\hline $\mathrm{C} 19\left(04^{\prime}\right)-\mathrm{G}^{*}(\mathrm{O} 11 \mathrm{H})$ & $\mathrm{NO}^{\mathrm{d}}$ & & & $9 \%$ & 2.887 & 154.9 \\
\hline
\end{tabular}

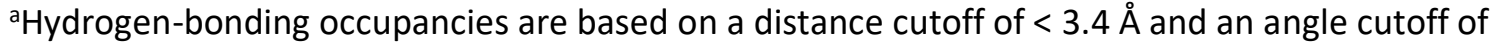
$<120^{\circ}$. Nucleobase are numbered starting at 1 on the $5^{\prime}$ side of the damaged strand and continues in the $3^{\prime}$ to $5^{\prime}$ direction in the undamaged complementary strand for the $5^{\prime}$-GGAGCAAG*GAAGG sequence context ( $\mathrm{G}^{*}=$ damage site). ${ }^{\mathrm{b}}$ Bulky moiety directed away from the lesion Watson-Crick binding face. "Bulky moiety directed toward the lesion Watson-Crick binding face. ${ }^{\mathrm{d}}$ Not observed.

Table S8. Hydrogen-bonding occupancies and geometric features (distances in Å and angles in deg.) for guanine, as well as the $5^{\prime}$ and $3^{\prime}$ flanking base pairs, in natural DNA with the sequence that mirrors the $\mathrm{HOCH}_{2}-\mathrm{G}$ adducted DNA. ${ }^{\mathrm{a}}$

\begin{tabular}{cccc}
\hline & Occupancy & Distance & Angle \\
\hline C18(N3)-G9(N1H) & $100 \%$ & 2.954 & 165.0 \\
C18(O2)-G9(N2H) & $100 \%$ & 2.873 & 163.7 \\
C18(N4H)-G9(O6) & $99 \%$ & 2.937 & 162.5 \\
T20(N3H)-A7(N1) & $100 \%$ & 2.940 & 164.8 \\
T20(O4)-A7(N6H) & $96 \%$ & 2.970 & 163.3 \\
C19(N3)-G*(N1H) & $100 \%$ & 2.948 & 165.4 \\
C19(O2)-G*(N2H) & $100 \%$ & 2.853 & 164.2 \\
C19(N4H)-G*(O6) & $99 \%$ & 2.933 & 162.7 \\
\hline
\end{tabular}

aHydrogen-bonding occupancies are based on a distance cutoff of $<3.4 \AA$ and an angle cutoff of $<120^{\circ}$. Nucleobase are numbered starting at 1 on the $5^{\prime}$ side of the damaged strand and continues in the $3^{\prime}$ to $5^{\prime}$ direction in the undamaged complementary strand for the $5^{\prime}$ GGAGCAAG*GAAGG sequence context. 
Table S9. Hydrogen-bonding occupancies and geometric features (distances in $\AA$ and angles in deg.) for the lesion, as well as the $5^{\prime}$ and $3^{\prime}$ flanking base pairs, in $\mathrm{HOCH}_{2}-\mathrm{A}$ adducted DNA with the lesion paired opposite T. ${ }^{\mathrm{a}}$

\begin{tabular}{lcccccc}
\hline & \multicolumn{3}{c}{$\mathrm{HOCH}_{2}-\mathrm{A}: \mathrm{T}^{\mathrm{b}}$} & \multicolumn{3}{c}{$\mathrm{HOCH}_{2}$-A:T (rotated) } \\
\cline { 2 - 7 } & Occupancy & Distance & Angle & Occupancy & Distance & Angle \\
\hline A19(N1)-T8(NH3) & $100 \%$ & 2.937 & 164.6 & $100 \%$ & 2.936 & 164.0 \\
A19(N6H)-T8(O4) & $96 \%$ & 2.985 & 162.8 & $95 \%$ & 2.996 & 163.6 \\
T21(N3H)-A6(N1) & $100 \%$ & 2.961 & 164.0 & $100 \%$ & 2.948 & 163.6 \\
T21(O4)-A6(N6H) & $96 \%$ & 2.962 & 162.9 & $94 \%$ & 2.984 & 163.5 \\
T20(N3H)-A*(N1) & $99 \%$ & 2.997 & 162.4 & $65 \%$ & 3.220 & 162.7 \\
T20(O4)-A*(N6H) & $96 \%$ & 2.984 & 162.6 & NO $^{\text {d }}$ & & \\
A6(N7)-A*(O10H) & $10 \%$ & 3.034 & 151.5 & $5 \%$ & 3.010 & 159.4 \\
T8(O4)-A* $(\mathrm{O} 10 \mathrm{H})$ & $7 \%$ & 2.969 & 150.6 & NO $^{d}$ & & \\
A $^{*}(\mathrm{~N} 7)-A^{*}(\mathrm{O} 10 \mathrm{H})$ & $7 \%$ & 3.015 & 143.6 & NO $^{\mathrm{d}}$ & & \\
\hline
\end{tabular}

aHydrogen-bonding occupancies are based on a distance cutoff of $<3.4 \AA$ and an angle cutoff of $<120^{\circ}$. Nucleobase are numbered starting at 1 on the $5^{\prime}$ side of the damaged strand and continues in the $3^{\prime}$ to $5^{\prime}$ direction in the undamaged complementary strand for the $5^{\prime}$-GGTGGAA*TTTCGG sequence context ( $A^{*}=$ damaged site). ${ }^{b}$ Bulky moiety directed away from the lesion Watson-Crick binding face. 'Bulky moiety directed toward the lesion Watson-Crick binding face. ${ }^{\mathrm{d}}$ Not observed.

Table S10. Hydrogen-bonding occupancies and geometric features (distances in $\AA$ and angles in deg.) for adenine, as well as the $5^{\prime}$ and $3^{\prime}$ flanking base pairs, in natural DNA with the sequence that mirrors the $\mathrm{HOCH}_{2}-\mathrm{A}$ adducted DNA. ${ }^{\mathrm{a}}$

\begin{tabular}{lccc}
\hline & Occupancy & Distance & Angle \\
\hline A19(N1)-T8(N3H) & $100 \%$ & 2.948 & 164.6 \\
A19(N6H)-T8(O4) & $95 \%$ & 2.994 & 161.7 \\
T21(N3H)-A6(N1) & $100 \%$ & 2.953 & 163.4 \\
T21(O4)-A6(N6H) & $96 \%$ & 2.967 & 162.2 \\
T20(N3H)-A*(N1) & $100 \%$ & 2.947 & 164.3 \\
T20(O4)-A*(N6H) & $94 \%$ & 2.996 & 161.5 \\
\hline
\end{tabular}

aHydrogen-bonding occupancies are based on a distance cutoff of $<3.4 \AA$ and an angle cutoff of $<120^{\circ}$. Nucleobase are numbered starting at 1 on the $5^{\prime}$ side of the damaged strand and continues in the $3^{\prime}$ to $5^{\prime}$ direction in the undamaged complementary strand for the $5^{\prime}$ GGTGGAA*TTTCGG sequence context. 
Table S11. Hydrogen-bonding occupancies and geometric features (distances in $\AA$ and angles in deg.) for the lesion, as well as the $5^{\prime}$ and $3^{\prime}$ flanking base pairs, in $\mathrm{HOCH}_{2}-\mathrm{A}$ adducted DNA with the lesion paired opposite $\mathrm{C}^{\mathrm{a}}$

\begin{tabular}{cccc}
\hline & \multicolumn{3}{c}{$\mathrm{HOCH}_{2}-\mathrm{A}: \mathrm{C}^{\mathrm{b}}$} \\
\cline { 2 - 4 } & Occupancy & Distance & Angle \\
\hline A19(N1)-T8(N3H) & $100 \%$ & 2.948 & 163.3 \\
A19(N6H)-T8(O4) & $97 \%$ & 2.961 & 162.7 \\
T21(N3H)-A6(N1) & $99 \%$ & 2.954 & 162.8 \\
T21(O4)-A6(N6H) & $93 \%$ & 2.992 & 162.8 \\
C20(N4H)-A*(N1) & $92 \%$ & 3.083 & 160.8 \\
A6(N7)-A*(O10H) & $6 \%$ & 3.018 & 158.0 \\
\hline
\end{tabular}

aHydrogen-bonding occupancies are based on a distance cutoff of $<3.4 \AA$ and an angle cutoff of $<120^{\circ}$. Nucleobase are numbered starting at 1 on the $5^{\prime}$ side of the damaged strand and continues in the $3^{\prime}$ to $5^{\prime}$ direction in the undamaged complementary strand for the $5^{\prime}$ -

GGTGGAA*TTTCGG sequence context ( $A^{*}=$ damaged site). ${ }^{b}$ Bulky moiety directed toward the lesion Watson-Crick binding face.

Table S12. Hydrogen-bonding occupancies and geometric features (distances in $\AA$ and angles in deg.) for the lesion, as well as the $5^{\prime}$ and $3^{\prime}$ flanking base pairs, in $\mathrm{HOCH}_{2}-\mathrm{A}$ adducted DNA with the lesion paired opposite A. ${ }^{a}$

\begin{tabular}{|c|c|c|c|c|c|c|}
\hline & \multicolumn{3}{|c|}{$\mathrm{HOCH}_{2}-\mathrm{A}: \mathrm{syn}-\mathrm{A}^{\mathrm{b}}$} & \multicolumn{3}{|c|}{ syn- $\mathrm{HOCH}_{2}-\mathrm{A}: \mathrm{A}^{\mathrm{b}}$} \\
\hline & Occupancy & Distance & Angle & Occupancy & Distance & Angle \\
\hline A19(N1)-T8(N3H) & $100 \%$ & 2.941 & 161.3 & $100 \%$ & 2.956 & 163.6 \\
\hline A19(N6H)-T8(O4) & $96 \%$ & 2.975 & 163.2 & $96 \%$ & 2.983 & 163.3 \\
\hline T21(N3H)-A6(N1) & $100 \%$ & 2.957 & 164.0 & $99 \%$ & 2.959 & 161.6 \\
\hline T21(O4)-A6(N6H) & $91 \%$ & 3.005 & 163.6 & $94 \%$ & 2.979 & 162.1 \\
\hline $\mathrm{A} 20(\mathrm{~N} 6 \mathrm{H})-\mathrm{A} 7(\mathrm{~N} 1)$ & $77 \%$ & 3.136 & 156.9 & $89 \%$ & 3.049 & 158.9 \\
\hline A6(N7)-A*(O10H) & $6 \%$ & 3.036 & 157.7 & $24 \%$ & 3.068 & 152.1 \\
\hline$A 20(N 6 H)-A^{*}(O 10)$ & $\mathrm{NO}^{\mathrm{c}}$ & & & $80 \%$ & 3.020 & 156.1 \\
\hline$A 6(N 6 H)-A^{*}(010)$ & $\mathrm{NO}^{\mathrm{c}}$ & & & $15 \%$ & 3.096 & 135.4 \\
\hline$A^{*}(\mathrm{~N} 1)-\mathrm{A}^{*}(\mathrm{O} 10 \mathrm{H})$ & $\mathrm{NO}^{\mathrm{c}}$ & & & $7 \%$ & 3.128 & 126.5 \\
\hline
\end{tabular}

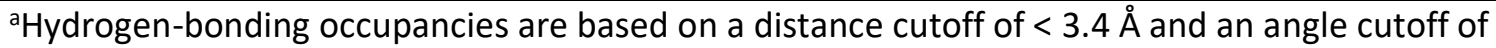
$<120^{\circ}$. Nucleobase are numbered starting at 1 on the $5^{\prime}$ side of the damaged strand and continues in the $3^{\prime}$ to $5^{\prime}$ direction in the undamaged complementary strand for the $5^{\prime}$-GGTGGAA*TTTCGG sequence context $\left(A^{*}=\right.$ damaged site). ${ }^{b}$ Bulky moiety directed toward the lesion Watson-Crick binding face. ${ }^{\mathrm{C}}$ Not observed. 
Table S13. Hydrogen-bonding occupancies and geometric features (distances in $\AA$ and angles in deg.) for the lesion, as well as the ${ }^{\prime}$ and $3^{\prime}$ flanking base pairs, in $\mathrm{HOCH}_{2}-\mathrm{A}$ adducted DNA with the lesion paired opposite $\mathrm{G} .^{\mathrm{a}}$

\begin{tabular}{cccc}
\hline & \multicolumn{3}{c}{$\mathrm{HOCH}_{2}-\mathrm{A}: \mathrm{G}^{\mathrm{b}}$} \\
\cline { 2 - 4 } & Occupancy & Distance & Angle \\
\hline A19(N1)-T8(N3H) & $100 \%$ & 2.930 & 165.2 \\
A19(N6H)-T8(O4) & $96 \%$ & 2.983 & 162.8 \\
T21(N3H)-A6(N1) & $100 \%$ & 2.955 & 164.0 \\
T21(O4)-A6(N6H) & $93 \%$ & 2.993 & 160.5 \\
G20(N1H)-A*(N7) & $99 \%$ & 2.965 & 158.9 \\
G20 (N2H)-A*(N7) & $47 \%$ & 3.171 & 142.0 \\
G20(O6)-A*(N6H) & $96 \%$ & 2.920 & 151.1 \\
G20(N6)-A*(O10H) & $39 \%$ & 2.890 & 151.3 \\
A19(N6H)-A*(O10) & $12 \%$ & 3.052 & 137.2 \\
A6(N6H)-A*(O10) & $8 \%$ & 3.117 & 137.3 \\
T8(O4)-A*(O10H) & $8 \%$ & 3.001 & 153.4 \\
\hline
\end{tabular}

${ }^{a}$ Hydrogen-bonding occupancies are based on a distance cutoff of $<3.4 \AA$ and an angle cutoff of $<120^{\circ}$. Nucleobase are numbered starting at 1 on the $5^{\prime}$ side of the damaged strand and continues in the $3^{\prime}$ to $5^{\prime}$ direction in the undamaged complementary strand for the $5^{\prime}$-GGTGGAA*TTTCGG

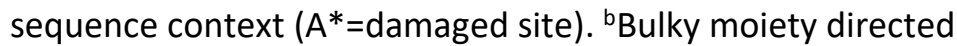
toward the lesion Watson-Crick binding face. 